\title{
An approach to developing a community-based HIV/AIDS intervention : the case of farm workers in Zimbabwe
}

Citation for published version (APA):

Laver, S. M. L. (1996). An approach to developing a community-based HIV/AIDS intervention : the case of farm workers in Zimbabwe. [Doctoral Thesis, Maastricht University]. Universiteit Maastricht. https://doi.org/10.26481/dis.19970131sl

Document status and date:

Published: 01/01/1996

DOI:

10.26481/dis.19970131sl

Document Version:

Publisher's PDF, also known as Version of record

Please check the document version of this publication:

- A submitted manuscript is the version of the article upon submission and before peer-review. There can be important differences between the submitted version and the official published version of record.

People interested in the research are advised to contact the author for the final version of the publication, or visit the DOI to the publisher's website.

- The final author version and the galley proof are versions of the publication after peer review.

- The final published version features the final layout of the paper including the volume, issue and page numbers.

Link to publication

\footnotetext{
General rights rights.

- You may freely distribute the URL identifying the publication in the public portal. please follow below link for the End User Agreement:

www.umlib.nl/taverne-license

Take down policy

If you believe that this document breaches copyright please contact us at:

repository@maastrichtuniversity.nl

providing details and we will investigate your claim.
}

Copyright and moral rights for the publications made accessible in the public portal are retained by the authors and/or other copyright owners and it is a condition of accessing publications that users recognise and abide by the legal requirements associated with these

- Users may download and print one copy of any publication from the public portal for the purpose of private study or research.

- You may not further distribute the material or use it for any profit-making activity or commercial gain

If the publication is distributed under the terms of Article $25 \mathrm{fa}$ of the Dutch Copyright Act, indicated by the "Taverne" license above, 
An Approach to Developing a Community-based HIV/AIDS Intervention

The Case of Farm Workers in Zimbabwe 


\section{Promotores}

Prof. dr. G.J. Kok

I'rof. dr. H.W. van den Borne

\section{Co-promotor}

Dr. Godfrey Woelk (University of Zimbabwe)

\section{Beoordelingscommissie}

Prof. dr. H. Schmidt (voorzitter)

Prof. dr. M.F.C. Bourdillon (University of Zimbabwe)

Dr. J.S.M. Krumeich

Prof. dr. G.S. Parcel

Prof. dr. ir. N.G. Röling (Landbouwuniversiteit Wageningen)

The study in this thesis was performed at the Maastricht Health Research Institute for Prevention and Care (HEALTH), which participates in the Netherlands School of Primary Care Research (CaRe), acknowledged in 1995 by the Royal Dutch Academy of Science (KNAW).

The study described in this thesis and the publication of this thesis was financially supported by:

* WOTRO, Netherlands Foundation for the Advancement of Tropical Research

* Stichting Aidsfonds, Netherlands Aids Fund

* Research Board, University of Zimbabwe

* John Wakeford Trust, Zimbabwe

* Commercial Farmers' Union (CFU), Zimbabwe

(C) Susan M.L. Laver 1996

ISBN: $0-7974-1689-7$

Cover design by Lisa Jean Deary

Typeset by Fontline Electronic Publishing, Harare, Zimbabwe

Printed by Précigraph Limited, Les Pailles, Mauritius 


\title{
An Approach to Developing a Community-based HIV/AIDS Intervention
}

\author{
The Case of \\ Farm Workers in Zimbabwe
}

\section{Proefschrift}

ter verkrijging van de graad van doctor aan de Universiteit Maastricht op gezag van de Rector Magnificus, Prof. mr. M.J. Cohen, volgens het besluit van het College van Decanen, in het openbaar te verdedigen op vrijdag 31 januari 1997 om 12.00 uur

door

Susan Margaret Leslie Laver 


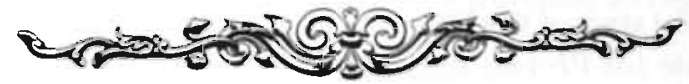

\title{
Dedication
}

\author{
For Tim \\ our son
}

whose young life was cut short at 16 before his dream came true 


\section{Acknowledgements}

To Bart van den Borne and Gerjo Kok of Maastricht University, my deepest appreciation for accepting me as a PhD student in spite of the thousands of miles which separated us over the years.

There were others who assisted in so many ways. To my academic colleagues and the secretarial staff of the Department of Health Promotion and the Health Research Institute for Prevention and Care (HEALTH), Maastricht University, my appreciation for their guidance. To Annie Gerlings, Lilian Lechner and Wies Weijts in particular, my special thanks.

To my colleagues in Zimbabwe, in particular Godfrey Woelk and Seter Siziya who offered their continued support throughout the long process of research, my heartfelt thanks. And to my research assistants Ghazala Suleman and Nicholas Madziwanzira whose cheerfulness and helpfulness helped me through many hurdles - thank you.

To the Ministry of Health staff, Mashonaland West Province Zimbabwe and in particular the Provincial Medical Director, Dr Katito, who encouraged me to carry out this work, my appreciation. And to the farm workers, the Farm Health Workers and the farm owners who permitted me to work alongside and to gain insight into their lives, my gratitude.

My appreciation is also extended to my funders without whom the research would have been impossible; the Netherlands Foundation for the advancement of Tropical Research (WOTRO), Stichting Aidsfonds, the Research Board of the University of Zimbabwe and the John Wakefield Scholarship Trust, Zimbabwe.

Lastly, my deepest thanks to my husband Gil, our son Bruce, my parents and Helga who, knowing the many odds that I faced during this period, never wavered in the belief that I would achieve this objective.

Susan M.L. Laver

Maastricht 1997 


\section{Contents}

\section{Chapter 1: Overview}

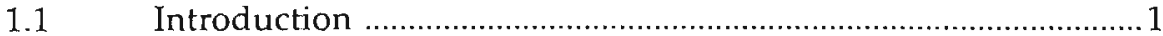

1.2 Zimbabwe - A Historical and Developmental Perspective ........2

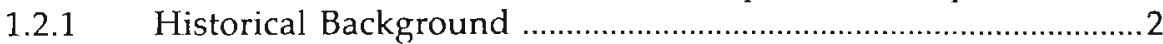

1.2.2 The Government and Administration ..................................... 2

1.2.3 The Demography ................................................................... 2

1.2.4 Social and Economic Development Since Independence ............3

1.2.5 Health in the First Decade of Independence .................................. 4

1.2.6 Health in the Second Decade of Independence .......................... 4

1.2.7 The Emergence of AIDS in the Second Decade of Independence ...5

1.2.8 The Construction of the Response to AIDS in Zimbabwe ..........6

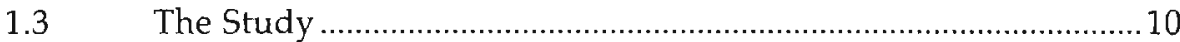

13.1 Statement of the Research Problem ............................................ 10

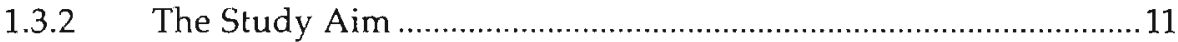

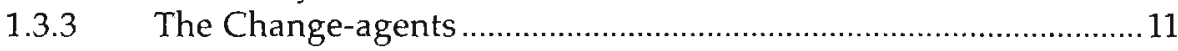

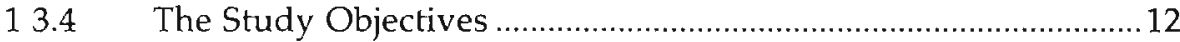

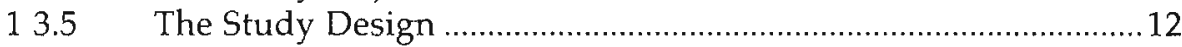

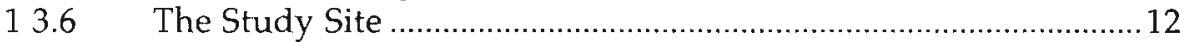

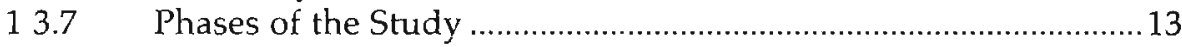

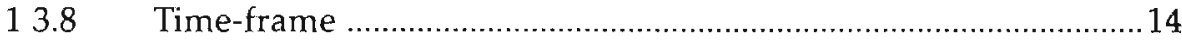

$1.4 \quad$ The Pre-intervention Survey ………......................................... 14

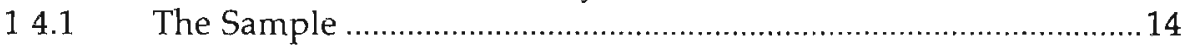

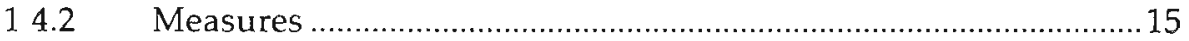

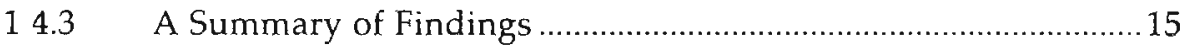

14.4 Conclusions from the Pre-intervention Survey …........................17

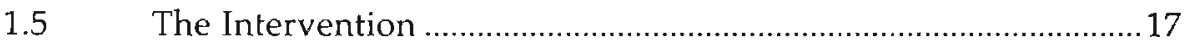

$15.1 \quad$ Goal and Objectives of the Intervention .....................................17

15.2 Theories Guiding the Intervention ............................................. 17

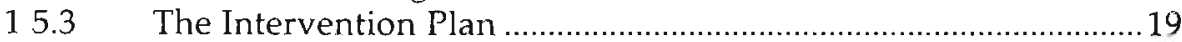

15.4 Strategy and the Methods of the Intervention ...........................20

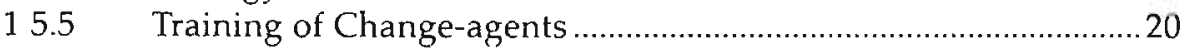

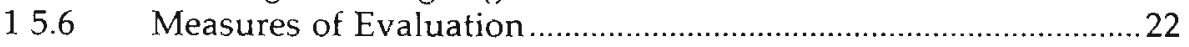

1.6 The Process Evaluation - a Summary of Findings .......................22

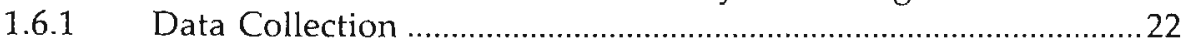

16.2 Lessons Learned from the Process Evaluation ............................22

1.6.3 Conclusions of the Process Evaluation .........................................24

1.7 The Post-intervention Study - a Summary of Findings ...............25

1.7.1 The Aim of the Post Intervention Study .......................................25 
3.4.8 Condom Use Among Men and Attitudes to Sex and Multi-partnering

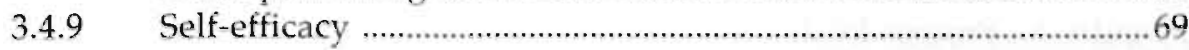

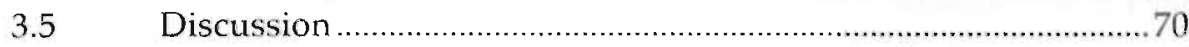

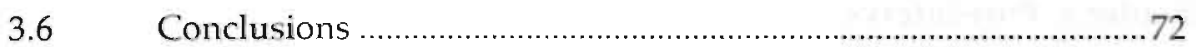

Chapter 4: Using Theory to Design an Intervention for HIV/AIDS in Farm Worker Communities in Zimbabwe

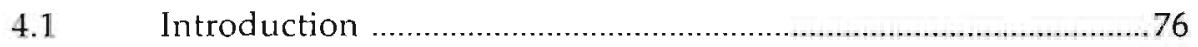

4.2 The Problem ....................................................................... 77

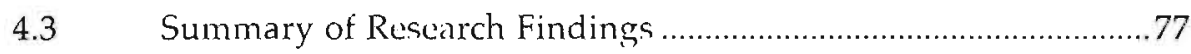

4.4 Goal and Objectives of the Intervention ....................................79

4.5 Theorie's Guiding the Intervention ...................................................8 80

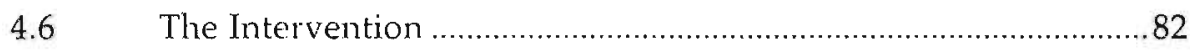

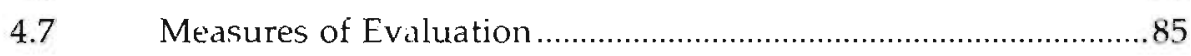

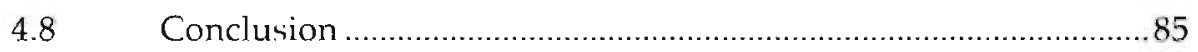

Chapter 5: Was the Intervention Implemented as Intended?: A Process Evaluation of an AIDS Prevention Intervention in Rural Zimbabwe

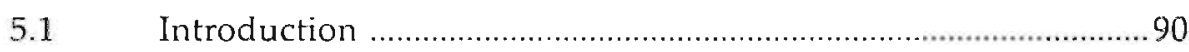

$5.2 \quad$ Background Research ............................................................91

5.3 Intervention Goal and Objectives ..............................................92

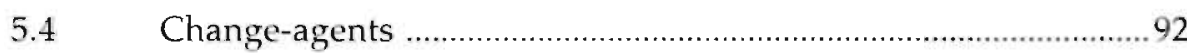

5.5 Theoretical Implications for the Development of the Intervention 92

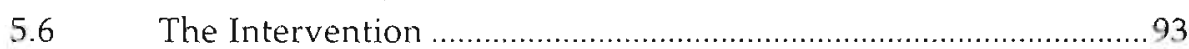

5.6.1 Selection of Farm Workers ........................................................93

5.6.2 Materials Development and Training ............................................93

5.6.3 Description and Implementation of the Intervention ..................94

5.7 Process Evaluation Measures ...................................................... 97

5.7.1 Data Analysis .................................................................. 97

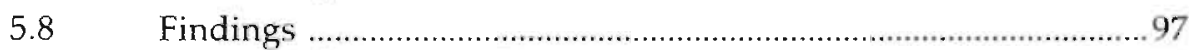

5.8.1 Factors Affecting the Process of the Implementation ................. 98

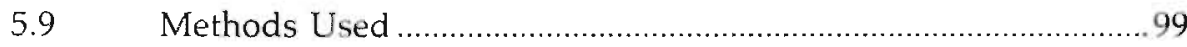

5.10 Effects of Labour Fluctuation and Availability of Disposable Income on Condom Demand ......................................................... 101

5.11 Patterns of Sexually Transmitted Infection During the Process

Evaluation Period.......................................................................... 102 
3.4.8 Condom Use Among Men and Attitudes to Sex and Multi-partnering

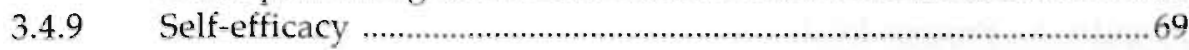

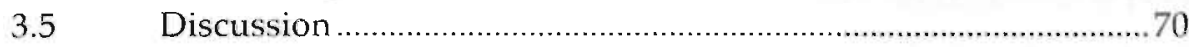

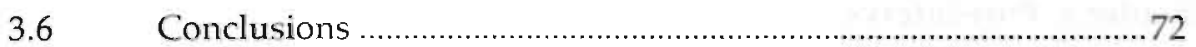

Chapter 4: Using Theory to Design an Intervention for HIV/AIDS in Farm Worker Communities in Zimbabwe

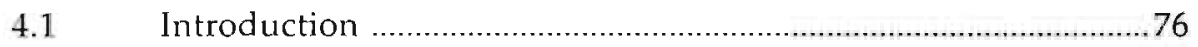

4.2 The Problem ....................................................................... 77

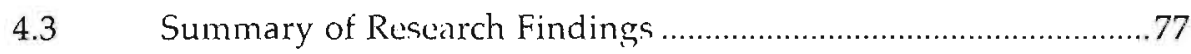

4.4 Goal and Objectives of the Intervention ....................................79

4.5 Theorie's Guiding the Intervention ...................................................8 80

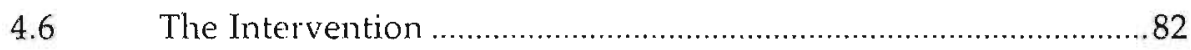

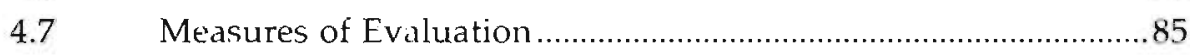

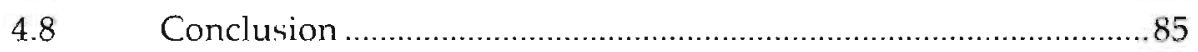

Chapter 5: Was the Intervention Implemented as Intended?: A Process Evaluation of an AIDS Prevention Intervention in Rural Zimbabwe

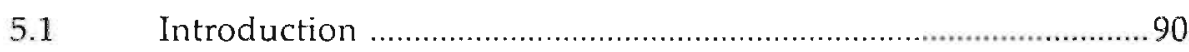

$5.2 \quad$ Background Research ............................................................91

5.3 Intervention Goal and Objectives ..............................................92

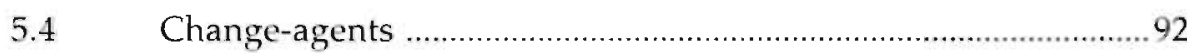

5.5 Theoretical Implications for the Development of the Intervention 92

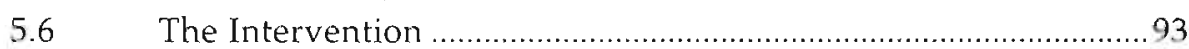

5.6.1 Selection of Farm Workers ........................................................93

5.6.2 Materials Development and Training ............................................93

5.6.3 Description and Implementation of the Intervention ..................94

5.7 Process Evaluation Measures ...................................................... 97

5.7.1 Data Analysis .................................................................. 97

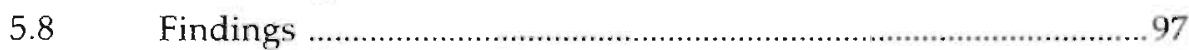

5.8.1 Factors Affecting the Process of the Implementation ................. 98

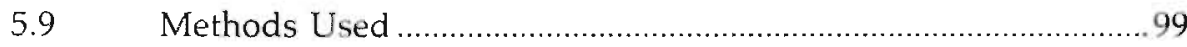

5.10 Effects of Labour Fluctuation and Availability of Disposable Income on Condom Demand ......................................................... 101

5.11 Patterns of Sexually Transmitted Infection During the Process

Evaluation Period.......................................................................... 102 


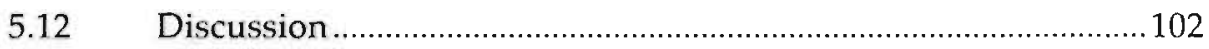

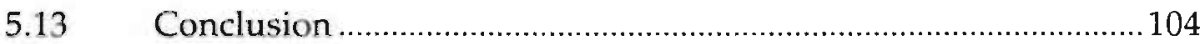

Appendix A : Process Evaluation Form Used by FHWs .........................108

Chapter 6: Post-intervention Survey

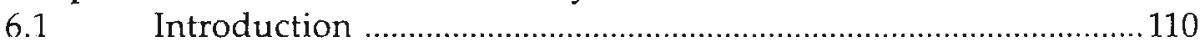

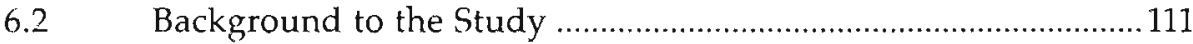

6.2.1 Farm Worker Environment and Social Networks Operating Within the Community .................................................................... 111

6.2.2 Description of the Intervention .................................................112

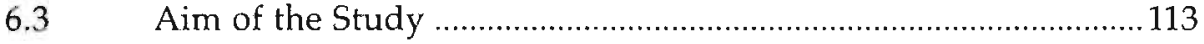

6.3.1 Study Objectives ........................................................................ 113

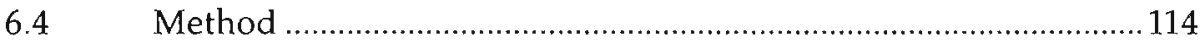

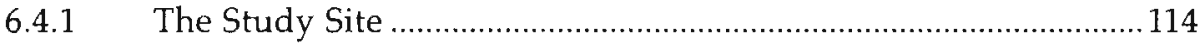

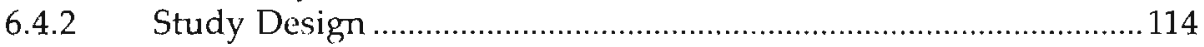

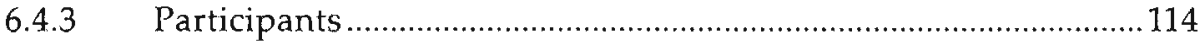

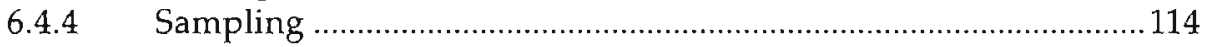

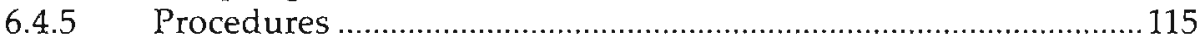

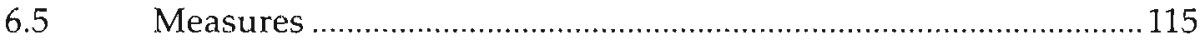

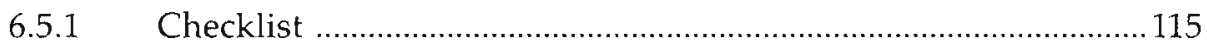

6.5.2 Demographic Differences Between Farm Groups ....................... 115

6.5.3 Scales to Measure Intervention Effects .......................................115

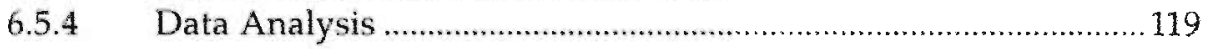

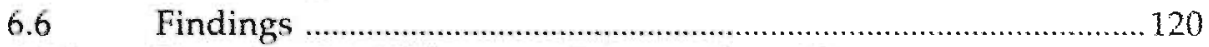

6.6.1 Demographic Differences Between Farm Groups ........................120

6.6.2 Comparison of Farm Groups ………....................................... 120

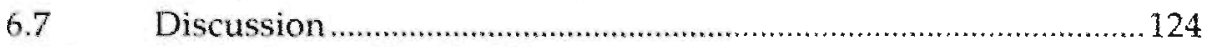

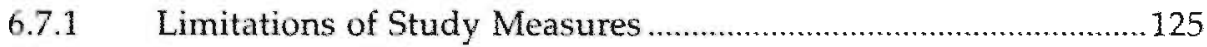

6.7.2 Intervention Effects .................................................................126

6.8 Conclusion - Implications for Future Interventions …................ 128

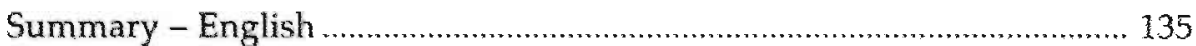

Summary - Dutch ….............................................................................. 140 


\section{Important Definitions}

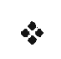

$\therefore$

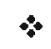

CFU

DPT

EHT

ESAP

FHW

GUD

$\mathrm{MCH}$

NGO

$\mathrm{NACP}$

OPV

PHC

PWA

RDC

STI

UDI

VCW

VHW

VIDCOS

WADCOS
The term 'community' infers non-institutional aggregations of people residing in rural Zimbabwe

Seasonal workers on commercial farms are part-time employees who may be employed for a period not exceeding eight months in any period of 12 months (Source: Collective Bargaining Agreement, National Employment Council for Agricultural Industry)

Casual workers may be wives of permanent farm workers or people who come from surrounding communal lands and neighbouring farms during peak seasons of farming activity

Commercial Farmers Union

Diphtheria Pertussis and Tetanus vaccine

Environmental Health Technician

Economic Structural Adjustment Programme

Farm Health Worker

Genital Ulcer Disease

Maternal Child Health

Non-Governmental Organisation

National AIDS Co-ordination Programme

Oral Polio Vaccine

Primary Health Care

Person With AIDS

Rural District Councils

Sexually Transmitted Infection

Unilateral Declaration of Independence (1965)

Village Community Worker

Village Health Worker

Village Development Committees

Ward Development Committees 


\section{List of Figures}

\section{Chapter 1}

Figure 1 Map of Zimbabwe

Figure 2 Summary of AIDS Cases by Year and Ginder: 1987 - December 1995

Figure 3 Summary of Intervention Plan

Figure 4 Sexually Transmitted Infections and Condom Distribution v Season, Labour Fluctuation and Disposable Income on Intervention Farms 1993-1994

Chapter 4

Figure 1 Summary of Intervention Proposal

\section{Chapter 5}

Figure 1 STIs and Condom Distribution v Season, Labour Fluctuation and Disposable Income on Intervention Farms (1993 - 1994)

\section{List of Tables}

\section{Chapter 1}

Table 1 Overview of Scales

Table 2 Summary of Post Intervention Differences by Gender

Table 3 Item Analysis: Efficacy Scale by Gender

\section{Chapter 3}

Table 1 Demographic Characteristics of Farm Workers

Table 2 Variables by Gender and Education

Table 3 Condom Use by Age, Education and Perception of Risk (men only)

Table 4 Self-efficacy by Risk Perception (women only)

\section{Chapter 6}

Table 1 Overview of Scales

Table 2 Demographic Differences between Farm Groups

Table 3 Post-test Differences on Scales by Gender and Farm Group

Table 4. Item Analysis; Efficacy Scale by Gender

\section{List of Photographs}

Page xiv

The Farm Health Worker Training Centre

The Trainers and the Farm Health Workers

Farm Workers Participating in a Discussion 
Figure 1:

\section{Map of Zimbabwe to show Mashonaland West Province}

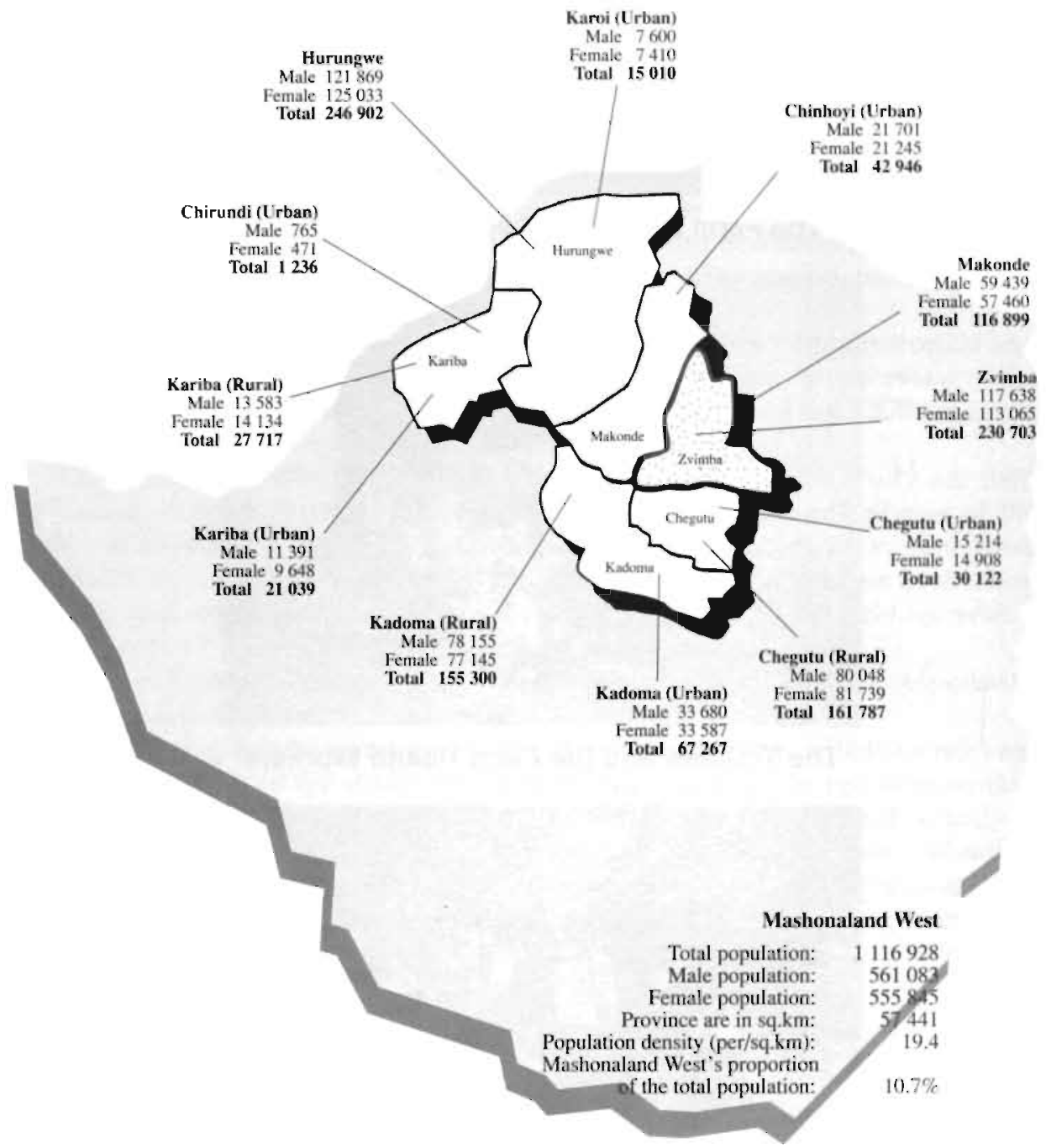




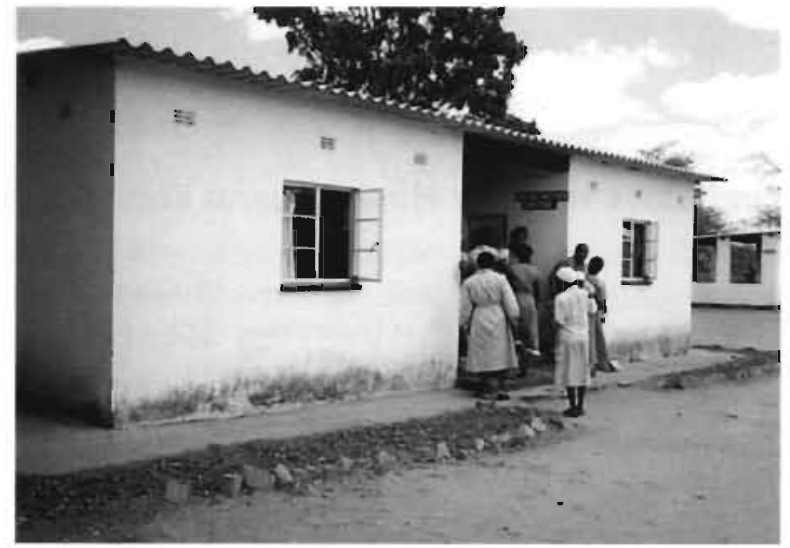

The Farm Health Worker Training Centre

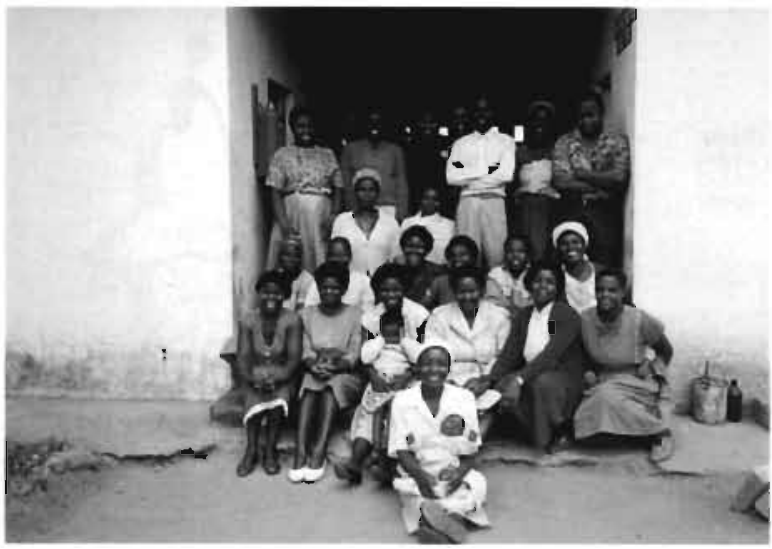

The Trainers and the Farm Health Workers

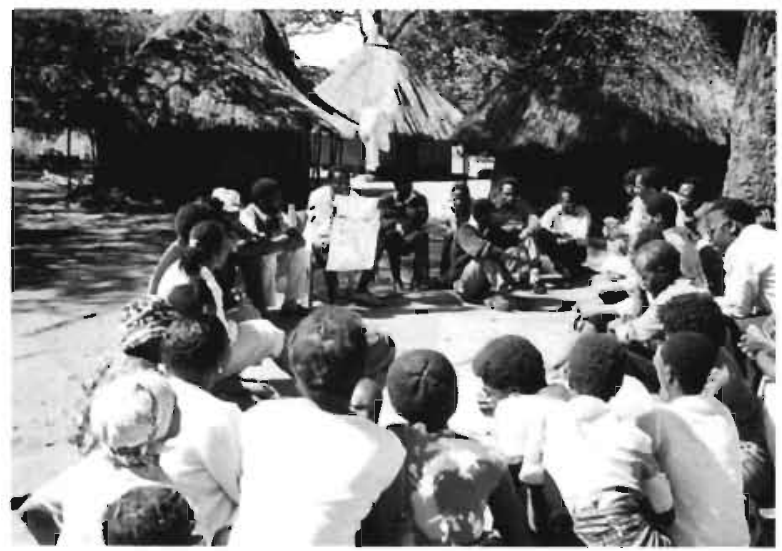

Farm Workers Participating in a Discussion 


\title{
Chapter 1
}

\author{
Overview
}

\subsection{Introduction}

This thesis is organised into six chapters. An approach to developing a community-based HIV prevention intervention for farm workers in Zimbabwe is described. The thesis details how the intervention was designed, implemented and evaluated using both a process and an end-point evaluation. It concludes with recommendations for future HIV/AIDS prevention initiatives in marginalised rural communities.

Chapter 1 provides an overview of the study. It starts with a historical and developmental perspective of Zimbabwe and goes on to give an overview of the health sector over two post-independence decades. It reviews the AIDS epidemic and the responses to the epidemic.

The research problem, the objectives and the design of the study are then presented. A brief description of the study site is provided and phases of the study are reviewed. The findings of the pre-intervention survey are summarised, the intervention design is presented and findings from the process evaluation and the post intervention study are reviewed. The chapter conclude's with a summary and the main recommendations.

Chapter 2 presents a literature review which concerns the eras of response to the HIV / AIDS epidemic in Zimbabwe.

Chapters $3,4,5$ and 6 comprise a series of published papers which are relevant to the main phases of the study. In Chapter 3 the results of the pre-intervention survey are described and in Chapter 4 a review of the theory used in this study to generate the intervention is presented. Chapter 5 deals with a process evaluation and answers the question, 'Was the intervention implemented as planned?'. In Chapter 6 the post-intervention survey results are presented together with recommendations for future community-based HIV/AIDS prevention interventions. 


\subsection{Zimbabwe - A Historical and Developmental Perspective}

\subsubsection{Historical Background}

Zimbabwe, or Rhodesia as it was prior to 1980 , is a southern African country bordered by Zambia, Botswana, the Republic of South Africa and Mozambique (Figure 1). The history of its people, whose livelihood through the ages has largely depended on agriculture, mining and trading, can be traced back over many centuries. European colonisation of Zimbabwe began in 1890 and until 1923 the country was administered as a colony in trust for the British Crown. In 1923, Rhodesia became a self-governing colony with a Westminster parliamentary system run exclusively by whites and a government which discriminated against indigenous people politically, socially and economically in one form or another. In 1965, after British negotiations failed to bring about an acceptance of a proposal for majority rule, the white minority government in Rhodesia made a Unilateral Declaration of Independence (UDI). There was an upsurge of African nationalism around this time and decades of bitter armed struggle against colonial rule finally gave way to political independence and Zimbabwe, in 1980.

\subsubsection{The Government and Administration}

Zimbabwe is a multi-party democracy with an Executive President and general elections are held every five years. At independence, a 'socialist' agenda was introduced. This was followed by a mixed 'socialist-democratic' agenda and in the 1990s a typical World Bank Structural Adjustment Programme is in place (Loewenson and Chisvo, 1993). In the absence of any meaningful opposition, the ruling party (ZANU PF) has been in power since 1980. The country is divided, for administrative purposes, into 10 provinces which include the capital city Harare, and Bulawayo. The provinces are further divided into districts which number 58 in total. Some 1377 wards and 6180 villages characterise the districts, each with a local level of administration.

Government cadres promote the development process at each level; for example at provincial level the provincial executive is responsible for programme planning and management; at district level, cadres such as the Environmental Health Technician (EHT) play a key role in preventive health. At the village level, an all purpose extension worker known as the Village Community Worker (VCW), formally the Village Health Worker (VHW), represents the government.

\subsubsection{The Demography}

The current population stands at about 11 million people with an annual population growth rate estimated at 3.13 per cent (CSO, 1992). The age distribution is similar to those in other African countries, with around 48 per cent of the population estimated to be under the age of 15 years. The dependency ratio, i.e. the ratio of children and young people to the number of people in the 
economically active group is almost 1:1 (Unicef, 1994). It is estimated that approximately 27 per cent of the population reside in rapidly expanding urban areas. Of the 73 per cent rural $\mathrm{d}$ wellers approximately 17 per cent live and work in large-scale commercial farming areas.

There are a number of different landholding systems. In communal areas, a system of communal landholding is based on usufructuary rights. In schemes where indigenous farmers have been resettled since independence, land may only be passed on to descendants. In contrast, a system of freehold tenure applies in commercial farming areas. Farm workers who live permanently on commercial farms do not, however, hold title to land on these farms.

The languages spoken as the mother tongue in Zimbabwe are Shona $(74 \%)$, Ndebele (18\%) and English (4\%) which is the official language in business and education (Unicef, 1994).

\subsubsection{Social and Economic Development since Independence}

With Independence, came a commitment to ending a racially divided social system where service provision was previously based almost exclusively on race and income. This led to widespread expectations within the populace that the social and economic inequalities of the past would be addressed through an agenda which would heed the needs of the racial, ethnic, language and social groups that characterised the country. A policy of reconciliation was enacted; resources were accessed and targeted towards defined areas of need and marked progress in social development was made. Real attempts to satisfy expectations were reflected in the pattern of public spending in education, health and the development of other social infrastructure during this period. For example, primary school enrolment rose from 1.2 million children in 1980 to 2.1 million in 1990 (Unicef, 1994) and in the health sector real government expenditure grew by 33 per cent in 1980/1981 and by 20 per cent in 1981/1982 (Unicef, 1994).

Government grew in absolute and relative terms in the 1980s and the state became the major instrument for righting the social wrongs of the colonial past. In so doing, it became the biggest single sector of the Zimbabwe economy (Unicef, 1994).

However, this was not to last and in the face of declining national income and increasing fiscal deficit, the rapid expansion of the civil service and high expenditure within the public sector which marked the eighties could not be sustained. In 1990 an Economic Structural Adjustment Programme (ESAP) was put in place to spur economic grow th by stimulating exports and investment through a liberalised economy. Public expenditure was curtailed and cuts in the civil service were proposed. Other measures put in place to realise ESAP objectives included the removal of consumer subsidies, price decontrol and cost recovery especially through the introduction of user fees (at health centres for example). Although ESAP has had a significant effect on opening up the economy, there is a growing body of evidence to suggest that it has also enhanced social stratification with a marked effect on the poor and more especially women and children (Bijlmakers et al., 1996; Hongoro and 
Chandiwana, 1994; Loewenson and Chisvo, 1994; Sanders and Sambo, 1991; UNICEF, 1994). A Poverty Alleviation Plan has now been put in place as a mechanism for addressing the negative dimensions of ESAP.

\subsubsection{Health in the First Decade of Independence}

Within the first decade of Independence and in line with the commitment to social change, a policy of Primary Health Care (PHC) was introduced to a hitherto fragmented, curative-based health care system. This was made possible through strong political will and by huge donor and public investment. A rapid expansion of health programmes such as immunisation, nutrition and family planning in the rural areas began. Health care for the majority was made accessible by the removal of racial, urban-rural barriers and through the development of local decision-making structures such as Village Development Committees (VIDCOS) and Ward Development Committees (WADCOS). The expansion of the health sector was backed by the introduction of the Village Health Worker (VHW) trained in preventive health and accountable to the community. Health indicators for that period show that the infant mortality rate (IMR) fell steadily from 120 per 1000 to 140 per 1000 live births before 1980 (CSO, 1989), to around 79 per 1000 in 1985 (Loewenson and Chisvo, 1994). A massive increase in immunisation coverage took place and malnutrition in children was reduced. Other positive indicators of change after 1980 were also shown by a reduction of child morbidity in respect of diseases such as malaria, measles and skin disease and maternal mortality fell from an estimated 150 per 100000 live births in 1980 to 87 per 100000 in 1985 (MoH, 1988; Loewenson and Chisvo, 1994).

Despite these dramatic improvements in primary health care, responsibility for planning and implementation of programmes remained in the hands of the government. There was little cvidence of decentralisation; participation by the community in planning and decision-making was politically constrained and in 1986 the change-agents who had been designated for this process (i.e., the Village Health Workers) were reassigned to a different Ministry to become multi-purpose development workers.

\subsubsection{Health in the Second Decade of Independence}

The beginning of the nineties saw the emergence of the Economic Structural Adjustment Programme (ESAP) which did not exclude the health sector. Budget allucations for health (Loewenson and Chisvo, 1994), education and social services were cut, and the introduction of food subsidies, price decontrol and market liberalisation combined with the effects of a prolonged period of drought served to exacerbate poverty, particularly in the rural areas. The rural-urban drift to the larger cities increased as men migrated in search of work; women generally remained in the communal areas; about 30 per cent of communal area households are de facto female headed (Unicef, 1994). 
Cost recovery measures instituted within the health care system resulted in reductions in drug availability and shortages of transport and manpower, all of which were to impede progress, particularly in rural communities. In summarising the effects of economic reform on health during this period, Loewenson and Chisvo (1994) make the following salient observations:

* the increased cost of living cut food consumption

* the demand for women's work raised the risks of under-nutrition during pregnancy

* cost recovery measures in the health sector depressed the use of Maternal Child Health Services (Renfrew,1992)

* Central hospital maternal mortality rates rose from 73 to over 200 per 100000 (Chisvo, 1993)

While the first decade of independence saw a huge increase in the number of fully vaccinated children ie, from 25 per cent in 1982 to 80 per cent by 1988 , coverage began to platcau in the early nineties when a steady decline was registered, with an estimated five to ten per cent infants dropping out before receiving their second dose of Oral Polio Vaccine (OPV) and of Diphtheria Pertussis and Tetanus (DPT) vaccine (UNICEF, 1994).

With the economic downturn in the second decade of independence came the growing realisation that HIV/AIDS, in addition to having an impact on the productive sector, was also seriously affecting the health of women and children.

\subsubsection{The Emergence of AIDS in the Second Decade of Independence}

After the first official reports of 119 AIDS cases in 1985, the number of cases in Zimbabwe have, as in many African countries, increased rapidly in recent years (Figure 1). By December 1996 it was estimated that around one million or 10 per cent of the total population $(\mathrm{MoH}, 1996)$ were infected with the virus. A cumulative figure of 51908 AIDS cases was reported at the end of December 1995 $(\mathrm{MoH}, 1995)$ and 300 people are said to be dying per week (The Herald, 14 November 1995). The distribution is bimodal with $14.1 \%$ (6885) cases reported to be in children under five years, and 71 per cent (34 797 cases) reported in the economically productive group, i.e. the 20 to 49 years age group. The male to female ratio is nearly 1:1 among adults, and among adolescents (15 to 19 years), incidence among females is six times greater than their male counterparts (Munodawafa and Gwede, 1996). A most notable feature of the epidemic is that infection is taking place at an increasingly early age and the protection of adolescent girls and young women remains one of the most pressing concerns for HIV prevention (SAFAIDS, June 1995). Figure 2 presents a summary of AIDS cases by year and gender from 1987-December 1995.

Sentinel surveillance studies reveal high positivity in certain groups with prevalence rates reaching 52 per cent in pregnant women presenting with sexually transmitted diseases at ante-natal clinics (U.S. Bureau of the Census, Population Division, 1996). The tragedy of orphanhood, which is expected to increase with 
the premature deaths of women, who customarily assume most responsibility for child rearing, is now unfolding. The vulnerable position of these children, previously not perceived as a problem in African culture, is a matter of deep concern (SAFAIDS and CFU, 1996). One study shows that by the millennium there will be some 200000 orphans living, and therefore dependant, on farm worker communities alone.

Almost all infection is transmitted through sexual intercourse or mothers passing the infection to the unborn or newborn. There is little evidence to suggest that transmission takes place through the intravenous drug route or through blood transfusion. The relationship between Sexually Transmitted Infections (STIs) and HIV infection is widely recognised, with STIs known to play a potentiating role in HIV transmission (Latif et al., 1989).

\subsubsection{The Construction of the Response to AIDS in Zimbabwe}

Chapter 2 provides a detailed perspective of the construction of the response to AIDS in Zimbabwe over the past decade.

Figure 2: Summary of AIDS Cases by Year: 1987 - December 1995

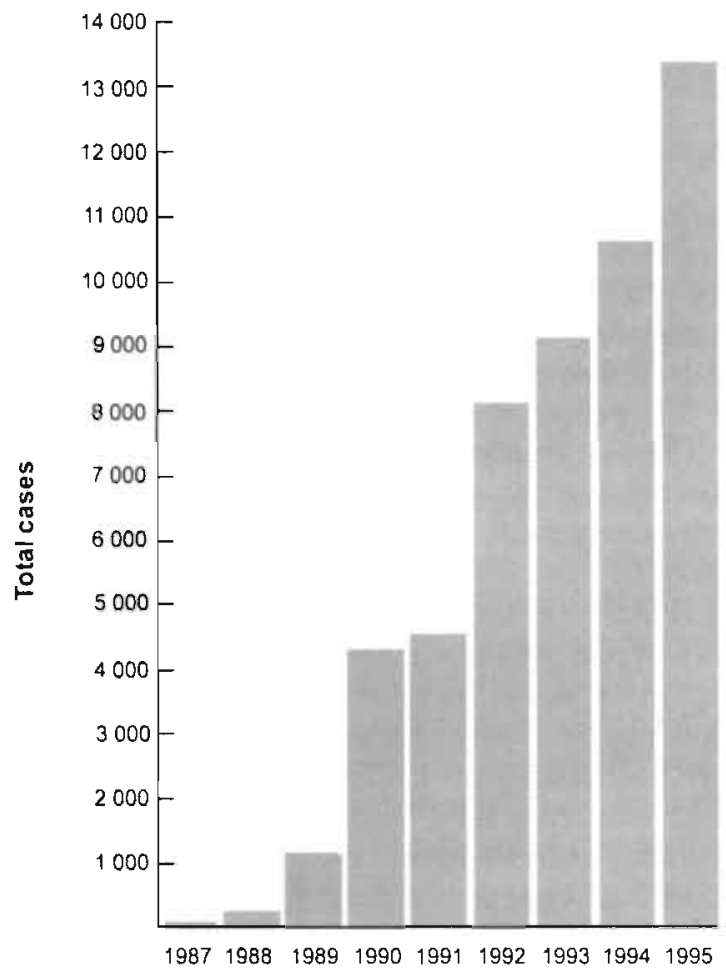

Year 
In analysing the response to the epidemic it must be stressed that AIDS erupted in Zimbabwe only five years after Independence and during a period when the leadership and the people, like much of the rest of the world, were not ready to confront such a threat. The government was responding decisively to a range of political and social demands of a newly independent nation, and an epidemic with an unknown face could not have come at a more inauspicious time. It was not entirely surprising, therefore that, when AIDS was openly acknowledged around 1985, under-reporting and political insensitivity dominated the response. According to the analysis made in this thesis a range of discourses has shaped the AIDS prevention agenda over the last decade. These discourses have fallen within four distinctive eras; an era of non-confrontation, an era of moral confrontation, an era of realisation and an era of reassessment and transformation.

The era of non-confrontation occurred in the mid-eighties and, as was the case in many countries, the public looked to the politicians and the medical experts for a reaction. A distinctive bio-medical discourse was to characterise the debate at that time and a conservative, expert-driven position was adopted by health professionals. Not unexpectedly the dominant discourse was medical and concerned with symptoms and modes of transmission. For the public however, AIDS in the early eighties was a disease without a face which had negative implications for certain lifestyles. The latent period between infection and the onset of AIDS-related symptoms led to a mistaken perception that the problem might go away or that a cure might even be found. In a period of drought, growing economic hardship and political upheaval which had beleaguered parts of the country, AIDS was perceived as an added problem which discriminated against the already marginalised and, according to some, was racially constructed. It was not by chance, therefore, that disputes, conflicting evidence and manifestations of mistrust dominated the discourse during this period. The appearance of the disease was attributed to external and uncontrollable sources through lay explanations which diverted attention from the biological, behavioural and environmental context in which the disease was rapidly spreading. Exogenous, endogenous and 'guilty versus innocent' or 'them and us' theories, which stigmatised and divided, were advanced to explain the nature of the epidemic. Even God was blamed (Homans, et al 1987). However many of the misperceptions were not, as the experts believed, simply an ignorance of the facts, but an interpretation of a new phenomenon about which the public had scanty information. This inevitably lead to denial and underestimation of its potential (Gwede and McDermott, 1992).

In this period the person with AIDS (PWA) as a full human person was absent and de-personalised as a 'patient'; women were typically seen to be 'prostitutes' or 'promiscuous people", members of "high risk groups' or "reservoirs of infection' (Bassett and Mhloyi, 1991; Seidel, 1993). Whereas 'experts' used western approaches to construct education programmes which targeted cognitive gain but little else (Ankrah, 1991; Global AIDS Policy Coalition, 1992; Health Study Branch, 1993; Pozniak, 1993), Wilson and colleagues (1989) called for participative interventions and initiated excellent programmes among sex workers during this period. 
It was also observed that although communities have confronted crises for decades they were neglected by the 'experts' as a resource in planning prevention activities.

\section{An Era of Moral Confrontation}

By the end of the eighties, attitudes of denial were fuelled by a new discourse which was morally constructed and primarily led by the church. In sharp contrast to the position of non-confrontation, the era of moral confrontation challenged values and lifestyles. Issues of celibacy and condom usage were to assume a central and crucial position in the debate (Mbizvo and Adamchack, 1989). The gender construction of the discourse was evident and intervention messages targeted moral values and called upon women to conform to a 'monogamous reproductive' existence and 'say no to unprotected sex'. This myopic approach had the effect of treating women's risk behaviour separately from the behaviour of men and failed to acknowledge the socially-sanctioned inequality between genders and the cultural context in which people interacted (Campbell, 1995). This was to impede intervention design and advance monocausal explanations for extremely complex social phenomena' (Campbell, 1995; Schiller, et al, 1994). Of this period, Seidel (1993) recalls: 'The already entrenched medical dominance and medical discourse, together with the more judgemental medical-moral discourse and their particular gender representations... served to inhibit further ... the process of empowerment, participation and solidarity'.

\section{An Era of Realisation}

By the early nineties, an era of realisation was to succeed the era of moral confrontation which had dominated the earlier phases of the epidemic. The discourse began to reflect a growing recognition that HIV / AIDS was socially, politically and economically constructed. This was guided by AIDS activists and NGOs who called for the devolution of programme responsibility from national governments to communitybased organisations. Attention was drawn to the need for a more appropriate agenda on AIDS prevention which would recognise that migrant labour systems, a long history of colonisation, inadequate health services which were destabilised by cost containment policies - as well as economic crises engendered by the structural adjustment programme (ESAP) - contributed as much to the spread of HIV as did unprotected sex. In underscoring this perspective in 1991, Sanders and Sambo said 'It is predominantly [these] factors, rather than the aberrant behaviour (a presumed African propensity for promiscuity) that require modification if the high risk of transmission is to be reduced'. Many other researchers concurred with this view at that time and later. For example, in 1994, Singer observed that '...AIDS has revealed itself as a disease of social relationship, not merely a social disease, but a disease of modern social order'.

With the rapid advance of the epidemic in the early nineties the discourse began to reflect an openness hitherto lacking in the AIDS debate. However, local researchers showed concern for, and cautioned against, the overwhelming concentration on intra-personal level change to the exclusion of concomitant concern for structural determinants which influenced transmission of the virus. Bassett and Mhloyi (1991), Wilson and Lavelle (1992) and organisations such as the Women's Action Group (WAG) were to make impressive contributions in 
this sphere, and, through their work, the weakened position of wornen and undisputed dominance of men in the sexual arena also became better articulated and understood (Adamchack et al, 1990; Wilson and Lavelle, 1992). In pledging to establish equality for women in the political, economic, social, cultural and civil spheres, the ratification of the UN Convention on the 'Elimination of All Forms of Discrimination Against Women' (CEDAW) by Zimbabwe was also to shift the gender discourse to a more central position on the AIDS agenda.

Importantly, AIDS activists and NGOs including the Zimbabwe Trade Unions began to demand devolution of programme responsibility from the national government to community-based organisations so that interventions could reflect local needs. Attention was repeatedly drawn to the need to involve PWAs as stakeholders at organisational and implementation level. Importance was also attached to promoting normative support for behaviour change through community and small group education - rather than through mass-media campaigns and didactic approaches which had shown little effect (Wilson et al, 1991; Laver, 1993).

A dialogue on screening policies then permeated the discourse as life assurance companies became increasingly alarmed when surveys showed that $48 \%$ of all individual payouts were for suspected or known AIDS-related deaths (SAFAIDS News, September 1995). Episodes of discrimination and violation of fundamental human rights occurred in some workplace situations (Loewenson, 1993; AIDS Scan, 1995) and churches, human rights groups and trade unions began to stress the need for a regional code on AIDS and employment. By mid-1995 the Southern African Trade Union Co-ordinating Council (SATUCC) in cooperation with the Organisation of African Trade Unions Unity (OATUU) Health, Safety and Environment Programme, had developed a draft policy to protect workers ' rights.

\section{An Era of Reassessment and Transformation}

Notwithstanding an analysis which reveals the often unreflective response of government and other organisations to the HIV / AIDS epidemic in the last decade, attention must be drawn to the enormous strides made so far in Zimbabwe to create awareness and to establish an effective system of screening blood and initiating a surveillance system to monitor HIV / AIDS prevalence.

However, there is evidence that while AIDS is taking its toll in Zimbabwe, HIV continues to spread. The epidemic confronts us at a time when the problem of sustaining health coverage within the context of a rapidly declining health budget is also a reality. The community, already under considerable stress financially, is being called upon to cope with the sick, the dying and a growing population of orphans. The concept of 'home-based' care for the terminally ill, though entirely appropriate in theory, may impose intolerable burdens on the poor.

If, as evidence suggests, attempts to control the spread of HIV infection are failing, and if it is true that the community with its long history of coping in the past, is once again on the HIV-prevention agenda, then there is a need to fuster the societal changes which will address the imbalanci's existing within rural constituencies. There is also a need to clarify what we mean by 'community' and to respect the fact that historical and political events have conspired over time to create differences in communities which make their needs unique. There are 
other imperatives which need to be addressed. These concern the need to transform gender imbalances and to reinforce the idea that men should take greater responsibility for self-protection and for the protection of their partners against HIV. The need to strengthen womens' ability to protect themselves from infection is also crucial. Finally there is an urgent need to transform the construction of interventions and actively lobby for the reversal of policies which exacerbate the impact of the epidemic on the most marginalised.

These observations are summarised in 1.9 of this chapter and are presented in detail in Chapter 6 .

\subsection{The Study}

\subsubsection{Statement of the Research Problem}

AIDS interventions in Africa have failed to initiate the wave of behaviour change that was anticipated in the early phases of the epidemic. Faced with new information about risk, people have been expected to alter their behaviour, but as Denscombe (1993) says, 'the evidence is that people do not always respond in a "rational" manner to messages about risk'. While there is a clear understanding that HIV in African communities is mainly transmitted through unprotected, heterosexual, vaginal intercourse, researchers also draw attention to the web of complex cultural factors that shape understanding and influence risk-taking behaviour. (Bassett and Mhloyi, 1991; Caldwell et al., 1989; Linville and Fischhoff, 1993; Mutambirwa, 1991; Sanders and Sambo, 1991).

Approximately 73 per cent of the population in Zimbabwe live in the rural areas. Notwithstanding the mounting epidemiological evidence of HIV infection countrywide (see 1.2.7), there are also data to confirm that infection is becoming increasingly prevalent in rural communities. One study showed, for example, that ante-natal clients $(\mathrm{N}=287)$ living on commercial farms and presenting at local health centres had a sero-prevalence level of 11.5 to 19.9 per cent (De May et al., 1992). In a further study in the same farming district, 25.9 per cent $(\mathrm{N}=197)$ antenatal mothers tested HIV positive and it was shown that between 35.7 and 49.2 per cent of STI patients ( $\mathrm{N}=205$ ) were HIV positive (De May et al., 1992). Data from catchment clinics in the same area showed 24371 reported episodes of STIs in the second quarter of 1994.

In 1993 when this study commenced, few planned AIDS prevention interventions had been carried out in rural workplace communities. For example, surveys conducted in commercial farming communities at two time intervals (Chinemana, 1990; Laver, 1993) also showed that knowledge about transmission of the disease was limited among farm workers and that an unmet demand for information existed. Condoms which are widely promoted for 'safer sex ' were unavailable. National campaign literature such as posters and pamphlets had failed to reach these disadvantaged rural communities (Williams and Ray, 1993). The didactic content of existing print media also showed that interventions were not planned against an understanding of the epidemic and the strong culture of 
dialogue which exists in rural communities (Linville and Fischhoff, 1993). Furthermore, it was evident that the needs of non-literate rural people, a high proportion of whom are women, had not been prioritised by the service providers in the AIDS sector.

In theory, the need for community participation in HIV / AIDS prevention was acknowledged; in practice however, western-type interventions designed for urban, industrialised settings are haphazardly relocated in rural communities where understanding of the epidemic is shaped by a cultural perspective which does not necessarily converge with that of the urban dweller. AIDS communicators therefore failed at that time to plan their interventions on the basis of a clear understanding of the issues that combine to influence the way that people perceive the problem of HIV/AIDS in local settings.

Of particular concern was the commercial farming sector of Zimbabwe which is the single largest employment sector in Zimbabwe, accounting for 53 per cent of all employment and some 26 per cent of formal employment (CFU, 1994). The sector consists of approximately 4600 mainly white-owned farms with an estimated two million people, or nearly a fifth of Zimbabwe's national residents, directly reliant on the farms. The major cash crop is tobacco and the sector as a whole contributes over 15 per cent of gross domestic product (SAFAIDS and CFU, 1996). Farm worker communities were, from the outset, marginalised in the national AIDS prevention effort. Poor organisation within these communities and the lack of support or resources to initiate local programmes of AIDS awareness, coupled with little investment by government or (until recently) other agencies, resulted in farm workers being isolated from preventive efforts. It was not until the CFU drew attention to the need for AIDS prevention programmes on commercial farms that a peer education programme was introduced in farm worker communities. It is against this background that the HIV / AIDS prevention intervention described in this thesis was developed.

\subsubsection{The Study Aim}

The overall aim of the study was to plan, implement and measure the process and impact of an HIV/AIDS prevention intervention on farrn workers from randomly selected farms in Zvimba District of Mashonaland West Province, Zimbabwe.

\subsubsection{The Change-agents}

The change-agents selected to implement the intervention in this study were a cadre of community-based workers known as Farm Health Workers (FHWs) who live and work on commercial farms. Normally women with a basic level of literacy; their task is to promote health and carry out basic preventive care in the farm. worker community. Their training comprises a six week course in Primary Health Care (PHC) which, at the time of this study, had limited input on the topic of 


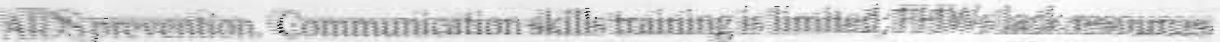

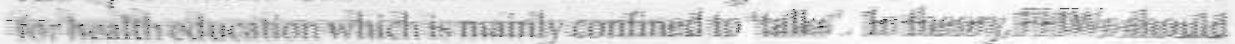

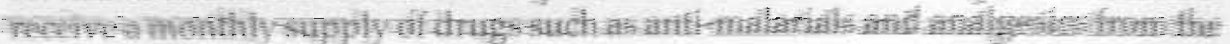

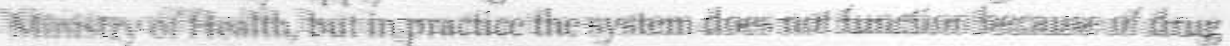
Wind adensport thortages.

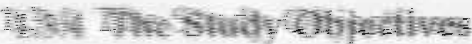

\section{Thendestinghectives wrereas fallows:}

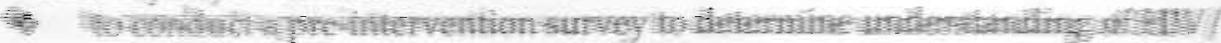

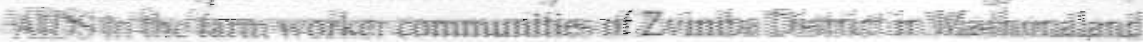

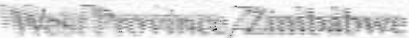

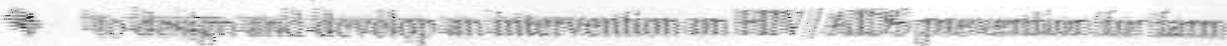

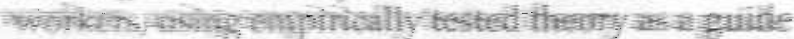

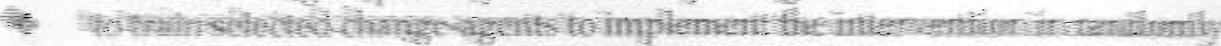

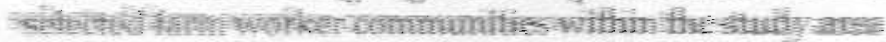

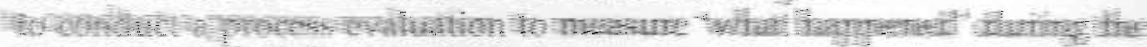

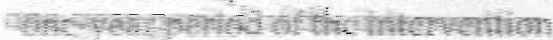

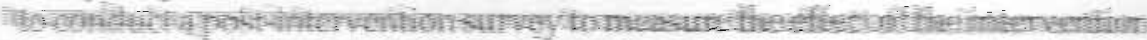

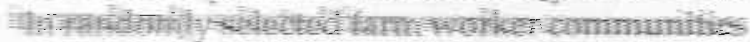

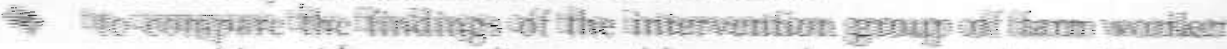
communities with a control group of farm worker communities where no intervention had been implemented

- to make recommendations on the basis of the findings

\subsubsection{The Study Design}

A quasi-experimental, intervention/control post-test only design (Cook and Campbell, 1979) with non-equivalent groups was used, i.e.:

Intervention Group
Control Group

\subsubsection{The Study Site}

The study took place in the Zvimba District of Mashonaland West Province of Zimbabwe. The district is situated $100 \mathrm{~km}$ north east of Harare and has a population of 1116928 people or approximately 10.7 per cent of the total population of Zimbabwe (CSO, 1992).

Zvimba District was selected because it represents one of the most important commercial farming areas in the country. The district also had good potential for success in the intervention. This was indicated by the level of support received for the project from the Ministry of Health at district, provincial and national levels. A willingness by commercial farm owners and their farm workers to participate was also a positive indication. 
In Zvimba District there are approximately 450 large-scale commercial farms where hundreds of farm workers are employed full time or seasonally. The main crops grown in the area are tobacco, wheat, maize and legumes. In the northern part of the district there are banana plantations. In theory, the first point of referral for health problems on commercial farms is the FHW although this is hampered in practice by inadequate training, the lack of resource materials for health promotion activities and a shortage of basic drugs. The study area has six health centres, including one district hospital. Access by farm workers to health care facilities is determined by distance and cost of transport; government clinics offer PHC free of charge to persons earning less than $\$ 400$ (US\$40) per month. Traditional healers who live and work in the farming area provide alternate health care to farm workers and play an important role in managing a range of illnesses, particularly during the peak periods of farming activity when access to clinics is limited.

\subsubsection{Phases of the Study}

The study had six phases. These are summarised as follows:

\section{Phase 1: Needs Assessment Phase}

The needs assessment was carried out in two stages:

* an informal needs assessment and problem identification was carried out early in 1993, prior to the intervention. During this period, focus group discussions were held with farm worker communities and community-based change-agents, i.e. FHWs and FHW trainers. Discussions were also held with farm owners. Background information about these communities and their needs in respect of HIV/AIDS was collected and ideas for the development of intervention materials were generated.

* a pre-intervention survey was carried out by trained research assistants using the interview method on 17 randomly-selected commercial farms from the study area. A total of 9 farms was randomly allocated to an 'intervention' group and 8 were allocated to a 'control' group, making a total of 17 farms in the study group. The survey is fully described in Chapter 3.

\section{Phase 2: Adaptation of Theory and Development of Intervention Materials and Methods}

Pre-intervention findings were conceptualised to guide the intervention design (see Figure 3 in this chapter). Materials development was a re-iterative process which commenced during the needs assessment period and continued throughout the project in response to expressed needs.

\section{Phase 3: Training Phase}

Training was conducted at two levels

- Level 1: Training of FHW Trainers (one week)

* Level 2: Training of FHWs (10 days) 


\section{Phase 4: Intervention Phase}

During this phase, the intervention was implemented in nine farm worker communities by the FHWs. Follow-up was conducted by the principal researcher at monthly intervals and data were collected throughout the intervention period for the process evaluation.

\section{Phase 5: Process Evaluation Phase}

Data for a process evaluation were collected throughout the one-year period of the intervention. The process evaluation is fully described in Chapter 5.

\section{Phase 6: Post-intervention Survey (Effect/Impact Evaluation)}

The post-intervention survey was conducted after 12 months. A pre-tested questionnaire was administered to farm workers in the control and intervention communities by trained research assistants. This study is fully described in Chapter 6.

\subsubsection{Time Frame}

The research was conducted over a period of three years, i.e. from January 1993 to December 1996. The intervention period spanned one year.

\subsection{The Pre-intervention Survey}

An insight into the factors which determine understanding of HIV / AIDS in farm worker communities was a pre-requisite for the development of a meaningful intervention. With this objective, a pre-intervention survey was carried out in the study area. This study is detailed in Chapter 3.

\subsubsection{The Sample}

The following procedure was used:

* Since FHWs would implement the intervention in the farm worker communities, only those commercial farms in Zvimba district on which FHWs were in full time employment could be included in the initial sample. From a pool of $240 \mathrm{FHWs}$ who had previously received training in basic PHC, 40 of the 'best' FHWs were selected by their trainers. The criteria for selection included the willingness of the FHW to participate, a good PHC training record, no previous training in HIV / AIDS prevention, and active participation in health promotion on the farms where they lived and worked.

* It was usual to convene training courses for FHWs in groups of 20 . From the selected group of 40 FHWs therefore, a sub-sample of 20 FHWs was randomly allocated to a 'control' group and 20 to an 'intervention' group for training in the Listening-Appraisal-Dialogue-Action method. 
* Since resources for follow-up were limited, eight FHWs from the group of controls were randomly allocated to a control group. From the intervention group, nine FHWs were randomly allocated to an intervention group (two farms in this group were part of one estate, but in separate locations), making a total of 17 farms in the study.

* Using employment registers on each of the 17 farms, 770 full-time resident farm workers were selected to participate in the pre-intervention survey. Seasonal workers were excluded.

Respondents were interviewed in the vernacular by male and female research assistants who used a pre-tested questionnaire. Since most of the study sample was functionally illiterate, a non-verbal technique was used to assist respondents to answer sensitive questions. This was achieved by asking respondents to rest a stone on or point to a colour-coded board where the colour green denoted the response 'I agree', orange denoted 'I am not sure' and red denoted 'I disagree'.

\subsubsection{Measures}

The socio-demographic characteristics of the target group, the social environment of farm worker community and the social networks operating within the community were examined. The Health Belief Model (Becker, 1974; Becker and Joseph, 1988) and the Attitudes, Self-efficacy and Social Norms (ASE) Model (De Vries et al., 1988), guided the development of questions which measured beliefs about infection, perception of risk, peer influence, condom use and attitudes to multi-partnering among men, and self-efficacy (i.e., 'the conviction that one can successfully execute the behaviour to produce the outcome') with respect to preventive behaviour among women.

\subsubsection{A Summary of Findings from the Pre-intervention Survey}

The pre-intervention survey is fully described in Chapter 3. An adaptation of the Social Ecological Model for Health Promotion (after McLeroy et al., 1988) guided the conceptualisation of the pre-intervention survey findings, i.e.:

* the intra-personal (individual) level dealt with constructs such as knowledge, attitudes, perception of risk, self-efficacy and social norms

* the socio-organisational level focused on findings related to social networks and the organisational culture of the community

* the policy level presented information related to existing regulation

At the intra-personal level, the findings showed that no differences in age, gender, marital status or education existed between the control and the intervention group. In sharp comparison to men, women had significantly $(p<.001)$ less education. Illiteracy was correspondingly high among females. Previous exposure to AIDSprevention activities was limited; a high percentage of farm workers reported that they 'knew very little about AIDS'. On selected items of knowledge, 
misunderstanding about HIV transmission existed, particularly among less educated men who had not attended any AIDS-awareness activities. Beliefs that AIDS is brought about by divine/ ancestral retribution were upheld by less educated women. Importantly, uneducated women who perceived themselves to be 'at some risk of HIV infection' also felt that they 'had no control over their sex life' ( $p<.001)$. Similarly, a high percentage of women $(80 \%)$ who felt at some risk of HIV infection also agreed that there was 'nothing they could do to protect themselves from $\mathrm{HIV}$ ' $(\mathrm{p}<.01)$. A significant number of women ( $p<.001$ ) who felt themselves to be at great risk of HTV infection said that they knew that their husbands 'had other partners'. Among more educated men, there was acknowledgment about multi-partnering and agreement that changes in behaviour are more likely to come about through changes in normative values. Condom use among men, which is probably the most effective barrier against STI infection, was shown to be associated with younger, more educated men.

At the socio-organisational level it was found that although farm workers live and work together, these communities do not necessarily function as an interdependent group. They are loosely organised with little power to make decisions. Their welfare is generally the concern of the farm owner who is the reference point for most major decisions concerning the workforce. Farm workers believed that there was little that the community could do to prevent the spread of HIV. Social groupings mobilise around 'farm football', the beerhall, the church and handicraft. The influx of seasonal workers at certain times of the year and their transient status was felt to re-enforce their 'right' to behave independently of community norms. They were 'blamed' for disruptive behaviour and prostitution in the farm worker community.

Although no community-based AIDS-prevention initiatives were identified on any of the farms in the study, PHC activities are carried out by FHWs. None had received any training in HIV/AIDS; their approach to health education is usually didactic and they lacked teaching resources. Although FHWs are the 'official change-agents' with respect to health promotion, our findings revealed that they lacked recognition and were held in poor esteem by the farm owners and the worker community.

At the policy level, Zimbabwe, like most other African countries, has no laws specifically covering employment-related AIDS issues such as HIV screening (Williams and Ray, 1993). At the time of the study no policy on AIDS for farm workers was in existence. Condoms were not freely available on any of the farms in the study. Supplies tended to be erratic and cost to the farm owner was a limiting factor. No policy for accessing or distributing condoms was evident.

Employers generally retain workers as long as they are able to perform their duties. When a worker dies, the farmer helps to pay the funeral expenses. Since deceased workers are likely to be second or third generation descendants of migrants from neighbouring countries, their dependants have no traditional home to which they may return in old age. In these circumstances, elderly dependants and a generation of children orphaned by AIDS are increasingly expected to characterise farm communities. 


\subsubsection{Conclusions from the Pre-intervention Survey}

It was concluded that unprotected sex and multi-partnering were the two most important behaviours which placed farm workers at risk of HIV infection. However, it was also clear that a wide array of social, organisational and political forces influenced the problem in farm worker communities. At the intra-personal level, women in particular are the targets of social inequity, feeling helpless, unable to control their sexuality and without the means to reduce the risk of HIV infection. At the socio-community level, the people are disempowered and participate only nominally in decision-making. At policy level, there are no regulations which enhance accessibility of condoms or protect AIDS sufferers and their dependants.

\subsection{The Intervention}

\subsubsection{Goal and Objectives of the Intervention}

The intervention was developed against a background of findings from Phase 1 of the study. The overall goal of the intervention was to decrease the risk of HIV / AIDS through unprotected sex, and to increase farm worker participation in AIDS-prevention activities. Specific objectives included the need to develop a multi-level intervention with a phased participatory methodology which would target change within the individual and the socio-organisational context, in which farm worker communities live and work (Figure 3).

Intermediate objectives of the intervention were concerned with raising dialogue and encouraging appraisal of lay beliefs, vulnerability to HIV/AIDS and barriers to behaviour change among the intervention communities. The intervention would also use methods to raise self-efficacy about protective behaviour in women and to target risk behaviour in men. At a policy level, improved access to treatment for STIs and free condom distribution were important objectives (Figure 3). In keeping with community organisation principles (Bracht, 1990), the intervention should be implemented by persons who were known to, and accepted by, the farm worker communities. FHWs already working in these communities were regarded as the most appropriate change-agents for the intervention.

\subsubsection{Theories Guiding the Intervention}

Chapter 4 provides a detailed description of how theory was used to design the intervention.

In this chapter, attention is drawn to the work of several authors (Amaro, 1995; Laver, 1993; McLeroy et al., 1988) who point out that AIDS-prevention interventions commonly fail to shift their focus beyond the cognitive level. In concurring with this position, McLeroy et al. (1988) say that this incorrectly assumes that 'the proximal causes of behaviour lie within the individual...rather than in the social environment'. Amaro (1995) stresses the need for researchers to locate models and theories which in addition to cognitive change, also target 
the social context of sexuality and the differences which shape risk behaviour between men and women. In this study, attention was focused on the need to conceptualise a prevention programme for farm workers in which change could be meaningfully activated beyond a cognitive level. Two models proved appropriate for this purpose.

The first concerned the ecological model of health promotion (McLeroy et al., 1988) which, in addition to proposing a variety of intervention strategies, also focuses attention on individual and social factors as targets for change at different levels.

The second theory of major importance to the development of the intervention was the theory for individual and social change originally developed by Paulo Freire (1972), and used extensively in health promotion and social development programmes by David Werner (Werner and Bower, 1982) and others (Auerbach and Wallerstein, 1987; Hope et al., 1984; Wallerstein and Bernstein, 1988; Wallerstein and Sanchez-Merki, 1994). In acknowledging the need for interplay between individual and social-organisational change, Freire's work also provides a philosophical framework for the development of strategies for interventions. In particular, the model had three major advantages for the intervention.

Firstly, it encompasses a participatory orientation to learning rather than a passive mode of delivering information. In Freire's words (Freire, 1972), 'we simply cannot go to the workers... to give them knowledge ur to impose upon them the model of the "good man" contained in a programme whose content we have ourselves organised".

Secondly, the model incorporates a listening-dialogue-action methodology which is an ongoing cyclical process (as opposed to a linear process), appropriate for motivating critical thinking within a target group where there is a need to 'revisit' and 're-appraise' key issues such as lay beliefs throughout the intervention.

Thirdly, the model as described by Wallerstein and Sanchez-Merki (1994) integrates protection-motivation theory, which proposes that decisions to act can be initiated through a variety of information sources, thus reducing the dependency on didactics (Wallerstein and Sanchez-Merki, 1994 quoting Rogers et al., 1978; Rogers, 1984).

In addition to the above, a number of other theories were reviewed for the development of the intervention. In conceptualising the targets of change for the intervention, for example, the Health Belief Model (HBM) (Becker, 1974; 1988) was useful. Described by Amaro (1995) as a cognitive model of behaviour change, the HBM attempts to explain individual behaviour according to one's perception of vulnerability, i.e. susceptibility, perceived threat, advantages and disadvantages of changing behaviour and barriers. The Social Cognitive Theory (Bandura, 1986), in which vicarious learning (modelling) is a central theme, also views behaviour as a function of a person's self-efficacy, i.e. the belief that one can successfully execute a behaviour in order to produce the outcome. This was especially important given the need to develop coping responses among women ("There is 
something I can do to prevent myself from getting HIV / AIDS') who were shown through the background research to be 'helpless' and sexually disempowered (Laver et al., 1994/1995).

Other theories which had implications for conceptualising the intervention at the intra-personal level included the theory of planned behaviour (Ajzen, 1987) which draws attention to what people - in particular influential people such as peers - would expect them to do in a particular situation. This was critical, given male attitudes to STI and multi-partnering.

Finally, attention was focused on the theory of change as it would apply to the tradition of organisation in the target community. Many authors propose interesting views on the organisational aspects of community interventions. Bracht (1990); Bracht and Kingsbury (1990); Minkler (1990); Minkler and Cox (1980) describe community organisation as 'the process by which community groups are helped to identify common problems, mobilize resources and in other ways develop strategies and goals for reaching the goals they have set'. Of particular importance to this study, and central also to the Freirian philosophy, were the issues of empowerment which, according to earlier work of Ross (1955) and later work of Freire (1972), must increase problem-solving, participation and the development of critical consciousness. In emphasising the role of change-agents (FHWs) in the diffusion process (Rogers and Shoemaker, 1971; Rogers, 1983) and the linkage approach (Havelock, 1971; Orlandi, 1987) in the social environment, the diffusion of innovations model also removes the focus somewhat away from the individual as the target for change (Graeff et al., 1993). According to this perspective, the intervention would be re-enforced at each level through a linkuge system made up of FHWs (the change-agents) and land owners.

In examining these models, an effort was made to keep those components which would enable the attainment of the objectives and permit the flexibility which was required in the conceptualisation of the intervention at each level of implementation.

\subsubsection{The Intervention Plan}

The intervention plan which draws together the levels of intervention, the theories of change, the targets of change and proposed strategies is presented in Figure 3.

In summary, the intervention targeted three levels, viz an intra-personal level, a socio-organisational level and a policy level (after McLeroy et al., 1988). The theories of change embraced the HBM (Becker, 1974), the Social Cognitive Theory (Bandura, 1986), the Theory of Planned Behaviour (Ajzen, 1987) and the Community Organisation Theory (Minkler, 1990; Rogers and Shoemaker, 1971; Rogers, 1983). The targets of change are specific to each level of the intervention. The strategies and methods for the intervention embraced the Freirian Structured Dialogue Model described by Wallerstein and Sanchez-Merki (1994), in which a cyclical 'ListeningAppraisal-Dialogue-Action' approach was used. 


\subsubsection{Strategy and the Methods of the Intervention}

In designing the strategy for the intervention, the need to decrease the role of the change-agent over time and increase community involvement in AIDS-prevention activities was clearly recognised. The stages of the intervention were cyclical and the process was reiterative (Figure 3 ).

* At the intra personal level of the intervention innovative methods were used to encourage active listening and appraisal of personal vulnerability to HIV / AIDS, through activities which raised critical thinking and dialogue: ('What is AIDS?'; 'How did it get to Zimbabwe?'; 'Has it reached the rural areas?'; 'Am I at risk?'; 'Is my family at risk?'). Agree/ disagree activities were used to assist farm workers to appraise beliefs: ('AIDS is a results of our ancestors' displeasure: Yes/No/Not sure'). Emphasis was then placed on generating cognitive change through an awareness of facts. Dialogue about self-protective behaviour was encouraged through methods such as picture codes (Laver, 1994) which raised sensitive issues about condom use among men, men's attitudes to women, peer influences and self-efficacy with respect to negotiating safe sex.

* At the socio-organisational level the intervention was concerned with an appraisal of issues within a broader societal/environmental context: ('What can we do to involve seasonal workers in AIDS prevention?'; 'What can men do?'; 'What can women do?'; 'What can we as a community do?'; 'What can the farm owner do?'). In this phase, the locus of control had shifted from the change-agent to the community, with empowerment, social responsibility and action as important objectives (i.e., shown by new initiatives such as AIDS clubs).

* At the policy level, the target of change concerned issues of condom distribution and improved access to STI treatment. The intervention also encouraged critical thought around the problem of AIDS orphans and dependants of sufferers in the community: ('What can the community do?'; 'What should the government do?'; 'What should the land owners do?').

In summary, the locus of control for the intervention shifted from the researcher at the problem definition/materials development and training stage, to a point at which the project was institutionalised within the community through the change-agents. However, given the non-participatory environment in which farm workers have historically found themselves, it was understood that this could be a difficult objective to achieve. Social action would depend on the support available for change; individual change would be the only possible outcome.

\subsubsection{Training of Change-agents}

The first stage of training involved a training workshop for trainers of FHWs. A workshop manual which contained a step-by-step description of the intervention methodology was prepared along with a range of resource materials which included a poster and several picture codes. In this workshop, particular attention was paid to developing skills which in turn would promote the adoption of a 
Figure 3: Summary of Intervention Plan

\begin{tabular}{|c|c|c|c|}
\hline $\begin{array}{l}\text { Level of Intervention (after } \\
\text { McLeroy et al 1988) }\end{array}$ & Theories of Change & Targets of Change & $\begin{array}{l}\text { Strategies/Methods (after } \\
\text { Freire 1972;1983; Wallerstein } \\
\text { \& Sanchez-Merki, 1994) }\end{array}$ \\
\hline \multirow[t]{2}{*}{ - Intra-personal level } & $\begin{array}{l}\text { Health Belief Model } \\
\text { (Becker, 1974; 1988) }\end{array}$ & $\begin{array}{l}\text { - Personal identification with the } \\
\text { problem } \\
\text { - Recognition of problem } \\
\text { - Lay beliefs } \\
\text { - Vulnerability ie, appraisal of } \\
\text { susceptibility, threat, advantages } v \\
\text { disadvantages of behaviour } \\
\text { change, barriers. } \\
\text { - Cognitive change } \\
\text { - Attitude change }\end{array}$ & $\begin{array}{l}\text { APPRAISAL } \\
\text { Agree/disagree activities } \\
\text { Poster }\end{array}$ \\
\hline & $\begin{array}{l}\text { - Social Learning Theory } \\
\text { (Bandura, 1986) } \\
\text { - Theory of Planned Behaviour } \\
\text { (Ajzen, 1987) }\end{array}$ & $\begin{array}{l}\text { - Self empowerment (efficacy) } \\
\text { - Response efficacy } \\
\text { - Social norms }\end{array}$ & $\begin{array}{l}\text { DIALOGUE } \\
\text { Flip chart } \\
\text { Picture codes } \\
\text { Condom distribution } \\
\text { Drama }\end{array}$ \\
\hline - Socio-organisational level & $\begin{array}{l}\text { Community Organisation } \\
\text { Theory } \\
\text { (Minkier, 1980; 1990; Rogers \& } \\
\text { Shoemaker 1971; Rogers, 1983) }\end{array}$ & $\begin{array}{l}\text { - Community empowerment } \\
\text { - Social responsibility } \\
\text { - Social action }\end{array}$ & $\begin{array}{l}\text { ACTION } \\
\text { Formation of AIDS clubs } \\
\text { Maintenance of condom supply } \\
\text { Peer education } \\
\text { Networking }\end{array}$ \\
\hline - Policy level & - Regulations & - Improve access to STI treatment & \\
\hline
\end{tabular}


participatory teaching approach among FHW trainees. Time was also set aside during the workshop for trainers to practice new teaching methods in the community.

In the second stage of the training programme, selected trainers trained the FHWs. Training took place within a rural hospital setting where there was ample opportunity for outreach into nearby communities for practice sessions (see photograph on piv). Each FHW was supplied with a complete resource kit before returning to the community to start the intervention.

\subsubsection{Measures of Evaluation}

The multi-dimensional nature of the intervention demanded that a single endpoint measurement would be inappropriate for the study, since it would fail to go beyond what quantitative data could support. It was also accepted that behaviour change in the target population was likely to take place gradually over time and certainly over a period greater than one year which was the time frame of this study. Given the time constraints of the study, it was considered important to measure and report on (a) the process of the intervention, i.e. what actually happened during the intervention, and (b) the effect of the intervention, i.e. what changes occurred after a 12 -month period.

\subsection{The Process Evaluation - A Summary of Findings}

The process evaluation is fully described in Chapter 5 .

\subsubsection{Data Collection}

Data for the process evaluation were collected through the following methods

- process data forms (Appendix A) completed by FHWs every month. Data pertaining to reach, i.e. numbers of groups convened, enquiries from other farms, new HIV / AIDS prevention initiatives within the community, methods of communication used, number of condoms distributed, new condom distribution points, STI incidence data, i.e. number of new AIDS cases reported to FHWs and catchment clinics within the project area

* seasonal data, i.e. data concerning the influx of seasonal workers at different times in the farming calendar, bonus months, leave periods etc.

* discussions, i.e. to collect data from FHWs at monthly meetings

* follow-up visits to intervention farms and discussions with farm owners

\subsubsection{Lessons Learned from the Process Evaluation}

Figure 4 presents a graphical summary of interacting factors which combined to illustrate 'what took place' on the intervention farms between 1993-1994, i.e. one year. In this figure, the farming seasons are shown together with information about the arrival and departure of seasonal workers, data related to condom distribution during the intervention period and STI incidence data obtained from catchment clinics. 


\section{At Interpersonal Level}

\section{* Structure of the Intervention}

Although the structure of the intervention was effective in promoting interest in HIV/AIDS in the farm worker communities, other factors limited the implementation of the intervention as planned. For example, change-agents demonstrated difficulty in persisting with a teaching methodology in which people are not the objects of an educational project, but participants in a process of change. FHWs also reported the problem that "people grew tired of certain picture codes', for example, and neither the resources (nor skills) for generation of new codes were in place.

\section{$\because$ The Strategy}

The culture of didactics, which still characterises health education activities in Zimbabwe, prevailed in spite of intensive training which promoted an alternative approach. In particular, FHWs experienced difficulty in achieving dialectic and active participation by the community. However, they were extremely successful in mobilising the community for 'appraisal' sessions when the agree/disagree activity was used.

\section{- Self-efficacy}

While recognising the need to promote the concept of self-efficacy with respect to self-protection, particularly in women, FHWs also acknowledged the difficulties of influencing cultural norms known to militate against the attainment of balancing power in sexual relationships.

\section{* Reach}

It was particularly difficult for FHWs to reach farm workers during the off season and the peak season on farms. During the off-season when more time was available for intervention activities, fewer people were available because a large number of farm workers took their leave. Conversely, in the peak season when more people were available, long working hours precluded intervention activities and fewer farm workers participated. In this period we found that men devoted recreation periods to binge drinking. Their wives, on the other hand, engaged in domestic chores after work.

\section{* Incidence of STI}

Seasonal peaks in the incidence of STI infections corresponded with those observed at district and provincial level. A decrease in the number of reported infections in the peak period of the farming calendar was not, as anticipated, due to the intervention, but due to limited time for treatment seeking at catchment clinics. Traditional healers reported an increase in STI reports in peak periods of farming activity.

\section{* Condom Distribution}

Condom supplies were maintained on the intervention farms throughout the study and FHWs were successful in setting up new distribution points within the community. Fluctuations in condom demand (Figure 4) coincided with the influx and departure of seasonal workers. Demand increased as it became known among workers from neighbouring farms that free condoms were available. 


\section{At Socio-organisational/Policy Level of Change}

\section{- Influence of Seasonal Workers}

The presence of seasonal workers in the peak season was felt to be disruptive. An influx of sex workers during this period corresponded with the increase in dispusable income in farm worker communities in peak periods.

* the process evaluation showed that farm worker communities demonstrated difficulty in responding to the challenge of the intervention, even in the face of an epidemic which will, in time, place further burdens upon them.

* while it was hoped that the intervention would encourage farm workers to become organised around an issue as important as HIV/AIDS, a lack of previous experience in collective action was shown to be a disabling factor in achieving this objective.

* in the face of other problems such as poverty and drought, workers perceived little sense of purpose in dealing with an 'external' threat which is likely to have an impact in the future.

* although it was observed that links between FHWs and farm owners were strengthened during the intervention, a reserved attitude towards authorities was still prevalent at the end of one year.

\subsubsection{Conclusions from the Process Evaluation}

In summary, the findings of the process evaluation led the researcher to:

$* \quad$ raise questions about the nature of HIV / AIDS prevention programmes in farm worker communities where reaching a threshold necessary for change is dependent on the social and environmental milieu in which the people live and work

- question the extent to which participation or otherwise in an intervention should be used as a valid index of success. In this context we ask whether the desire for participation carries more significance for outsiders than for the farm workers themselves

* recognise the perspectives held by the community about their ability to participate and their capacity to change. While HIV / AIDS interventions have a role in motivating cognitive and attitude change, the motivation to seriously confront and re-pattern risk behaviour will possibly best evolve from within the community

* recognise that the agenda for HIV/AIDS prevention in farm worker communities must therefore be more closely constructed by the people themselves

* question an approach which is dependent on a single change-agent

* recommend that a group of change-agents, i.e. men and women, should be elected by the farm worker communities for training in the ListeningAppraisal-Dialogue-Action method. This, it was concluded, would have an impact at both an intra-personal and socio-organisational levels and allow for greater reach during periods when time is limited for group activities at the workplace.

* promote process evaluation as an in-built component of intervention studies 
In answer to the question 'Was the intervention implemented as planned?', the conclusion was 'Only partially'.

\subsection{The Post-intervention Study}

A full description of the post-intervention study is presented in Chapter 6.

The end-point evaluation was conducted one year after the HIV/AIDS prevention intervention was implemented in nine farm worker communities in Zvimba District of Zimbabwe. The intervention (1.5.2) was designed according to a combination of Freire's Social Change Theory and the Ecological Model for Health Promotion (Laver, et al., 1994/1995). A participatory methodology (1.5.4) was developed to provoke critical thought about the problem of HIV / AIDS, to encourage self-protective behaviour especially among women, and to create a climate for preventive action within farm worker communities. A process evaluation (Laver et al., 1996/1997), which is described in Chapter Five, was carried out during the intervention period. Importantly, it provided an insight to the contextual environment in which the intervention took place and assisted in reaching an understanding of 'what happened' during the intervention period.

\subsubsection{Aim of the Post-intervention Study}

The aim of the post intervention study was to measure the effects of an HIV/ AIDS prevention intervention in a randomly-selected study population of farm workers, permanently living and working on commercial farms in one district of Zimbabwe.

\subsubsection{Study Objectives}

At an intra-personal level, it was hypothesised that the intervention would have a significant effect on raising cognitive understanding of HIV/AIDS, increase condom use, and incruase self-efficacy in women with respect to self-protective behaviour.

At a socio-organisational level, it was hypothesised that the intervention would improve support by authority (farm owners and farmers' organisations) for AIDSprevention activities, lead to a change in policy for condom distribution and improve access of farm workers to STI treatment.

\subsubsection{The Method}

The study site is described in 1.3.6.

A quasi-experimental post-test-only design with non-equivalent groups was used to measure the effect of the intervention after 12 months (Cook and Campbell, 1979). The study participants were full-time adult male and female farm workers who permanently resided and worked on commercial farms in the Zvimba District of Mashonaland West Province in Zimbabwe. Seasonal workers were excluded because they did not meet the criteria for residency or permanency. 
STIS AND CONDOM DISTRIBUTION v SEASON, LABOUR FLUCTUATION AND DISPOSABLE INCOME ON INTERVENTION FARMS

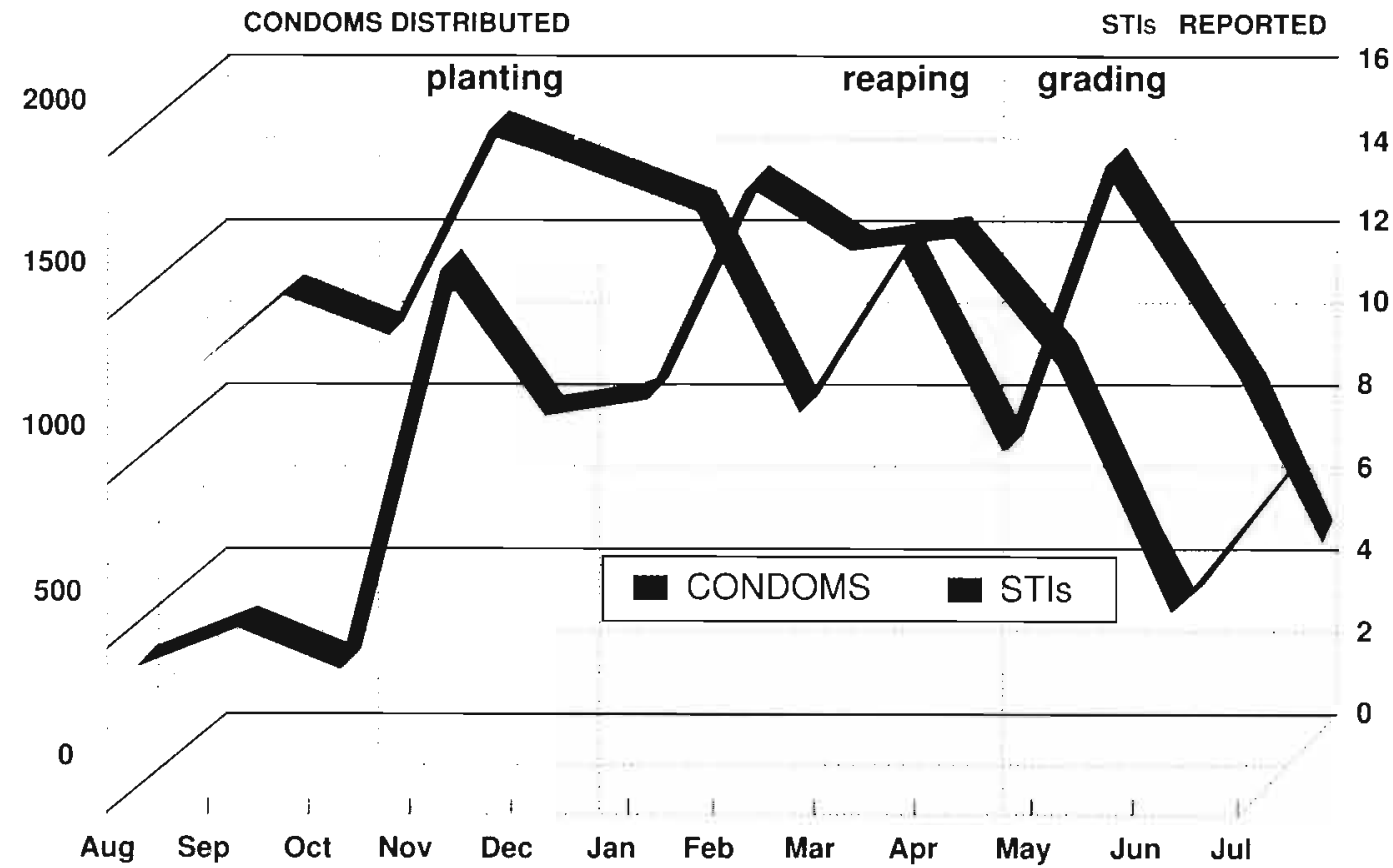


Participants were selected from 17 farms randomly assigned in the preintervention phase of the project, i.e. nine farms to an 'intervention' group and a further eight farms to a "control' group. For the purposes of the analysis, however, four farms from the 'control' group were re-assigned to an 'unplanned intervention group'. This became evident during the process evaluation (Laver, et al., 1996/1997) when it was discovered that (a) workers from one farm adjacently situated to an intervention farm had been attending intervention activities and (b) on the other three control farms, HIV/AIDS projects had been implemented by a non-governmental organisation. In their intervention, it was found the change-agents were men, with peer-education and condom distribution as the main focus in those farm worker communities.

The criteria for including farms in the study were a willingness of the owner and the community to participate and a requirement that each farm should have, in residence, a trained FHW who was functionally literate and actively engaged in PHC activities within the farm worker community, but who had not received training in AIDS prevention (Laver et al., In press). Participation rate was 100 per cent, although some respondents declined to answer all of the questions.

On each of the 17 farms, a random number table and a numbered employment register was used to select 50 farm workers for interview. In order to ensure equal representation of men and women in the sample, wives of the men randomly selected from the employment register were also interviewed where possible. The total sample size was 853 farm workers, of whom 452 (229 male, 223 female) were drawn from the 'intervention' group. In the 'control' group the sample size was 199 (101 male and 98 fernale). In the 'unplanned intervention' group the total sample was 202 (100 male and 102 female).

The intervention groups and the control group of farm workers were similar in respect of gender, marital status, nationality and wage. However, significant differences were found between groups in respect of education $(p<.01)$, age $(p<.05)$ and religious affiliation $(\mathrm{p}<.01)$.

Data were collected over a period of six weeks, and exactly 12 months after the intervention was implemented. The interview method was used to administer a pre-tested questionnaire. Three male and three female Shona-speaking research assistants with previous research experience in farm worker communities conducted the interviews, which took no longer than 20 minutes per respondent. In order to obviate bias which may have resulted through shyness, female researchers interviewed female workers and male research assistants interviewed male workers. The experimental status of the farms surveyed in the study was unknown to the interviewing team. Interviews were conducted in a comfortable, secluded place. To ensure further privacy to the interview process, respondents were invited to indicate their responses to sensitive statements or questions by pointing to a coloured board where the colour green denoted a 'yes' response, orange indicated 'not sure' and red indicated 'no'. 


\subsubsection{Measures}

A checklist was used to make background observations about the social and environmental context in which farm workers live and work. Demographic differences between farm groups were measured by rine questions regarding gender, age, education, literacy, religious affiliation, wage, nationality and marital status.

\section{Scales to Measure Intervention Effects}

There being no validated instruments to measure reliably and validly the intervention effects in farm worker communities, where literacy and education is known to be low, a data set was formed from a pool of statements and short questions collected from the farm worker community during the pre-intervention phase of the study.

Test items were drawn from the data set and converted into scales to test different constructs of knowledge, condom use, self-efficacy and perceived support by authority for HIV prevention. Scale construction was performed by selecting groups of variables, determining the number of items to be considered, extracting a set of factors from the correlation matrix and rotating the factors to increase interpretability. In this way items were factor-analysed and refined until a reliable and sensitive research instrument with an internal consistency (Cronbach's alpha $>.50$ ) was reached (Tabachnick and Fidell, 1983). Table 1 provides an overview of scales used to measure intervention effects in the study.

\subsubsection{Summary of Findings}

A detailed presentation of findings from the post-intervention study is presented in Chapter 6. Significant differences in education, age and religion were found between groups in the study population. Importantly, it was found that there was a significantly younger female population in the unplanned intervention group and an older male population in the control group. It was also shown that significantly $(p<.01)$ more females $(66 \%)$ reported a religious affiliation when compared with males $(33 \%)$. The analysis showed that there was a significant $(\mathrm{p}<.001)$ difference between males and females in education, with 62.2 per cent of the females not having attended school when compared with 32 per cent males. The differences which were found to exist between gender, age, education and religion in the study sample were therefore used as co-variates in further analysis.

\section{Intervention effects and non-effects}

At the intra-personal level, we found significant differences in knowledge about HIV / AIDS between the intervention and control groups (Table 2). In particular, the intervention was successful in increasing knowledge in educationally disadvantaged women. When compared with men, women reported having participated in fewer intervention activities. It was noted that men attended activities during working hours when time was allocated for that purpose - while women participated voluntarily in free time which was limited because of the need to do houschold chores. With respect to perceived susceptibility to HTV, we found that the intervention had an effect in increasing 'worry' and perceived vulncrability to HIV, particularly among women. It was strikingly evident, however, that even when armed with infurmation 
Table 1: Overview of Scales Used to Measure Intervention Effects in the Study

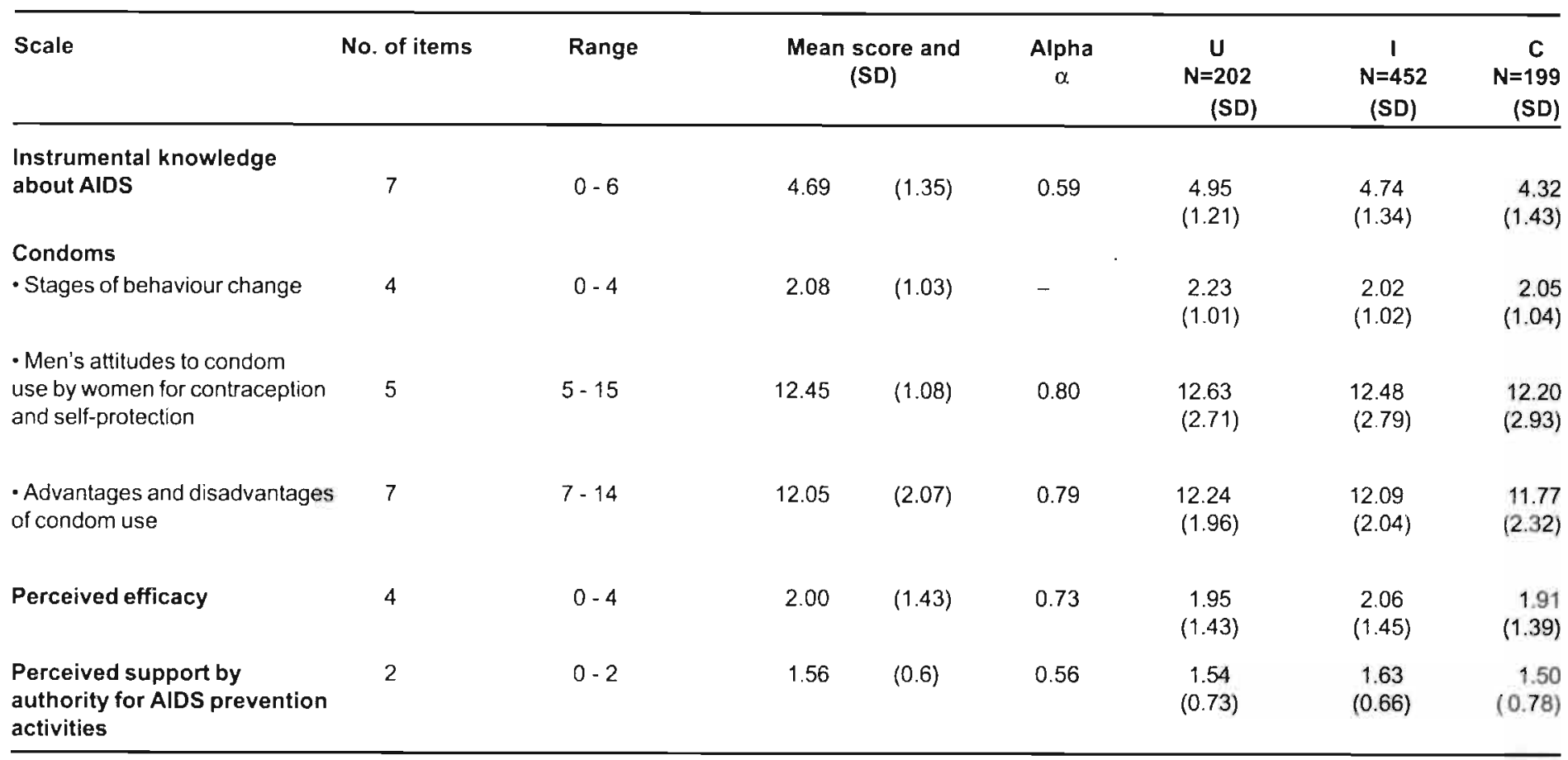

$\mathrm{U}=$ Unplanned intervention group

$I=$ Intervention group

$\mathrm{C}=$ Control Group

* The higher the score, the more positive the result 
and concern about HIV / AIDS, our efforts to increase self-efficacy in females failed, with a significant number of women articulating helplessness and powerlessness to transform their risk status. Attention is drawn to Table 3 which shows the striking gender differences in self-efficacy measures. In the opinion of the researcher, achieving a threshold necessary for increasing self-efficacy in interventions is beyond cognitive gain, and far more dependent on reducing the relative sexual imbalance which currently exists between men and women. In this respect, the researcher concurs with Levine $e$ t al. (1993), who point out that self-esteem variables correlate highly to positive behaviour changes and that 'if we are to increase the self-worth of women, they must be [encouraged] to feel that they have something to contribute instead of being perceived as inadequate'.

On the issue of condom use, the study showed that male and female farm workers across all three farm groups perceived the advantages of using condoms. However, 'Use always for sex' was low $(5.4 \%)$ with no difference between farm groups; under half $(43 \%)$ ) of respondents said they 'had not tried using condoms but do sometimes think about' using condoms. Males strongly disagreed ( $p<.001$ ) that condoms should be used by married couples, and it was noted that on the behaviour change scale for condom use, the score for 'use' among women (of whom at least 95 per cent were married) was significantly ( $\mathrm{p}<.001)$ lower than men. It was apparent, therefore, that if men use condoms, use is with girlfriends rather than wives. The difficulty of motivating people to move from a stage of ambivalence to a stage of action which requires overt modification of behaviour, and finally towards continued use, should not be underestimated. This is of importance given the considerable attention that has been given to the risks that women face from heterosexual contact (Bassett and Mhloyi, 1991; Chin, 1990; Campbell, 1990; de Bruyn, 1992). While the issue of condom use continues to be closely tied to issues of male dominance in the sexual arena, the effectiveness of condoms in preventing transmission of the virus will be difficult to promote. In acknowledging the difficulties in creating change in this sphere, we agree with Campbell (1995) in her important discourse on male gender roles and the implications for women's AIDS risk and prevention, that there is an urgent need to build on the existing culture of association between 'masculinity' and 'sexual power' in men, by teaching that they too have a responsibility for ensuring safe sex.

At the socio-organisational level, it was initially found that difficulty was experienced in setting an agenda for the intervention. It was recognised that time should be allocated to the generation of formal and informal networks, so that an agenda could be developed to address local policy on issues concerning intervention activities and condom distribution. As a result, the intervention was successful in increasing perceived support by authorities, i.e. farm owners, for HTV-prevention activities. Condom availability was also significantly increased on intervention farms, with a high percentage of workers on the intervention farms acknowledging that condoms were 'always available' (as opposed to 'Sometimes/Never' available). In the one-year period of the intervention, however, we did not succeed in creating an enabling climate for the development of community-based initiatives such as 'antiAIDS clubs'. When asked to become involved in peer education activities, for 
Table 2: Post-test Differences on Scales by Gender and Farm Group

\begin{tabular}{|c|c|c|c|c|c|c|c|c|c|c|c|c|c|}
\hline \multirow[b]{3}{*}{ Scale } & \multicolumn{2}{|c|}{$\begin{array}{l}\text { Overall Gender } \\
\text { Means }\end{array}$} & \multirow{3}{*}{$\begin{array}{l}\text { p values } \\
\text { for } \\
\text { gender } \\
\text { differ- } \\
\text { ence }\end{array}$} & \multicolumn{6}{|c|}{ Gender Means by Farm Group } & \multirow{3}{*}{$\begin{array}{c}\text { p value for } \\
\text { gender by farm } \\
\text { group }\end{array}$} & \multicolumn{3}{|c|}{$\begin{array}{l}\text { p values for farm } \\
\text { comparisons }\end{array}$} \\
\hline & \multirow{2}{*}{$\begin{array}{c}\text { Male } \\
(n=430)\end{array}$} & \multirow{2}{*}{$\begin{array}{l}\text { Female } \\
(n=423)\end{array}$} & & \multicolumn{2}{|c|}{ Unplanned Interventio } & \multicolumn{2}{|c|}{ on Intervention } & \multicolumn{2}{|c|}{ Control } & & \multirow{2}{*}{$\mathrm{I} / \mathrm{C}$} & \multirow{2}{*}{ I/U } & \multirow{2}{*}{$\mathrm{U} / \mathrm{C}$} \\
\hline & & & & $\begin{array}{c}M \\
(n=100)\end{array}$ & $\begin{array}{c}F \\
(n=102)\end{array}$ & $\begin{array}{c}M \\
(n=229)\end{array}$ & $\begin{array}{c}F \\
(n=223)\end{array}$ & $\begin{array}{c}M \\
(n=101)\end{array}$ & $\begin{array}{c}F \\
(n=98)\end{array}$ & & & & \\
\hline $\begin{array}{l}\text { Instrumental } \\
\text { knowledge }\end{array}$ & 4.45 & 4.93 & $<.001$ & 4.81 & 5.08 & 4.42 & 5.06 & 4.17 & 4.47 & .033 & $<001$ & .299 & $<.001$ \\
\hline \multicolumn{14}{|l|}{ Condoms } \\
\hline - Behaviour change & 2.34 & 1.81 & $<.001$ & 2.43 & 2.03 & 2.35 & 1.69 & 2.22 & 1.87 & .230 & .307 & .902 & .261 \\
\hline $\begin{array}{l}\text { - Attitudes to condom } \\
\text { use by women for } \\
\text { contraception and } \\
\text { self-protection }\end{array}$ & 12.95 & 11.94 & $<.001$ & 13.24 & 12.03 & 12.82 & 12.97 & 12.97 & 11.41 & .109 & .098 & .947 & .114 \\
\hline $\begin{array}{l}\text { - Advantages and } \\
\text { disadvantages of } \\
\text { condom use }\end{array}$ & 12.03 & 12.15 & .503 & 12.20 & 12.32 & 12.02 & 12.37 & 11.89 & 11.69 & .320 & .098 & .947 & .114 \\
\hline Perceived efficacy & 3.06 & 0.92 & $<.001$ & 2.91 & 1.00 & 3.17 & 0.92 & 2.95 & 0.86 & .176 & .290 & .080 & .642 \\
\hline $\begin{array}{l}\text { Perceived support by } \\
\text { authority for AIDS } \\
\text { prevention activities }\end{array}$ & 1.69 & 1.44 & $<, 001$ & 1.52 & 1.48 & 1.78 & 1.47 & 1.66 & 1.35 & .036 & .049 & .031 & .753 \\
\hline
\end{tabular}


Table 3: Item Analysis : Efficacy Scale by Gender

Item $\begin{gathered}\text { Male } \\ (n=430)\end{gathered} \quad \begin{gathered}\text { Female } \\ (n=423)\end{gathered} \quad$ p-value

Agree that you have the right to choose about your sex life

Agree that I would be afraid to deny sex to my partner

Agree that there is something the people on this farm can do to prevent HIV

Agree there is something the community can do to prevent HIV
395

$(92.3 \%)$

41

$(9.4 \%)$

262

$(60.9 \%)$

265

$(61.6 \%)$
36

$(8.5 \%)$

$<.001$

184

$(44.1 \%)$

$<.001$

46

$(10.9 \%)$

$<.001$

75

$(17.7 \%)$

example, the FHWs reported that many farm workers expected rewards, felt there was nothing they could do about the problem of AIDS and that they 'had no time for such things" (Laver, et al., 1996/1997).

The gender differences in response to the issue of community empowerment were striking. The study showed that, in the face of an epidemic which is poised to place high demands on women and limited resources, they feel irresolute about the ability of the 'community' to bring about change. Their high levels of knowledge appear to have sharpened their understanding of the problem but their perception of a solution is clearly defined within socio-cultural gender roles. Responses from men on this issue confirmed that gender socialisation appears to contribute to high levels of selfefficacy and a powertil perception of sexual identity and control at individual and community level. The intervention was therefore clearly unsuccessful in assisting men to define their role in responding to the epidemic.

\subsection{Conclusions and Lessons Learned}

In this study, an HIV / AIDS-prevention intervention was planned, implemented and measured using a process and an end-point evaluation. Theory guided its development and the measurement of constructs for the evaluation. The conceptualisation of the intervention at the intra-personal, socio-organisational and policy level in poor communities with limited experience of participation in decision-making posed a challenge.

Importantly, we must ask what has been learned from this intervention that will transform approaches to HIV-prevention activities in farm worker communities in future? While it is clear that historical and political events have conspired over time to create differences which make the needs of these communities unique, there are 
certain imperatives which are crucial to the transformation of our interventions. In the discussion which follows, attention is drawn to a number of factors which impeded the measurement of the intervention, and implications for future interventions are presented.

\subsubsection{Limitations of the Study}

\section{Study Measures}

Although empirically tested theories (Freire, 1972; Wallerstein and Sanchez-Merki, 1994) guided the development of the intervention approach and the selection of constructs for the end-point evaluation, there were certain limitations. These were concerned with (a) measuring changes where the time frame of the intervention was limited to one year and (b) the difficulties of constructing a valid and reliable research instrument to measure end-point change in an educationally disadvantaged community.

However, it is equally important to point out that the decision to incorporate the method of process evaluation to provide an insight into "what actually happened" during the intervention was appropriate. The findings of the process evaluation, which are published elsewhere (Laver, et al., 1996/1997) confirmed that the endpoint results were determined by a number of factors which lay outside the scope of our intervention. To illustrate the importance of process evaluation, it was learned, for example, that high levels of condom demand recorded by change-agents during the intervention period (Laver et al., 1996/1997) were clearly attributable to factors which were outside the immediate goals of the intervention. Firstly, it was leamed that condom demand rapidly increased as it became known that they were freely available on intervention farms. Secondly, it was learned that condoms had a 'resale' value which increased their demand, i.e. they were 'sold' to 'outsiders' during the intervention period, which is a factor not to be underestimated in poor communities. Thirdly, it was observed through the process evaluation that the increase in the number of non-permanent workers during the busy season coincided with an increase in demand on intervention farms which may have affected an end-point intervention. In addition to these findings it was discovered that there was no link between epidemiological findings and cycles of work during the farming season. It may have therefore been erroneously concluded that a decline in STI incidence at one point was as a result of the intervention and not-as was learned from the process evaluation-due to limited access to health care by farm workers during peak periods in the farming calendar. These factors undoubtedly had important implications for the findings of the end-point evaluation reported in this study.

Although scales were developed with acceptable levels of reliability to address the major research questions for the study, there was a weaknesses in the end-point evaluation design. The study would have been strengthened through closer cxamination of the mechanisms which farm worker communities employ to solve problems, i.e. given their long history of non-participation in decision-making. Further benefits may have been accrued had a less superficial analysis of intra-personal and organisational change been conducted. This may have led to answers which would 
have pointed to a deeper understanding of barriers to behaviour change in farm worker communities. The problem of developing indicators and methods of evaluating a community-based intervention remains a challenge.

\section{Limitations of the Intervention Design and the Change-agents}

An intervention in itself does not guarantee a reduction in morbidity or change in behaviour. The study assisted in highlighting difficulties experienced by our changeagents in using a methodology where people are not the objects of an educational project, but participants in a process of change. In particular, it was noted that the culture of didactics which still characterises health education activities in Zimbabwe, prevailed, in spite of intensive training which promoted the use of a participatory methodology. A further issue of importance is that the change-agents were women, and, although they were keen to facilitate dialogue around issues of individual perceptions of risk avoidance, they naturally identified with the real difficulties of influencing cultural norms known to militate against the attainment of this objective. An approach which is dependent on a single change-agent is therefore questionable. It is suggested that greater support for the intervention would have been generated by a group of peers, i.e. men and women which would strengthen the "community organising' approach. In this respect, perhaps the intervention would have upheld and synthesised the perspectives articulated by the community about their inability to participate and their lack of capacity to change. In this respect the researcher can concur with Schulz et al., (1995), who say that 'for health educators and others engaged in community-based approaches to foster individual and collective change, gaining an increased understanding of the correlates of empowerment is important'.

\section{Limitations Imposed by the Contextual Environment of the Intervention}

The contextual environment - social and physical - in which an intervention in farm worker communities takes place, is complex. In addition to the perspectives held about STI/HIV/AIDS and the ways in which the problem interfaces with culture among workers, the social and environmental milieu in which the people live and work are important factors which influence participation and action in a communitybased intervention. While it was hoped that the intervention would encourage people to become organised around an issue as important as HIV / AIDS, it is possible that the lack of previous experience in collective action was a disabling factor in achieving this objective in a farm worker community. It was concluded from the observations that, in the face of other problems such as poverty and drought, it was not without reason that workers perceived little purpose in dealing with an 'external' threat which will only impact their lives in 'time'. The impact of the farming calendar on the intervention was another important factor, and we learned that the carefully planned reiterative nature of our intervention was disrupted by seasonal demands on workers at different times of the year. The influx of seasonal workers, whose behaviour did not necessarily conform to community norms, was thought to attract prostitution and alcohol abuse. These factors, when aggregated, provided a valuable insight into the overview of a programme whose success or failure may well have been determined by issues outside the scope of the intervention. 


\subsubsection{Implications for Future Interventions}

Firstly, as Campbell (1995) stresses, gender power differences must be recognised in the AIDS debate, and there is an urgent need to target men directly, rather than through women. This calls for a clear recognition that intervention strategies must (a) reenforce the role of males from an early age to take responsibility for their health, the health of their female partners and to practise safe sex, (b) create a climate which deemphasises the need for females to take primary responsibility for safer sex practices, (c) acknowledge the fundamental differences in power relations between men and women and (d) assist men to define their role in fighting the epidemic. It is also recognised that male and female constituents of the community must work together to achieve these objectives.

Secondly, there is a need to pursue vigorously 'every means possible to strengthen women's immediate ability to protect themselves in the face of current economic and cultural forces allied against them' (Heise and Elias, 1995). Because of the problems with condom use (Campbell, 1995), other forms of prophylaxis such as spermicide, which will enable protection without the risk of confrontation, must be explored further.

Thirdly, intervention approaches which assume that communities are powerless and those which "control" the flow of information through didactics, now lack empirical support in terms of creating effective HIV/AIDS-prevention behaviour (Carballo et al., 1989; Des Jarlais and Friedman, 1990; Green, 1992a; 1992b; Krieger and Margo, 1991; Laver et al., 1994/1995; Miotti et al., 1992; Pela and Platt, 1989; Wasserheit, 1992). This calls for transformation in the construction of interventions within a setting which increases perceptions of learned hopefulness, proactive behaviour, and reduces alienation. In this context, the work of Werner and Bower (1982), Freire (1983), Wallerstein and Sanchez-Merki (1994), Wallerstein and Bernstein (1988), Hope et al. (1984), provide examples of how the theory of praxis, i.e. reflection (appraisal), dialogue and action (praxis) can be integrated with the principles of community organisation (Bracht, 1990). Through this approach, involvement of the community is maximised relative to the 'expert' who facilitates change through activities which heighten debate, maximise the opportunity for self-learning (Ankrah, 1991; Prual et al., 1991), and increase the opportunity for networking at every level.

And fourthly, there is an urgent need to reverse the trend of government's inability to activate policy to protect the poor from budgetary cutbacks in the health sector. It must also be recognised that the effects of economic reform will exacerbate the impact of AIDS in poor and vulnerable communities upon whom the epidemic will undoubtedly make the greatest demands.

\subsection{Recommendations for Future Interventions}

In the words of Loewenson (1993), 'The AIDS epidemic has the contradictory features of being one of the most devastating blows that we have experienced in Africa, while at the same time teaching us new lessons about health actions'. Programmes which neglect the policies and discourses which shape the AIDS agenda and fail to address the cultural and sub-cultural differences inherent in the beliefs, attitudes, and values 
of individuals (Adamchack et al., 1990; Ankrah, 1989; Bassett and Mhloyi, 1991; Earickson, 1990; Green, 1992a; 1992b; Packard and Epstein, 1991; Schoepf, 1992) of or communities run the risk of joining the long list of failures.

On the basis of these findings from this study, we ask what would be changed and what would the next intervention look like?

* Firstly, it is recommended that the empirically tested social change approach proposed by Wallerstein and Sanchez-Merki (1994) is used. However, given the findings of this study, discretion is advised. In particular, attention is drawn to the need to strengthen the capacity for change at the intra-personal level by increasing skills training, particularly in respect of building self-efficacy among in women. This does not imply that future interventions should be targeted at women - or at men through women. On the contrary, the intervention would pay close attention to illuminating gender power differentials and investing time in helping men (who are already efficacious about their ability to control their sexuality) to acknowledge that they must not be passive by-standers in AIDS prevention and that they too have an important role to play in fighting the epidemic.

- With respect to the intervention methodology, methods such as picture codes to foster the process of appraisal, and reflection to promote change at individual level, should be further developed. However, alternate methods which foster group consensus and aim at achieving a unified sense of purpose with respect to HIV prevention at an organisational level, should be generated.

* Support for the intervention should be generated, not through a single changeagent but through a group of peers, i.e. men and women, which would presuppuse a "community-urganising" approach. In this respect, the need for a widter community response, which facilitates the synthesis of perspectives articulated by the community about their inability to participate and their lack of capacity to change, should be promoted. A mechanism for operationalising future interventions through an integrated policy for social development in farm worker communities is considered essential if efforts to enhance interaction among community stakeholders and create a sense of purpose with respect to HIV prevention are to succeed.

* The potential for increasing networks with key partners such as farm owners and other organisations who are already working towards change in farm worker communities, would be vigorously explored.

* Policy concerning condom access and condom distribution within farm worker communities would be more actively targeted. The issue of increasing access to STI treatment, already shown to be an important factor in reducing transmssion of HIV (Grosskurth et al, 1995), would be critically examined. The possibility of devolving responsibility for treatment to a local level, i.e. to key persons already living on commercial farms, would also be considered in the context of the present state of economic decline in the health sector.

* The process of developing appropriate measures to empirically test and then to amend community-based interventions would continue. 


\section{References}

Adarnchak, D.J., Mbizvo, M.T. and Tawanda, M. (1990) Male knowledge of and attitudes: and practices towards AIDS in Zimbabwe. AIDS Education and Prevention, 4, 245-250.

AIDS Scan (1995) 4 (12 \& 13), Harare, Zimbabwe: AIDS Counselling Trust.

Ajzen, I. (1987) Attitudes, traits and actions: Dispositional prediction of behaviour in personality and social psychology. Advances in Experimental Social Psychology, 20, 161

Amaro, H. (1995) Love Sex and Power. Considering women's realities in HIV Prevention. American Psychologist, 50 (6), 437-447.

Ankrah, E.M. (1989) AIDS. Methodological Problems in studying its prevention and spread. Social Science and Medicine, 29, 265-276.

Ankrah, E.M. (1991) AIDS and the social side of health. Social Science and Medicine, 32, 967-980.

Auerbach, E.R. and Wallerstein, N. (1987) ESL for Action problem Posing at Work; Teachers Guide. Reading, Mass: Addison Wesley.

Bandura, A. (1986) Social Foundations of Thought and Action: A Social Cognitive Theory. Englewood Cliffs, NJ: Prentice-Hall Inc.

Busictt, M.T. and Mhloyi, M. (1991) Women and AIDS in Zimbabwe: The making of an epidemic. International Joumal of Health Services, 21, 143-156.

Becker, M. (1974) The Health Belief Model and sick role behaviour. Health Education Monographs, 2, 409-419.

Becker, M. and Joseph, J. (1988) AIDS and behavioural change to avoid risk. A review. American Journal of Public Health, 78, 384-410.

Bijlmakers, L., Bassett, M.T. and Sanders, D. (1996) Health and Structual Adjustment in Rural and Urban Zimbabwe. Research Report No. 101. Uppsala, Sweden: The Scandinavian Institute of African Studies.

Bracht, N. (1990) Introduction In Health Promotion at the community level, ed. Bracht. N. PP 19-25. Newbury Park, CA: Sage.

Bracht, N. and Kingsbury, L. (1990) Community organisation principles in health promotion: A five-stage model. In Health Promotion at the community level ed. Bracht, N. pp 6888. Newbury Park, CA: Sage.

CSO Central Statistical Office (1989) Denographic and Health Suroey, Harare, Zimbabwe: Government Printers.

CSO Central Statistical Office (1992) Census 1992, Harare, Zimbabwe: Government Printers. 
Caldwell, J., Caldwell, P. and Quiggin, P. (1989) Disaster in an alternate civilization. Health Transition Centre, No. 2, The Australian National University.

Campbell, C.A. (1995) Male gender roles and sexuality: implications for women's AIDS risk and prevention. Social Science and Medicine, 41, 197-210.

Campbell, C.A. (1990) Women and AIDS. Social Science and Medicine, 30, 407.

Cook, T.D. and Campbell, D.T. (1979) Quasi-experimentation: Design and Analysis Issues in Field Settings, Boston, MA: Houghton Mifflin.

Carballu, M., Cleland, J., Carael, M., and Albrecht, G. (1989) Research Agenda: A Cross National Study of Patterns of Sexual Behavior. The lommal of Scx Rescarch, 26, 287299.

CFU (1994) Anmual Statistics, Harare.

Chin, J. (1990) Current and Future dimensions of the HIV/AIDS pandemic in women and children. The Lancet, 336, 221.

Chinemana, F. (1990) Report of AIDS Knowledge, Attitudes and Practises Survey in commercial farming areas of Marondera District. Report prepared for World Vision Zimbabwe and the Marondera Health Team.

Chisvo, M. (1993) Government Spending on Social Services and the Impact of Structural Adjustment in Zimbabwe. Report produced for UNICEF-Zimbabier, Harar, Zimbabue.

De Bruyn, M. (1992) Women and AIDS in developing countries. Social Scince and Medicine, 249.

De May, P., Hukuimwe, H.A., Matsitukwa, L., Makasa, B.P. and De Colombani, P. (1992) HIV Sentinel Surveillance in Mashonaland West Province: HIV Sero-prevalence Survey in the Commercial farming Area of Zvimba district, March-July. A Final Report. PMD, Mashonaland West Province.

De Vries, H., Dijkstra, M. and Kuhlman, P. (1988) Self-Efficacy: The Third Factor Besides Attitude and Subjective Norm as Predicators of Behavioural Intention. Health Education Research, 3, 272-282.

Denscombe, M. (1993) Personal health and the social psychology of risk taking. Health Education Research, 8 (4), 505-517.

Des Jarlais, D.C. and Friedman, S.R. (1990) Target groups for preventing AIDS among intravenous drug users. In Psyclosocial perspectives on AIDS: Etiology, prevention and trentment, ed. Temoshok, L. and Baum, A. pp 35-50. Hillsdale NJ: Lawrence Earlbaum Associates Inc.

Earickson, R.J. (1990) International behavioral responses to a health hazard: AIDS. Social Science and Medicine, 31, 951-962.

Freire, P. (1972) Pedagogy of the Oppressed. New York: Seabury Press.

Freite, P. (1983) Edwation for critical Conscionsness. New York: Seabury Press/Continuum Press. 
Graeff, J.A., Elder, J.P. and Booth, E.M. (1993) Conmunication for Health and behaviour Change, A developing Country Perspective. San Francisco: Jossey-Bass Publishers.

Green, E.C. (1992a) Sexually transmitted disease, ethnomedicine and health policy in A.frica. Social Science and Medicine, 35, 121-130.

Green, E.C. (1992b) The anthropology of sexually transmitted disease in Liberia. Social Science and Medicine, 35, 1457-1468.

Global AIDS Policy Coalition (1992) AIDS in the world. Cambridge, Mass: Harvard University Press.

Grosskurth, H., Mosha, F, Todd, J., Mwïarubi, E., Klokke, A., Senkoro, A., Mayaud, P., Changalucha, J., Nicoll, A., ka-Gina, G., Newell, J., Mugeye, K., Mabey, D. and Hayes, R. (1995) Impact of improved treatment of sexually transmitted diseases on HIV infection in rural Tanzania: randomised controlled trial. The Lancet, 346, 530-536.

Gwede, C. and McDermott, R. (1992) AIDS in sub-saharan Africa: implications for health education. AIDS Education and Prevention, 4 (4), 350-361.

Havelock, R. (1971) Planning for Innovation Through Dissemination and Utilisation of Knowledge, Ann Arbor, Mich: Institute for Social Research.

Health Study Branch. (1993) Recent HIV seroprevalence leveis by country. Research note No. 9" June, HIV/AIDS Surveillance Data Base, Washington: U.S. Bureau of the Census, Center for Lntemational Research.

Heise, L.L. and Elias, C. (1995) Transforming AIDS prevention to meet women's needs; a focus on developing countries. Social Science and Medicine, 40 (7), 931-943.

Hongoro, C. and Chandiwana, S. (1994) Effects of User fees on Health Care in Zimbabwe. Blair Research Laboratory/ MoHCW, Mimeo, Harare, Zimbabwe.

Hope, A., Timmel, S. and Hodzi, C. (1984) Training for Transformation: A handbook for Community Workers. Gweru, Zimbabwe: Mambo Press.

Homans, H., Aggleton, P. and Warwick, I. (1987) Participatory Health Education Strategies for Health Educators with a Responsibility for Adult Education About AIDS. London: AVERT in collaboration with the Health Education Authority.

Krieger, N. and Margo, G. (1991) Women and AIDS: Introduction. International Journal of Health Services, 21, 127-130.

Latif, A.S., Katzenstein, D.A., Bassett, M.T., Houston, S., Emmanuel, J.C. and Marowa, E. (1989) Genital ulcers and transmission of HIV among couples in Zimbabwe. AIDS Education and Prevention, 3, 519-523.

Laver, S. (1993) A preliminary report of a pre-intervention survey of knowledge attitudes beliefs of 770 farm workers with respect to HIV/AIDS. Unpublished monograph. Department of Community Medicine, University of Zimbabwe, Harare, Zimbabwe.

Laver, S. (1994) Picture Codes in AIDS education. World Health Forum, 15, 39-41. 
Laver, S., Van den Borne, B., Kok, G. and Woelk, G. (In press). A Pre-intervention Survey to Determine Understanding of HIV/AIDS in Farm Worker Communities of Zimbabwe. Awaiting publication by AIDS Education and Prevention. (Accepted November, 1995).

Laver, S., Van den Borne, B. and Kok, G. (1994/1995) Using Theory to Design an Intervention for HIV / AIDSPrevention in Farm Workers in Rural Zimbabwe. International Quarterly of Community Health Education, 15 (4), 349-362.

Laver, S., Van den Borne, B. and Kok, G. (1996/1997) Was the Intervention implemented as intended?: A process Evaluation of an AIDS Prevention Intervention in Rural Zimbabwe. International Quarterly of Community Health Education, 16 (1), 25-46.

Levine, O., Britton, H., James, T.T., Jackson, A.P. and Hobfall, S.E. (1993) The Empowerment of Women: A Key to HIV Prevention. Journal of Socinl Psychology, 21, 320-330.

Linville, P.W. and Fischhoff, B. (1993) AIDS Risk Perceptions and Decision Biases. In The Social Psychology of HIV Infection, ed. Pryor, J.B. and Reeder, G. D. pp 55-57. Hillsdale, New Jersey: Lawrence Erlbaum Associates.

Loewenson, R.L. (1993) Potentials and Constraints to Trade Union Action on AIDS: Lessons from Zimbabwe. Paper presented to SENASO, Namibia, May.

Loewenson, R. and Chisvo, M. (1994) Tansforming Social development: The Experience of Zimbabwe. Report prepared for UNICEF, Harare, Zimbabwe.

Mbizvo, M.T. and Adamchak, D.J. (1989) Condom Use and Acceptance; A Survey of Male Zimbabweans. Central African Journal of Medicine, 35 (11), 519-523.

McLeroy, K.R., Bibeau, D., Steckler, A., and Glanz, K. (1988) An Ecological Perspective on Health promotion Programs. Health Education Quarterly, 15 (4), 351-377.

Minkler, M. and Cox, K. (1980) Creating Critical Consciousness in Health: Applications of Freire's Philosophy and Methods to the Health Care Setting. International Journal of Health Services, 311-322.

Minkler, M. (1990) Group Intervention Models of Health Behaviour Change. In Health Behaviour and Health education. Theory and research, ed. Glanz, K., Lewis, F. M. and Rimer, B. K. pp 253-287. San Francisco: Jossey-Bass Health Series.

Miotti, P.G., Chiphangwi, J.D. and Dallabetta, G.A. (1992) The situation in Africa. Baillieres Clinical Obstetrics and Gymaecology, 6, 165-186.

MoH. (1988) Summary of nutrition surveys carried out since 1980, Mimeo, Harare, Zimbabwe.

MoH. (1995). HIV and STI Surveillance Zimbabwe Quarterly Report April - June. Health Information Unit and National AIDS Co-ordination Programme.

Munodawafa, D. and Gwede, C. (1996) Patterns of HIV / AIDS in Zimbabwe: Implications for Health Education. AIDS Education and Prevention, 8 (1), 1-10.

Mutambirwa, I. (1991) Aspects of sexual behaviour in local cultures and the transmission and prevention of HIV / AIDS. In Tradition and Transition: NGOs respond to AIDS, ed. 
Mercer and Scott, J. M. Baltimore: The Johns Hopkins University School of Hygiene and Public Health.

Orlandi, M.A. (1987) Promoting Health and Preventing Disease in Health Care Settings: An Analysis of Barriers. Preventive Medicine, 16, 199-130.

Packard, R.M. and Epstein, P. (1991) Epidemiologists, social scientists, and the structure of medical research on AIDS in Africa. Social Science and Medicine, 33, 771-794.

Pela, A.O. and Platt, J.J. (1989) AIDS in Africa: Emerging trends [Comment]. Social Science and Medicine, $28,1-8$.

Prual, A., Chacko, S. and Koch-Wezer, D. (1991) Sexual behaviour, AIDS and poverty in Sub-Sahara Africa [Editorial]. International Journal of Sexually Transmitted Diseases and AIDS, 2, 1-9.

Pozniak, A. (1993) Clinical management of HIV disease in developing countries. In HIV infection in women, ed. Johnson, M. A. and Johnstone, F. D. pp 93-108. London: Churchill Livingstone, Inc.

Renfrew, A. (1992) ESAP and Health. Gweru, Zimbabwe: Mambo Press.

Rogers, E. and Shoemaker, F. (1971) Communication of Innovations, (2nd ed.). New York: Free Press.

Rogers, E. (1983) Diffusion of Innovations. New York.: Free Press.

Rogers, R.W. (1984) Changing health-related attitudes and behaviour: the role of preventive health psychology. In Interfaces in Psychology. ed. McGlyn, R, Maddox, J., Stoltenbury, C. and Harvey, R.J. Lubbock, TX: Texas Tech University Press.

Rogers, R.W., Deckner, C.W. and Mewborn, C.R. (1978) An expectancy -value theory approach to the long term modification of smoking behaviour. Journal of Clinical Psychology, 34, 562-566.

Ross, M. (1955) Community Organisation: Theory and Principles. New York: Harper and Row.

SAFAIDS and CFU (March 1996) Orphans on Farms: Who cares? An Exploratory Study into Fostering Orphaned Children on Commercial Farms in Zimbabwe. Report prepared by Southern Africa AIDS Information Service and Commercial Farmers Union.

SAFAIDS News (June 1995) Southern African AIDS Information Dissemination Service News Bulletin, 3 (2), Harare.

SAFAIDS News (September 1995) Southern African AIDS Information Dissemination Service News Bulletin, 3 (3), Harare.

Sanders, D. and Sambo, A. (1991) AIDS in Africa: the implications of economic recession and structural adjustment. Health Policy and Planning; 6 (2), 157-165.

Schiller, N., Crystal, C.S. and Lewellen, D. (1994) Risky Business: The Cultural Construction of AIDS Risk Groups. Social Science and Medicine, 38 (10), 1337-1346. 
Schoepf, B.G. (1992) Sex, gender and society in Zaire. In Sexual behaviour and netioorking: Anthropological and socio-cultural studies on the transmission of HIV, ed. Dyson, T. pp 366. Liege, Belgium: Derouaux-Ordina.

Schulz, A.J., Israel, B.A., Zimmerman, M.A. and Checkoway, B.N. (1995) Empowerment as a multi-level construct: perceived control at the individual, organisational and community levels. Health Education Research. 10 (3), 309-327.

Seidel, G. (1993) The Competing Discourses of HIV / AIDS in Sub-Saharan Africa: Discourses of Control and Exclusion. Social Science and Medicine, 36 (3), 175-194.

Singer, M. (1994) The politics of AIDS. Social Science and Medicine, 38 (10), 1325-13.35.

Tabachnick, B.G. and Fidell, L.S. (1983) Using Multivariate Statistics, Harper and Row.

The Herald: Zimbabwe, 14 November, (1995).

US Bureau of Census Population Division. International Programs Centre HIV/AIS Surveillance Data Base (July 1996).

UNICEF (1994) A Situntionnl Aualysis of Women and Children in Zimbabwe; Harare, Zimbabwe.

Wallerstein, N. and Bernstein, E. (1988) Empowerment education: Freire's Ideas Adapted to Health Education. Health Education Quarterly, 15, 379-394.

Wallerstein, N. and Sanchez-Merki, V. (1994) Freirian Praxis in health education: research results from an adolescent prevention programme. Health Education Research. Theory and Practice, 9 (1), 105-118.

Wasserheit, J.N. (1992) Epidemiological synergy: Interrelationships between human immunodeficiency virus infection and other sexually transmitted diseases. Sexually Transmitted Diseases, 19 (2), 61-77.

Werner, D. and Bower, B. (1982) Helping Health Workers Learn. Palo Alto, CA: The Hesperian Foundation.

Williams, G. and Ray, S. (1993) Work Against AIDS. Workplace-based AIDS Initiatives in Zimbabwe. Strategies for Hope Series No. 8. Kenya: Action Aid. AMREF.

Wilion, D., Chiroro, P., Lavelle, S. and Mutero, C. (1989) Sex worker, client sex behaviour and condom use in Harare, Zimbabwe. AIDS Cari, 1 (3), 269-280.

Wilson, D., Dubley, I., Msimanga, S. and Lavelle, L. (1991) Psychosocial predictors of reported HIV-preventive behaviour change among adults in Bulawayo, Zimbabwe. Central African Journal of Medicine, 37 (7), 196-202.

Wilson, D., Manual, A. and Lavelle, S. (1992) Personality characteristics of Zimbabwean men who visit prostitutes: Implications for AIDS prevention programmes. Personality and Indioidual Differences, 13 (3), 275-279. 


\title{
Chapter 2
}

\section{Confrontation or Compassion? The Construction of the Response to AIDS in Zimbabwe: A Perspective}

\author{
Laver, S.M. ${ }^{1}$, Van Den Borne, B. ${ }^{2}$, Kok, G. ${ }^{3}$ and Patrikios, H. \\ Submitted for publication
}

\begin{abstract}
AIDS 'officially' erupted in Zimbabwe at a time when the leadership and the people of Africa, lik' much of the world, were not ready to confront such a threat. The response to the epidemic has, over the past decade, been characterised by a range of discourses which have shaped the AIDS prevention agenda. According to our perspective, these discourses have fallen within four distinctive eras, i.e. an era of non-confrontation, an era of moral confrontation, an era of realisation and an era of re-assessment. Our conclusions call for a transformation of the AIDS discourse to address the imbalance in health care caused by budgetary cutbacks which marginalise those communities upon whom the major burden of the AIDS epidemic is falling. We draw attention to the need to confront the gender inequities which increase the risk of HIV transmission in women and, in particular, we call for intervention strategies which reinforce the role of males in taking responsibility for protected sex. The conclusions stress the importance of pursuing every means possible to strengthen women's ability to protect themselves against infection. Lastly, we call for a change in the construction of interventions within settings which pay attention to empirical research and use methods which increase learned hopefulness, proactive behaviour and compassion.
\end{abstract}

1. Senior Lecturer, Department of Community Medicine, University of Zimbabwe Medical School, Harare, Zimbabwe.

2. Professor of Patient Education, Department of Health Education, University of Maastricht, Netherlands.

3. Professor and Scientific Director of Maastricht Health Research Institute for Prevention and Care, University of Maastricht, Netherlands.

4. Medical Librarian, University of Zimbabwe Medical School, Harare, Zimbabwe. 


\subsection{Introduction}

How will the history of the AIDS epidemic in Zimbabwe be recorded? Will it expose an attitude of non-confrontation or will it be a chronicle of compassion for those upon whom this tragic epidemic is leaving it's imprint? In this paper we review a range of discourses which have shaped the AIDS agenda in the last decade. According to our analysis these discourses have fallen within four distinctive eras, i.e. an era of non-confrontation, an era of moral confrontation, an era of realisation and an era of reassessment.

\subsection{AIDS in Zimbabwe}

AIDS 'officially' erupted at a time when the leadership and the people of Africa, like much of the world, were not ready to confront such a threat (Gwede and McDermott 1992). Zimbabwe was no different. A long history of confrontation with various forms of upheaval included a bitter struggle for independence which was won in 1980. By the mid-eighties, the new government was responding decisively and effectively to the combination of demands and expectations of an independent nation (Loewenson and Chisvo, 1994). An epidemic with an unknown face could not have come at a more inauspicious time.

After the first official reports of 119 unspecified AIDS cases in 1987 (Zimbabwe Demographic and Health Survey, 1994) the number of cases in Zimbabwe has, as in many African countries, increased rapidly. By mid-1995 it was estimated that around one million or 10 per cent of the total population were infected with the virus $(\mathrm{MoH}, 1995)$. A cumulative figure of 48882 AIDS cases was reported by the end of September $1995(\mathrm{MoH}, 1995)$ and 300 people are reported to be dying every week (The Herald, Zimbabwe, 14 November 1995). The distribution is bimodal with 14.1 per cent (6885) cases reported to be in children under five years, and 71 per cent ( 34797 cases) falling within the economically productive group, i.e. between the ages of 20 and 49 .

The male to female ratio is nearly 1:1 among adults and among adolescents (15 to 19 years) incidence in females is six times greater than their male counterparts (Munodawafa and Gwede, 1996). A most notable feature of the epidemic is that infection is taking place at an increasingly early age and the protection of adolescent girls and young women remains one of the most pressing concerns for HIV prevention (SAFAIDS, June 1995).

Sentinel surveillance studies reveal high positivity in certain groups with seroprevalence rates reaching 52 per cent in pregnant women presenting with sexually transmitted infections at ante-natal clinics (U.S. Bureau of the Census, Population Division, 1996). The tragedy of orphanhood, exacerbated by the increase in premature deaths of women who customarily assume most responsibility for child rearing, is now unfolding. The vulnerable position of orphans, previously not perceived as a problem in traditional African culture in Zimbabwe, is a matter of deep concern (SAFAIDS and CFU, 1996). One study shows that by the millennium, there will be some 200000 orphaned child ren living and depending 
on Zimbabwe's 4600 farm worker communities alone (SAFAIDS and CFU, March 1996). Finding a solution to this problem has been placed high on the AIDS agenda. As Powell et al. (1994) point out, "conventional approaches to orphan care inherited from the west, are neither "desirable nor viable" for Zimbabwe".

Almost all HIV infection is transmitted through sexual intercourse or mothers passing the infection to the unborn or newborn; there is little evidence of transmission through the intravenous drug route or through blood transfusion. The relationship between Sexually Transmitted Infections (STIs) and HIV infection is widely recognised; with STIs known to play a potentiating role in HIV transmission (Latif et al., 1989).

\subsection{The Eras of Response to the AIDS Epidemic}

For the purposes of this discussion we defined four eras in which the response to the HIV / AIDS epidemic has occurred over the last decade in Zimbabwe.

\subsubsection{An Era of Non-confrontation}

AIDS was first recognised worldwide around 1983 but the significance of the "ne' $w$ ' epidemic was acknowledged in Zimbabwe in the mid cighties; the extent of the problem at that time was unknown. As was the case in many countries, the public looked to the politicians and the medical experts for a re'spons'. How rver, given the commitment by government to political reform and social development in that period, it was not entirely unpredictable that the political response to the new public health threat would be characterised by insensitivity and denial. AIDS, it was soon realised, would be an expensive disease and as Sabatier (1988) pointed out, "in many AIDS-affected countries in Africa, annual per capita health spending is less than the cost of a single blood test'. A distinctive bio-medical discourse was to characterise the AIDS debate during that period (Hunt, 1996; Pitts and Jackson, 1989; Seidel, 1993) and a conservative 'expert-driven' position was adopted by health professionals. Hunt (1996) reflects that 'first, this "stance] conveyed the notion that the epidemiological pattern of disease was based on biological phenomena - and biology cannot be changed... second, it conveyed the outlook that if biology cannot be changed, there was little humans could do to change'.

Not unexpectedly, the dominant discourse in popular and the scientific media during this period was medical and concerned with symptoms and modes of transmission. The extent of the epidemic was difficult to quantify however, because sero-prevalence data were suppressed. A MEDLINE search conducted to locate published articles about HIV / AIDS in Zimbabwe revealed that between 1985 and 1989,46 per cent $(n=24)$ of the papers reflected a bio-medical content. In 1990 alone, we found that this figure rose to 63 per cent $(n=19)$ with a decrease to 42 per cent $(n=45)$ between 1991 and 1995. In a review of newspaper articles during that period Pitts and Jackson (1989) revealed that there were few articles with a local basis, and that between January 1987 and September 1988 there was only a short term increase in press coverage of issues related to HIV/AIDS. 
Interestingly, the authors also suggested that the paucity of articles on counselling and care at that time indicated denial of the long-term implications of the epidemic. Zimbabwe showed little of the sensationalist and prejudiced accounting of AIDS found in some British press coverage although the ubiquitous poster 'AIDS Kills' was widely circulated. In offering a possible explanation for this response, Van de Walle (1990) observed of this period that, initially underreporting and consequent low estimates were used to support national arguments that: (a) the disease is actually negligible compared to other killers (such as malaria or measles); (b) there is a racist conspiracy to the Western mass media to discredit Africa; and (c) the control efforts of international agencies are forms of neocolonialism...'

For the public, AIDS in the early eighties was a disease without a face which had negative implications for certain lifestyles. The latent period between infection and the onset of AIDS-related symptoms led to a mistaken perception that the problem might go away or that a cure might even be found. The axiom 'the further away the less serious ...' (Kok, 1983) therefore led to an underestimation of its presence and a gross under-estimation of its potential (Gwede and McDermott, 1992). Gilmore and Somerville (1994), explain however, that 'when people, as individuals, a group or society are confronted with a frightening or intolerable situation their response can be to attempt to flee or escape from it when escape or destruction are unavailable..., then denial or displacement are likely to be involved in the response'.

It was not surprising therefore, that disputes, conflicting evidence and manifestations of distrust about the origin and transmission of AIDS diverted attention from 'bio-medical' explanations which mystified the public. The appearance of the disease was attributed to external and uncontrollable sources through lay explanations. For example, AIDS was regarded as an American conspiracy to discourage sex (Pitts and Jackson, 1993). Exogenous, endogenous and 'guilty versus innocent' - 'them and us'- theories which stigmatised and divided, were advanced to explain the nature of the epidemic and even God was blamed (Gilmore and Somerville, 1994; Homans et al., 1987; Sacks, 1996). However, in reviewing the preponderance of beliefs which characterised the AIDS debate during that period, Mutambirwa (1991) did not dismiss all lay theories as being misinformed. Indeed, she took the position that 'although those from outside the 'indigenous' culture may tend to see local beliefs as haphazard and illogical, in fact those beliefs often represent a coherent and well-defined belief system from a local point of view'. Many of the beliefs were not, as the experts believed, simply an ignorance of the facts, but an interpretation of a new phenomenon about which the public had only scanty information.

Of further interest in this early period is that although communities in Zimbabwe have endured confrontations with crises for decades, the expert-driven medical agenda of AIDS in the early phases of the epidemic neglected from the outset to involve communities in dialogue about prevention initiatives. In refereed literature we were only able to locate two articles which specifically drew attention to the need for grass-root participation in AIDS awareness programmes (Foster, 1990; Laver, 1988), although it must be stressed that this need was increasingly 
recognised and Wilson and colleagues, for example, conducted excellent work which revealed the lack of organisation among sex workers and called for the development of participative interventions (Wilson et al., 1989).

\subsubsection{An Era of Moral Confrontation}

By the end of the eighties, attitudes of denial and non-confrontation were fuelled by a new discourse which was morally constructed and primarily led by the church (also described by Seidel, 1990; 1993). In sharp contrast to the position of non-confrontation, the moral discourse confronted and challenged values and lifestyles. The issues of celibacy and condom usage were to assume a central and crucial position in the debate (Mbizvo and Adamchack, 1989). There was heated controversy on the promotion of condoms for scxual encounters outside marriage; one survey showed, for example, that secondary school teachers were divided about promoting condom use and could not decide 'when', 'what' and 'if' the topic should be taught in AIDS prevention programmes in the school setting (Munodawafa, 1991). In defiance of the church, however, condoms were championed through the media which exhorted the public to 'love carefully'.

The gender construction of the moral discourse was also dominant in that it mainly targeted the urban elite with simplistic slogans such as 'stick to one partner' and 'love faithfully'. Of concern was that women were typically depicted as 'prostitutes' or 'promiscuous people', members of 'high risk groups' or 'reservoirs of infection' (Bassett and Mhloyi, 1991; Seidel, 1993). The discourse focused on sex workers as 'transmitters of HIV, rather than recipients or victims of it' (Sacks, 1996); the fact that for many women, sexual relations with men, whether within or outside marriage, were inextricably linked to economic and social survival, remained unacknowledged (Bassett and Mhloyi, 1991). The awareness campaign perpetuated the image of irresponsible prostitutes and used messages conveying 'useless advice' to women with little power over their sexuality (Seidel, 1990; 1993).

As a result, few prevention efforts at that time were directed at males despite surveys which showed that behaviour change to avoid HIV infection was low, even when men reported a history of sexually transmitted infections and extramarital sex relations (Adamchack et al, 1990). Women's risk behaviour was therefore treated separately from men (Campbell, 1995) and campaign messages advocated at that time the need for women to use their skills to negotiate safe sex with men, despite the risk of violence, exile, etc inherent in this process. This approach to prevention campaigning was described as 'myopic' by Campbell (1995), and Schiller et al. (1994) said that 'it impeded intervention design and advanced monocausal explanations for extremely complex social phenomena'.

It was evident in these eras that 'the already entrenched medical dominance and medical discourse, together with the more judgemental, unsympathetic medical-moral discourse and their particular gender representations had by now ... served to inhibit further ... the process of empowerment, participation and solidarity in AIDS prevention' (Seidel, 1993). Western assumptions, values, and 
ideas were replicated in the construction of educational interventions which primarily targeted cognitive gain in this era (Pozniak, 1993; Health Study Branch, 1993; Georges and Georges-Courbot, 1990). It was also obvious that insufficient attention was being paid to developing the social infrastructure that was required for the implementation of recommendations (Nzila et al., 1991).

However, this was to gradually change as the World Health Organisation (WHO) openly supported the participation of non-governmental organisations (NGOs) in the global mobilisation against AIDS. Zimbabwe saw the establishment in 1988, of the first two AIDS organisations - the Family AIDS Counselling Trust (FACT) and the AIDS Counselling Trust (ACT) - although it must be recorded that a number of other informally constituted organisations had already made a start towards promoting public awareness about HIV / AIDS.

\subsubsection{An Era of Realisation}

By the early nineties, an era of realisation was to succeed the era of moral confrontation which had dominated the earlier phases of the epidemic. This period was accompanied by a call for a more relevant agenda on AIDS prevention which brought into focus the person with AIDS (PWA), hitherto absent and depersonalised as 'patients and victims' in the medical discourse. Activists repeatedly drew attention to the need to involve PWAs as 'stakeholders' within AIDS prevention organisations. The apathy which characterised the social response to AIDS in Zimbabwe during this period clearly conflicted, however, with calls to demonstrate compassion for PWAs and difficulty was experienced in shaping an appropriate agenda for their participation in programmes.

Attention was also drawn to the impact of migrant labour systems, discriminatory labour laws, inadequate health services destabilised by cost recovery policies and low incomes, as it became evident that these factors contributed as much to the spread of HIV as unprotected sex (Loewenson and Chisvo, 1994). The discourse repeatedly called for realisation and recognition that the epidemic was socially, politically and economically constructed (Campbell, 1995; Keogh, 1994; Schiller et al., 1994; Seidel, 1993; Loewenson and Chisvo, 1994). In underscoring this perspective in 1991, Sanders and Sambo pointed out that, 'it is predominantly 'these] factors, rather than aberrant behaviour (a presumed African propensity for promiscuity) that require modification if the high risk of transmission is to be reduced'. In 1994, Merril Singer again underscored this perspective and said, '...AIDS has revealed itself as a disease of social relationship, not merely a social disease, but a disease of modern social order'. The public, however, continued to look to the medical profession and the media for information and none of these sources succeeded in engendering a debate which encouraged people to reflect beyond the notion that women and sex were the most intractable causes of HIV infection.

Local researchers cautioned against the overwhelming concentration on intrapersonal level behaviour change to the exclusion of concomitant concern for other structural determinants which influenced transmission within the broader context of Zimbabwean society. Bassett and Mhloyi (1991), Wilson et al. (1992) and other 
organisations, such as the Women's Action Group (WAG), were to make impressive contributions in this sphere and, through their work, the weakened position of women and undisputed dominance of men in the sexual arena also became better articulated and understood (Adamchack et al., 1990; Wilson et al., 1992). In pledging to establish equality for women in the political, economic, social, cultural and civil spheres, the ratification of the UN Convention on the 'Elimination of All forms of Discrimination Against Women' (CEDAW) by Zimbabwe was also to shift the gender discourse on AIDS to a more central position.

Importantly, AIDS activists and NGOs including the Zimbabwe Trade Unions began to demand devolution of programme responsibility from the national government to community-based organisations so that interventions could reflect local needs. The need was also recognised to promote normative support for behaviour change through community and small group education, rather than through mass media campaigns and didactic approaches which had shown little effect (Wilson et al., 1991; Laver, 1993).

A new dialogue on screening policies then began to infiltrate the discourse as life assurance companies became increasingly alarmed when surveys showed that 48 per cent of all individual pay-outs were for suspected or known AIDSrelated deaths (SAFAIDS News, September 1995). Episodes of discrimination and violation of fundamental human rights occurred in some workplace situations (Loewenson, 1993; AIDS Scan, 1995) and churches, human rights groups and trade unions began to stress the need for a regional code on AIDS and employment. By mid-1995 the Southern African Trade Union Coordinating Council (SATUCC) in cooperation with the OATUUU Health, Safety and Environment Programme, had developed a draft policy to protect workers' rights.

\subsubsection{An Era of Re-assessment: Where to Now?}

By the mid-nineties, the huge burden of the AIDS epidemic has become a reality in Zimbabwe at a time when the problem of sustaining existing health coverage within the context of an economic order (ESAP), is placing an increasing strain on diminishing financial resources in the public sector. Under conditions of stagnant growth, there has been a re-assessment of the health policy which has decentralised medical care and introduced a system of user fees (Loewenson and Chisvo, 1994; Hongoro and Chandiwana, 1994). In imposing these policies, Bijlmakers et al., (1996) point out that the Government of Zimbabwe has also acknowledged that ${ }^{\circ}$...during the period of transition, certain population groups would be adversely affected by changes in the economic environment... '. In the face of an epidemic where the nearest medical assistance may be three hours away in a wheelbarrow, the concept of 'home-based' care for the terminally ill must conjure up apprehension in the minds of those upon whom the extra burden of AIDS will now fall. As Nkowane (1993) says, 'the capacity of the relatives to cope with the burden of an individual with HIV/AIDS - a terminal illness often associated with stigma in many communities - may be a major determinant for acceptance or rejection of that person and their family'. Added to this is the 
growing population of AIDS orphans and with this problem comes the realisation that 'the community', with its long history of coping in the past, is once again challenged - with limited resources - to respond to another crisis.

\subsection{Transforming the Response}

What have we learned from the past which will transform our approach to AIDS prevention in the future? If, as evidence suggests, we are failing in our attempts to control the spread of HIV infection, and if it is true that 'the community' will increasingly be designated as a resource in this epidemic, we need to clarify what we mean by 'community'. We also need to respect the fact that historical and political events have conspired over time to create differences in communities which make the needs of each one unique.

There are four imperatives which we believe to be crucial to the transformation of our response to the epidemic.

First is the urgent need to contain the adverse effects of economic reform and of budgetary cutbacks in the health sector. It must also be recognised that the effects of economic reform will exacerbate the impact of AIDS in poor and vulnerable communities upon whom the epidemic will undoubtedly make the greatest demands. In this context Bijlmakers et al. (1996) recommend, and we support their position, that '... more resources 'should] be made for primary health care facilities and no fees should be charged for services provided at this level, so as to make them accessible to all'. Programme implementors also need to acknowledge the significance of findings from recent studies, for example Grosskurth et al. (1995), where easy access to treatment for SIIs has been effective in reducing HIV transmission rates. Clearly, STI treatment centres must be decentralised so that farming and other rural communities have easy access to free treatment without loss of confidentiality or fear of stigmatisation. This can only be achieved by reviewing current drug policies and through training and equipping community-based health care providers to become more meaningfully involved in this process.

Secondly we agree with Campbell (1995) that we must confront gender power differences and acknowledge widely the need to target men directly, rather than through women. This calls for a clear recognition that intervention strategies must: (a) reinforce the role of males in taking responsibility, from an early age, for their health, the health of their female partners and the need to practise safe sex; (b) create a climate which de-emphasises the need for females to take primary r'sponsibility for safer sex practices; and (c) acknowledge the fundamental ditferences in power relations between men and women.

Thirdly, we concur with Heise and Elias (1995) who advocate the need to pursue vigorously 'every means possible to strengthen women's immediate ability to protect themsilves in the face of current economic and cultural forces allied against them: Because of resistance to condom use, other forms of prophylaxis, such as spermicides which enable protection without the risk of confrontation, must be explored further (Campbell, 1995) and made widely available. 
Lastly, we need to recognise that interventions which 'control' the flow of information through didactics and assume that communities are passive and powerless, lack empirical support in terms of achieving change at intra-personal or socio-organisational level (Carballo et al., 1989; Des Jarlais and Friedman, 1990; Green, 1992a; 1992b; Krieger and Margo, 1991; Laver et al., 1995; Miotti et al., 1992; Pela and Platt, 1989; Wasserheit, 1992). The work of Werner and Bower (1982), Freire (1983), Wallerstein and Sanchez-Merki (1994), Wallerstein and Bernstein (1988) and Hope et al. (1984) provide examples of how the theory of praxis, i.e. reflection (appraisal), dialogue and action (praxis) can be integrated with the principles of community organisation (Bracht, 1990). In this approach, involvement of the community is maximised relative to the 'expert' who facilitates change through activities which heighten debate and amplify the opportunities for self-learning (Ankrah, 1991; Prual et al., 1991). We therefore need to transform interventions within the context of settings which (a) increase perceptions of compassion, learned hopefulness and proactive behaviour, as well as reducing alienation and (b) provide meaningful insights to programmes and move beyond using 'condom counts' or numbers of didactic sessions as the only indicators of success. Replication of HIV prevention projects must therefore be contingent upon empirical research which demonstrate success and failures, however minor.

\subsection{Conclusion}

In the words of Loewenson (1993), "the AIDS epidemic has the contradictory features of being one of the most devastating blows that we have experienced in Africa, while at the same time teaching us new lessons about health actions'. National HIV/AIDS prevention programmes and donor-assisted interventions which neglect the discourses which have shaped the AIDS agenda over time, therefore run the risk of joining the long list of failures (Adamchack et al., 1990; Ankrah, 1989; Bassett and Mhloyi, 1991; Earickson, 1990; Green, 1992a; 1992b; Packard and Epstein, 1991; Schoepf, 1992).

Although we have reviewed often unreflective recourse by government and organisations to programmes of HIV prevention, we do not negate the enormous strides made so far in Zimbabwe. These include setting up an effective system to screen blood, creating awareness and establishing a surveillance system to monitor the prevalence of HIV and AIDS in Zimbabwe. Added to this is the enormous effort which has been invested in promoting home-based care as an alternate to expensive hospital-based care (Williams and Ray, 1993). Nonetheless, the simple message we: wish to advance is that it is time now to apply what we have learned from past experience to transform our approaches in the future. The situation in which communities find themselves at this stage of the epidemic, calls for reassurance that their involvement will be supported by an understanding that changes in the health care delivery svistem must be brought about to ensure access and treatment for the most marginalised. We conclude that rather than trying to change people to fit programmes, it will be more effective to fit programmes around people.

Confrontation or compassion? How will our response be judged in time? 


\section{References}

Adamchak, D.J., Mbizvo, M.T. and Tawanda, M. (1990) Male knowledge of and attitudes and practices towards AIDS in Zimbabwe. AIDS Education and Prevention, 4, 245-250.

AIDS Scan (1995) 4 (12 \& 13), Harare, Zimbabwe: AIDS Counselling Trust.

Ankrah, E.M. (1989) AIDS: Methodological problems in studying its prevention and spread. Social Science and Medicine, 29, 265-276.

Ankrah, E.M. (1991) AIDS and the social side of health. Social Science and Medicine, 32, 967-980.

Bassett, M.T. and Mhloyi, M. (1991) Women and AIDS in Zimbabwe: The making of an epidemic. International Journal of Health Services, 21, 143-56.

Bijlmakers, L.A., Bassett, M.T. and Sanders, D.M. (1996) Health and Structural Adjustment in Rural and Urban Zimbabwe. Research Report No. 1. The Scandinavian Institute of African Studies, Uppsala, Sweden.

Bracht, N. (1990) Introduction, In Health Promotion at the community level, ed. Bracht, N. pp 19-25. Newbury Park, CA: Sage.

Campbell, C.A. (1995) Male gender roles and sexuality: implications for women's AIDS risk and prevention. Social Science and Medicine, 41 (2), 197-210.

Carballo, M., Cleland, J., Carael, M. and Albrecht, G. (1989) Research Agenda: A Cross National Study of Patterns of Sexual Behavior. The Journal of Sex Research, 26, 287-299.

Des Jarlais, D.C. and Friedman, S.R. (1990) Target groups for preventing AIDS among intravenous drug users. In Psychosocial perspectives on AIDS: Etiology, prevention and treatment. ed. Temoshok, L. and Baum, A. pp 35-50. Hillsdale NJ: Lawrence Earlbaum Associates Inc.

Earickson, R.J. (1990) International behavioral responses to a health hazard: AIDS. Social Science and Medicine, 31, 951-962.

Foster, G. (1990) Raising awareness through community mobilisation. Tropical Doctor, $20(2), 68-70$.

Freire, P. (1983) Education for Critical Consciousness. New York: Seabury Press/ Continuum Press.

Georges, A.J. and Georges-Courbot, M.C. (1990) Epidemiologie des infections VIH en Afrique 'Epidemiology of HIV infections in Africa]. Revue des Praticien, 40, 21312135.

Gilmore, N. and Somerville, M. (1994) Stigmatisation, Scapegoating and Discrimination in Sexually transmitted Diseases: Overcoming "them and Us". Social Science and Meuticine, 39 (9), 1339-1358. 
Green, E.C. (1992a) Sexually transmitted disease, ethno-medicine and health policy in Africa. Social Science and Medicine. 35, 121-130.

Green, E.C. (1992b) The anthropology of sexually transmitted disease in Liberia. Social Science and Medicine, 35, 1457-1468.

Grosskurth, H., Mosha, F., Todd, J., Mwijarubi, E., Klokke, A., Senkoro, A., Mayaud, P., Changalucha, J., Nicoll, A., ka-Gina, G., Newell, J., Mugeye, K., Mabey, D. and Hayes, R. (1995) Impact of improved treatment of sexually transmitted diseases on HIV infection in rural Tanzania: randomised controlled trial. The Lancet, 346, 530-536.

Gwede, C. and McDermott, R. (1992) AIDS in sub-saharan Africa: implications for health education. AIDS Education and Prevention, 4 (4), 350-361.

Health Study Branch (1993) Recent HIV seroprevalence levels by country. Research Note Nr. 9. June, HIV/AIDS Surveillance Data Base, U.S. Bureau of the Census, Center for International Research, Washington. DC.

Heise, L.L. and Elias, C. (1995) Transforming AIDS prevention to meet women's needs; a focus on developing countries. Social Science and Medicine, 40 (7), 931 -943.

Homans, H., Aggleton, P. and Warwick, I. (1987) Participatory Health Education Strategies for Health Educators with a Responsibility for Adult Education About AIDS. London, UK: AVERT in collaboration with the Health Education Authority.

Hongoro, C. and Chandiwana, S. (1994) Effects of User fees on Health Care in Zimbabwe, Blair Research Laboratory/ MoHCW, Mimeo, Harare, Zimbabwe.

Hope, A., Timmel, S. and Hodzi, C. (1984) Training for Transformation: A handbook for Community Workers. Gweru, Zimbabwe: Mambo Press.

Hunt, C.W. (1996) Social Vs Biological: Theories on the Transmission of AIDS in Africa. Social Science and Medicine, 42 (9), 1283-1296.

Keogh, P., Allen, S., Almedal, C. and Temahagili, B. (1994) The Social Impact of HIV Infection on Women in Kigali, Rwanda: A Prospective Study. Social Science and Medicine, 38 (8), 1047-1053.

Kok, G. (1983) The further away, the less serious: effect of temporal distance on perceived value and probability of a future event. Psychological Reports, 52, 531535.

Krieger, N. and Margo, G. (1991) Women and AIDS: Introduction. International Journal of Health Services 21, 127-130.

Latif, A.S., Katzenstein, D.A., Bassett, M.T., Houston, S., Emmanuel, J.C. and Marowa, E. (1989) Genital ulcers and transmission of HIV among couples in Zimbabwe. AIDS Education and Prevention, 3, 519-5.23. 
Laver, S. (1988) African communities in the struggle against AIDS: The need for a new approach. Paper presented to the First International Conference on the Global Impact of AIDS, Barbican Centre, London, UK, 8-10 March.

Laver, S. (1993) AIDS education is more than telling people what not to do. Tropical Doctor, 23, 156-160.

Laver, S., Van den Borne, B. and Kok, G. (1994/1995) Using theory to design an intervention for HIV/AIDS prevention in Farm Worker Communities in Rural Zimbabwe. International Quarterly of Health Education, 15 (4), 349-362.

Loewenson, R. (1993) Potentials and Constraints to Trade Union Action on AIDS: Lessons from Zimbabwe. Paper presented to SANASO Conference, Namibia.

Loewenson, R. and Chisvo, M. (1994) Transforming social development: The Experience of Zimbabwe. Report prepared for UNICEF Harare, Zimbabwe.

Mbizvo, M.T. and Adamchak, D.J. (1989) Condom use and acceptance: a survey of male Zimbabweans. Central African Journal of Medicine, 35 (11), 519-523.

Miotti, P.G., Chiphangwi, J.D. and Dallabetta, G.A. (1992) The situation in Africa. Baillieres Clinical Obstetrics and Gyneacology, 6, 165-186.

MoH. (1995) HIV \& STI Surveillance Zimbabwe Quarterly Report April - June. Health Information Unit and Natimal AIDS Co-ordination Programme.

Munodawafa, D. (1991) Attitudes of teachers towards implementing AIDS prevention education programmes in secondary schools in Zimbabwe. Central African Journal of Medicine, 37 (12), 390-393.

Munodawafa, D. and Gwede, C. (1996) Patterns of HIV/AIDS in Zimbabwe: Implications for Health Education. AIDS Education and Prevention, 8 (1), 1-10.

Mutambirwa, J. (1991) Aspects of sexual behaviour in local cultures and the transmission and prevention of HIV/AIDS. In Tradition and Transition: NGOs respond to AIDS, ed. Mercer and Scott J.M., Baltimore: The Johns Hopkins University School of Hygiene and Public Health.

Nkowane, A.M. (1993) Breaking the silence: the need for counselling of HIV/AIDS patients. International Nursing Review, 40 (1), 17-20, 24.

Nzila, N., Läla, M., Thiam, M.A., Mayimona, K., Edidi, B., Van Dijk, E., Behets, F., Hassig, S. Melson, A. and Mokwa, K. (1991) HIV and other sexually transmitted diseases among female prostitutes in Kinshasa. AIDS Education and Prevention, $5,715-721$.

Packard, R.M. and Epstein, P. (1991) Epidemiologists, social scientists, and the structure of medical research on AIDS in Africa. Social Science and Medicine, 33, 771-794.

Pela, A.O. and Platt, J.J. (1989) AIDS in Africa: Emerging Trends [Comment]. Social Science and Medicine, 28, 1-8. 
Pitts, M. and Jackson, H. (1989) AIDS and the press; an analysis of the coverage of AIDS by Zimbabwe newspapers. AIDS Care, 1 (1), 77-83.

Pitts, M. and Jackson, H. (1993) Press coverage of AIDS in Zimbabwe: a five year review. AIDS Care, 5 (2), 223-230.

Powell, G., Morreira, S., Rudd, C. and Ngonyama, R. (1994) 'Orphan policy and practice in Zimbabwe', A study conducted for the Department of Social Welfare, Ministry of Public Service, Labour and Social Welfare, Zimbabwe.

Pozniak, A. (1993) Clinical management of HIV disease in developing countries. In HIV infection in women, ed. Johnson, M.A. and Johnstone, F.D. pp 93-108. London: Churchill Livingstone, Inc.

Prual, A., Chacko, S. and Koch-Wezer, D. (1991) Sexual behaviour, AIDS and poverty in Sub-Sahara Africa 'Editorial]. International Journal of Sexually Transmitted Diseases and AIDS, 2, 1-9.

Sabatier, R. (1988) Blaning others. Prejudice, race and worldwide AIDS. London: The Panos Institute.

Sacks, V. (1996) Women and AIDS: An Analysis of Media Misrepresentations. Social Science and Medicine, 42 (1), 59-73.

SAFAIDS News (Tune 1995) Southern African AIDS Information Dissemination Service No'in's Bulletin. Harare.

SAFAIDS News (September 1995) Southern African AIDS Information Dissemination Seroice News Bulletin, 3 (4), Harare.

SAFAIDS and CFU (March 1996) Orphans on Farms: Who Cares? An exploratory Study into Foster Care for Orphaned Children on Commercial Farms in Zimbabwe.

Sanders, D. and Sambo, A. (1991) AIDS in Africa: the implications of economic recession and structural adjustment. Health Policy and Plaming, 6 (2), 157-165.

Schiller, N., Crystal, C.S. and Lewellen, D. (1994) Risky Business: The cultural Construction of AIDS Risk Groups. Social Science and Medicine, 38 (10), 1337 1346.

Schoepf, B.G. (1992) Sex, gender and society in Zaire. In Sexual behaviour and networking: Anthropological and socio-cultural studies on the transmission of HIV, ed. Dyson, T. pp 366. Liege, Belgium: Derouaux-Ordina.

Seidel, G. (1990) 'Thank God I said No to AIDS': on the changing; discourse of AIDS in Uganda. Discourse \& Society, 1 (1), 61-84.

Seidel, G. (1993) The Competing Discourses of HIV/AIDS in Sub-Saharan Africa: Discourses of Control and Exclusion. Social Science and Medicine, 36 (3), 175-194.

Singer, M. (1994) The politics of AIDS. Social Science and Medicine, 38 (10), 1325-1335. 
The Herald, Zimbabwe, 14 November, (1995)

United States Bureau of the Census, Population Division, International Program Centre HIV/AIDS Surveillance Data Base, (July 1996).

Van de Walle, E. (1990) The social impact of AIDS in Sub-saharan Africa. Milbank Quarterly, 68 (Suppl. 1), 10-32.

Wallerstein, N. and Bernstein, E. (1988) "Empowerment education: Freire's Ideas Adapted to Health Education". Health Education Quarterly, 15, 379-394.

Wallerstein, N. and Sanchez-Merki, V. (1994) Freirian Praxis in health education: research results from an adolescent prevention programme. Henlth Education Research. Theory and Practice, 9 (1), 105-118.

Wasserheit, J.N. (1992) Epidemiological synergy: Interrelationships between human immunodeficiency virus infection and other sexually transmitted diseases. Sexually Transmitted Diseases, 19 (2), 61-77.

Werner, D. and Bower, B. (1982) Helping Health Workers Learn. Palo Alto, CA: The Hesperian Foundation.

Williams, G. and Ray, S. (1993) Work Against AIDS. Workplace-based AIDS initiatives in Zimbabwe. Strategies for Hope: No 8. Kenya: ActionAid. AMREF.

Wilson, D., Chiroro, P., Lavelle, S. and Mutero, C. (1989) Sex worker, client sex behaviour and condom use in Harare, Zimbabwe. AIDS Care, 1 (3), 269-280.

Wilson, D., Dubley, I., Msimanga, S. and Lavelle, L. (1991) Psychosucial predictors of reported HIV-preventive behaviour change among adults in Bulawayo, Zimbabwe. Central African Journal of Medicine, 37 (7), 196-202.

Wilson, D., Manual, A and Lavelle, S. (1992) Personality characteristics of Zimbabwean men who visit prostitutes: Implications for AIDS prevention programmes. Personality and Individual Differences, 13 (3), 275-279.

Zimbabwe Demographic and Health Survey, (1994). 


\title{
Chapter 3
}

\section{A Pre-intervention Survey to Determine Understanding of HIV/AIDS in Farm Worker Communities of Zimbabwe.}

\author{
Laver, S.M.L. ${ }^{1}$, Van den Borne, B. ${ }^{2}$, Kok, G. ${ }^{3}$ and Woelk, G. ${ }^{4}$ \\ In Press. AIDS Education and Prevention.
}

\begin{abstract}
A cumulative total of 41298 AIDS cases has been reported in Zimbabwe as of March 1995. Of concern is the growing evidence of high levels of sero-prevalence among rural farm workers.

In 1993 a pre-intervention survey was conducted by interview in one district to examine behavioural factors likely to place farm workers in marginalised rural communities at risk of STD/HIV infection. 770 commercial farm workers from 17 randomly-selected commercial farms participated in the study. We found that women in farm worker communities are educationally disadvantaged when compared with men ( $p<.001)$ and have had little exposure to AIDS prevention activities. Beliefs that AIDS is brought about by divine/ancestral retribution were upheld by less educated women $(p<.007)$. A significant association was found with respect to perceived risk of HIV and low selfefficacy among uneducated women, who articulated helplessness and an inability to protect themselves from HIV infection. Among more educated men, we found acknowledgement of multi-partnering and evidence that changes in behaviour are nore likely to develop as a result of changes in normative values $(p>05)$. Condom use among men, which is probably the most effective barrier against STIs, was shown to be associated with age $(p<.01)$ and education $(p<.01)$. The study concludes with recommendations for an appropriate interoention.
\end{abstract}

1. Senior Lecturer, Department of Community Medicine, University of Zimbabwe Medical School, Harare, Zimbabwe.

2. Professor of Patient Education, Department of Health Education, University of Maastricht, Netherlands.

3. Professor and Scientific Director of Maastricht Health Research Institute for Prevention and Care, University of Maastricht, Netherlands.

4. Senior Lecturer, Department of Community Medicine, University of Zimbabwe Medical School, Harare, Zimbabwe. 


\subsection{Introduction}

AIDS interventions in Africa have failed to initiate the wave of behaviour change that was anticipated in the early phases of the epidemic. Reports indicate that the disease has reached endemic proportions in some parts of the continent and that there is a shift towards lower income, unskilled people (Williams and Ray, 1993) with an increasing number of people testing positive for HIV in rural areas (Torrey and Way, 1991; Williams and Ray, 1993; Zainet, 1993). Faced with new information about risk, people have been expected to alter their behaviour, but as Denscombe (1993) says 'the evidence is that people do not always respond in a "rational" manner to messages about risk'. While there is a clear understanding that HIV in African communities is mainly transmitted through unprotected heterosexual vaginal intercourse, researchers show the importance of recognising that HIV transmission is also influenced by a web of complex cultural factors that shape understanding and influence risk-taking behaviour (Airhihenbuwa et al., 1992; Bassett and Mhloyi, 1991; Cald well et al., 1989; Linville and Fischhoff, 1993; Mutambirwa, 1991). In spite of this, AIDS communicators often fail to plan their interventions on the basis of a clear understanding of the issues that combine to influence the way that people perceive the problem of HIV and AIDS in local settings.

() particular concern are poor, rural communities whose needs have been marginalised in AIDS prevention campaigns. In theory, community involvement in AIDS awareness programmes is given high priority; in practice it is evident that western-type interventions designed for urban, industrialized settings are often relocated in communities whose understanding of the epidemic is shaped by a cultural perspective of HIV / AIDS which does not necessarily converge with that of the urban dweller. The didactic delivery of information through channels such as print media suggests that interventions fail to take into account the strong culture of dialogue which exists in rural communities.

\subsubsection{The Problem in Zimbabwe}

The official estimate of HIV infection in Zimbabwe by early 1995 stood at around one million or 10 per cent of the total population (Farag, 1995). The National AIDS Coordination Programme (NACP) estimates the real figure to be approximately three times the reported figure (Zainet, 1993). In 1993, Williams and Ray observed that 'as in other countries, AIDS in Zimbabwe is primarily a disease of adults of working age: over 80 per cent of those infected are aged between 15 and 60, with men and women affected in roughly equal numbers'. Sexually Transmitted Infections (STIs), and in particular genital ulcer disease (GUD), the incidence of which is increased by multi-partnering and unprotected sex, are known to be important risk factors in HIV transmission with a total of 197162 episodes reported nationwide by the second quarter of 1994 (NACP, 1994).

Despite the fact that approximately 73 per cent of the population in Zimbabwe lives in the rural areas (UNICEF, 1994) few planned AIDS prevention interventions have been carried out in rural work-place communities (NACP, 1994). Surveys 
conducted in commercial farming communities at two time intervals (Chinemana, 1490; Laver, 1994) showed, at that time, that knowledge about transmission of the diseare was limited in farm workers, that there was still an unmet demand for information and condoms, which are widely promoted for 'safer sex', were unavailable. A survey by the NACP (NACP, 1994) revealed that national campaign literature, such as posters and pamphlets, has failed to reach disadvantaged rural communities at district and community level. The didactic content of print media also showed that the needs of illiterate communities have not been prioritised by the service providers in the AIDS sector.

Of particular concern in this respect is the commercial farming sector of Zimbabwe where approximately 4600 land owners (Frazer-Mackenzie, 1992) employ some

270000 farm workers or 17 per cent of the total workforce. In the face of mounting concern over the growing prevalence of HIV infection in farm worker communities, the absence of planned AIDS prevention interventions is noteworthy. Epidemiological data from one farming area showed, for example, that ante-natal clients $(\mathrm{N}-287)$ living on commercial farms and presenting at local health centres showed a sero-prevalence of 11.5 to 19.9 per cent (De May et al., 1992). In a later study in the same farming district 25.9 per cent $(\mathrm{N}=197)$ antenatal mothers tested HIV positive and it was shown that between 35.7 and 49.2 per cent of STI patients $(\mathrm{N}=205)$ were HIV positive. Data from catchment clinics in the same area showed 24371 reported episodes of STIs in the second quarter of 1994 (NACP, 1994).

\subsection{Aim of the Study}

In this paper we present observations and findings from a survey that was carried out in 1993 in a sample of 770 farm workers randomly selected from 17 commercial farms in the Zvimba commercial farming area in the Mashonaland West Province of Zimbabwe. The aim of the study was to examine factors which affect the interpretation of HIV / AIDS by farm workers in marginalised communities in Zimbabwe. This information would be used as the basis for developing an intervention that would promote preventive behaviour with respect to HIV/AIDS in these communities.

Our findings were viewed through a combination of behavioural models which integrated the Health Belief Model (HBM) as described by Janz and Becker (1984) and the attitudes, subjective norms and self-efficacy expectations model, also called the ASE Model, as described by De Vries et al. (1988). The HBM model provided a framework for understanding the existence of lay beliefs among farm workers about the perceived threat of AIDS, i.e. where a combination of perceived susceptibility and perceived severity are labelled as perceived threat (Glanz ef al., 1990) and perceived benefits and barriers to behaviour changes. The ASE model made a number of contributions by explaining health-related behaviours not included in the HBM. The most important of these is the explicit introduction of self-cfficacy which was used in this study to explain the judgement by women of how able they felt to 'execute courses of action required to deal with prospective 
situations' (Bandura, 1986) such as unprotected sex. Attention was paid to the measurement of attitudes by men towards certain behaviours such as multipartnering, and also to the effect of peer influence on behaviour. Also examined were knowledge and the effect of socio-demographic variables, particularly literacy, educational attainment, age and the social environment of the farm worker community, which were believed to affect individuals' perception of AIDS and indirectly influence behaviour.

\subsection{Method}

\subsubsection{The Study Site}

The study took place in the Zvimba District of Mashonaland West Province of Zimbabwe. The district is situated $100 \mathrm{~km}$ north east of Harare and has a population of 1116928 people or approximately 10.7 per cent of the total population of Zimbabwe (CSO, 1992).

The Zvimba district was selected because it represents one of the most important commercial farming areas in Zimbabwe. The district also had a good indication of probable success for the intervention planned for the next phase.

In Zvimba there are approximately 450 large-scale commercial farms where farm workers are employed full-time or seasonally. The main crops grown in the area are tobacco, wheat, maize and legumes. Banana plantations are found in the northern part of the district.

In theory, the first point of referral for health problems on commercial farms is the Iarm Health Worker (FHW); this is constrained in practice through inadequate training and a shortage of basic drugs. The are six health centres in the area including one district hospital. Government-run clinics offer primary health care (PHC) free of charge to persons earning less than $Z \$ 400$ (US\$40) per month. Distance from health care centres and cost of transport are determining factors which influence attendance by farm workers. Traditional healers who live and work in the farming area provide alternate health care to farm workers and play an important role in managing a range of illnesses, particularly during the busiest periods of farming activity when access to clinics is limited.

\subsubsection{The Study Sample}

A total of 770 farm workers (382 men and 388 women) from 17 randomly-selected commercial farms in Zvimba participated in the survey (Table 1). Participation in the study was voluntary. Although there was 100 per cent participation, some r'spondents declined to respond to some questions. Selection of farm workers was determined with the aid of a numbered employment register and a random number table. (Only full-time, permanently rusident farm workers were included in the sample; we excluded seasonal workers because they are transient and would not have been representative of the permanent farm worker community. In order to he sure that women would have equal representation in the sample, we interviewed the wives of men randomly selected from the employment register. 
Slightly more women $(1.0 \%)$ than men were interviewed; this was because working widows $(\mathrm{N}=7)$ were also included. The sample drawn from each farm was proportional to the size of the full-time labour force employed on that farm.

\subsubsection{Procedures}

Most of the study sample was functionally illiterate. This had two important implications; firstly each respondent had to be personally interviewed and secondly, we limited the number of questions so that respondents did not easily tire. We trained five Shona-speaking research assistants (two female nurses and three male environmental health workers) already familiar to the farming community to carry out the interviews. Each interview, which was conducted in the vernacular language, took about 20 minutes to complete. In order to ensure open disclosure during the interview, female interviewers interviewed female respondents. In addition to conducting the interview in a comfortable, secluded environment we also offered respondents the opportunity of indicating their response to sensitive questions using a non-verbal technique. This was achieved by asking respondents to rest a stone on or point to a colour-coded board where the colour green denoted the response 'I agree'; orange indicated 'not sure' and red indicated 'I disagree'.

\subsubsection{Measures}

Informal discussions with key informants, such as FHWs on each of the 17 farms, yielded information pertaining to the social environment of the farm workers. In particular, we enquired about social networks operating within the community, availability of recreational facilities, condom availability and exposure to AIDS education activities. A pre-tested questionnaire was used to collect the quantitative data for the study. The items of interest for the present discussion are described below.

\section{Socio-demographic Characteristics of Farm Workers}

The socio-demographic characteristics of the farm workers who participated in the study were measured by six questions regarding age, educational attainment, wage, nationality, marital status and religious affiliation.

\section{Attendance at AIDS Education Activities, Perceived Understanding and In- strumental Knowledge of AIDS}

Attendance at AIDS education activities was measured by one statement: "I have attended some/no AIDS education activities on this farm? "This was followed by a question which invited respondents to mention the kind of activities attended (drama, talks, video etc). One item measured perceived level of understanding of HIV / AIDS: 'At this time I feel I know: a lot/something/very little about AIDS'. Two items measured instrumental knowledge of AIDS on a three-point scale of agree, not sure, disagree, i.e.: 'Mosquitoes spread AIDS' and 'The chances of getting AIDS are greater if one has a Sexually Transmitted Disease". 


\section{Beliefs about Infection}

Four items measured lay beliefs about AIDS on a three-point scale of agree, not sure, disagree; each item was designed to measure the existence of exogenous beliefs which were thought to influence perceptions of vulnerability to infection in illiterate farm worker communities. These included: 'Many people on our farm believe AIDS is a result of our ancestors' displeasure'; 'Many people on this farm believe AIDS to be an old disease'; 'People think that AIDS is a disease of poor people'; and 'Getting AIDS is a matter of bad luck'.

\section{Perception of Risk}

The dimension of perceived susceptibility as it refers to an individual's subjective perception of the risk of contracting HIV was measured by the following item: 'At this time I am: at great risk/some risk/no risk of getting AIDS'.

\section{Pcer Influences}

Two items measured the effect of peer influence on men and women on a threepoint scale of agree, not sure, disagree. These were: 'People will only change their behaviour when a close friend or relative dies of AIDS'; and 'People will find it easier to change their sexual behaviour if others decide to do the same'.

\section{Condom Use and Attitudes to Multi-partnering Among Men}

Condom use by men was measured by: "I use condoms: every time I have sex/ for casual sex only/never use condoms at all'. The item 'Using condoms affects my sexual pleasure' measured barriers to use on a three-point scale of agree, not sure, disagree. Attitudes by men to multi-partnering were measured on a threepoint scale of agree, not sure disagree by the following: 'It is true that most men expect to have more than one partner these days'; and 'Most men expect to get STD sooner or later'.

\section{Self-efficacy in Women.}

Self-efficacy or 'the conviction that one can successfully execute the behaviour required to produce the outcomes' (Bandura, 1986) was measured by four items among women only: 'Even if I want, I have no control over my sex life'; 'There is nothing I can do to prevent my self from getting AIDS'; 'I know that my partner has other partners"; "Most married women expect their husbands to have other partners: These items were measured on a three-point scale of agree, not sure, disagree.

\subsubsection{Data Analysis}

Data were analysed using Epi-info Version 5. The variables which measured instrumental knowledge, lay beliefs, peer influence, and self-efficacy were coded according to the scale of $1=$ agree, $2=$ not sure, $3=$ disagree. A scale was also used to interpret the results of the analysis of condom usage, where $1=$ "always use condoms', 2 = "use condoms only with girlfriends' and 3 = "never use condoms". Similarly, risk perception was measured on a scale with $1=$ " $[\mathrm{I} \mathrm{am}]$ at great risk of getting AIDS'; 2 = 'some risk of getting AIDS' and 3 = 'no risk of getting AIDS'. Perceived levels of understanding about AIDS was measured on the scale where 
1 = 'I know a lot about AIDS'; 2 = 'I know something about AIDS' and $3=$ 'I know very little about AIDS'. Age was categorised in two groups: less than 35 years; and 35 years and over. Frequency distributions were used to describe demographic variables. The analysis of variance provided the t-test, when comparing two means and the F-statistic for comparison of more than two means. Where the Bartlett's test for homogeneity of variance showed the samples to be different, the Kruskal-Wallis one-way analysis of variance (equivalent to $X^{2}$ ) provided the statistic and the $p$-value. The significance of the interactions was examined through the $\mathrm{p}$-values at the $99.9 \%(\mathrm{p}<.001), 99 \%(\mathrm{p}<.01)$ and $95 \%(\mathrm{p}<05)$ levels of confidence.

\section{Table 1: Demographic Characteristics of Farm Workers}

Demographic Profile

Male $(\mathbf{N}=382)$

$\mathrm{N} \%$

Female ( $\mathbf{N}=388$ )

$\mathrm{N} \%$

\section{Marital Status}

Customary Marriage

$320 \quad(86.5)$

$50 \quad(13.5)$

318

59

Unmarried/widow/

widower/divorced

\section{Nationality}

Zimbabwean

Malawian

Zambian

Mozambique

Other

$\begin{array}{rr}337 & (89.8) \\ 14 & (3.7) \\ 8 & (2.1) \\ 15 & (4.0) \\ 1 & (0.3)\end{array}$

Age

$<35$ years

\section{Education}

No education*

$\begin{array}{rr}83 & (21.7) \\ 207 & (54.2) \\ 67 & (17.5) \\ 25 & (6.5)\end{array}$

200

1-7 years

8-11 years

166

$12 \mathrm{yrs}$ and over

4

\section{Age}

Range

Mean

Standard deviation

$\begin{array}{ll}8.4 & 7.7\end{array}$

* Significant difference between males and females $X^{2}=72.35 \quad p=<0.001$ 


\subsection{Results}

\subsubsection{Socio-demographic Characteristics of Farm Workers}

Table 1 presents the demographic characteristics of the sample. As the study area is situated in close proximity to countries that border Zimbabwe in the northwest, we anticipated that significantly more non-Zimbabweans would be represented in our sample. Our discussions in the community revealed, however, that original migrant workers on commercial farms have now been replaced by second or third generation descendents and that some seasonal workers, who were excluded from our sample, were more likely to be non-Zimbabwean. A slightly higher percentage of males $(10.1 \%)$ versus females $(7.1 \%)$ werc foreigners. The mean wage earned was $Z \$ 194.00$ (US\$19) per month with a range of $Z \$ 77$ (US\$7.7) to Z\$1800 (US\$180): women dominated the lowest wage categories. There was a significant difference $\left(X^{2}=72.35 ; p<.001\right)$ with respect to gender and education where significantly more females $(\mathrm{N}=2.00)$ had not been educated. A statistically significant association was found between age and education $(p<.001)$, where younger men $(90.8 \%)$ were more educated compared to older men $(58.2 \%)$. Among educated women, the majority $(59.1 \%)$ were under the age of 35 .

\subsubsection{The Farm Worker Environment}

Permanent farm workers are housed as family units within 'compounds' on commercial farms. Dwellings range from brick-under-asbestos to mud and thatch. Although minimum environmental standards have been recommended by the Ministry of Health $(\mathrm{MoH})$, it was noted that water supplies were inadequate and sanitation was poor in some compounds. Diarrhoea was reported to be the most prevalent health problem in children, and among adults 'chest complaints' were felt to be most common. Health records from catchment clinics showed seasonal peaks in childhood diarrhoea (October to February), Sexually Transmitted Infections (September to December) and Upper Respiratory Tract Infections (May to August).

All 17 farms in the sample had a beerhall which, apart from football, was the focal point for recreation; three farms had a public radio. However only one farm had a public television set. Free primary school education up to Grade 7 was available for children of dependents on 11 farms in our study. Where schools were not available, children attended school on neighbouring farms.

\subsubsection{Social Networks Operating Within the Community}

Many commercial farms are isolated from large towns by long distance and a poor system of public transport. The workplace on farms provided an environment of shared identity; it is a 'community' where men and women not only work together but live and spend recreation time together. However, our findings also revealed that the community does not necessarily function as an interdependent group. This is mainly due to a fluctuation in the worker population 
during the peak season when seasonal workers temporarily inflate numbers. Decision-making becomes more diffuse and our discussions with members of different farm communities highlighted a widely held perception that seasonal workers are particularly hard to reach and difficult to influence. It was also felt that their transient status tends to reinforce not only their marginalisation but their 'right' to behave independently of community norms. Seasonal workers are also perceived to attract commercial sex workers to farms, particularly on pay days.

The welfare of farm workers is generally the concern of the farm owner who is the reference point for most major decisions concerning the workforce. Collective action is rare in farm worker communities who lack leadership and organisational skills. Our study revealed, for example, that although workers committees have been set up on all the farms in our study sample, these provide a more useful reference point for the farm owners than for farm workers whose power to bargain or reach decisions is limited. A paternalistic approach to decision-making is therefore still prevalent in farm worker communities and the outcome of negotiations is mostly dependent on the farm owner.

Women and child ren represent the most vulnerable section of the farm worker community, having the highest rates of mortality and ill health. In peak periods of farming activity they provide a labour pool for unskilled contract work. During these periods women and young girls carry the double workload of domestic chores and hard labour leaving little opportunity for self-development. During the low season when opportunities for employment are limited, married women become more dependent on their husbands for cash while young unemployed girls often turn to prostitution in order to secure an income.

Social groupings tend to mobilise around interests such as football, the church, handicraft and, on some farms, burial societies. We failed to locate any communitybased initiatives which had targeted health as the central issue, and none which had evolved in response to the AIDS epidemic. Our observations of high access areas such as beerhalls, schools and community centres revealed the presence of only two outdated AIDS posters on 17 farms; no leaflets or other sources of information were visible or available. Radios are most common source of information in farm communities, but not all households have radios. Newspapers provide a source of information mainly for literate men, although access is limited and supplies are irregular. Evidence of local initiatives in AIDS prevention in the farm communities in the study were confined to talks by farm owners.

\subsubsection{Attendance at AIDS Education Activities, Perceived Understanding and Knowledge of AIDS}

Although there was a clear expectation by 93 per cent of respondents that the FHW was the most appropriate person to receive training and carry out HIV prevention activities in the farm worker community, our study revealed that none of the FHWs trained under the Ministry of Health scheme in Zvimba district $(\mathrm{N}=250)$ had received comprehensive training in AIDS prevention. 
Our findings showed no association between gender and attendance at AIDS education activities. However, a close association was found in respect of education and non-attendance, with significantly $(\mathrm{p}<.01)$ more uneducated males $(91.5 \%)$ not having attended any AIDS education activities (Table 2). A trend towards an association ( $p=0.08$ ) was also found among uneducated females with 86.6 per cent having not attended any HIV prevention activities. Drama accounted for five per cent of the activities attended; talks, films and visits by $\mathrm{MoH}$ outreach teams accounted for 12 per cent.

No significant differences were found among our respondents in respect of gender or education and 'perceived levels of understanding about AIDS'. It was noted, however, that a large percentage of males $\left(82.6^{\prime} \circ\right)$ and females $\left(83.8^{\circ},{ }^{\prime}\right)$ agreed with the statement that 'At this time I feel I know nothing about AIDS".

Selected items of knowledge measured unproven means of transmission (mosquitoes) and a known route of transmission through STIs. Our results showed a significant association $(\mathrm{p}<.01)$ between gender and the statement 'Mosquitoes spread AIDS' where more males ( $47.6 \%$ ) than females incorrectly agreed (Table 2). No other associations were found among males or females in respect of this item.

A strong association $(p<.001)$ was found with respect to gender and the statement 'The chances of getting AIDS are greater if one already has an STD' with significantly more males $(76.6 \%)$ in agreement when compared with females $(56.4 \%)$.

We also found a strong correlation with education where significantly more educated males $(81.6 \%)$ agreed with this statement $(\mathrm{p}<.001)$. A significant association $(\mathrm{p}<.05)$ was also recorded among educated females with 64.9 per cent in agreement with this statement (Table 2).

With respect to age, a trend $(p=0.06)$ was observed with younger females $(61.6 \%)$ agreeing with the statement. No significant differences in age were recorded among men.

\subsubsection{Beliefs about Infection}

Four items were used to measure lay beliefs about AIDS.

With respect to gender, our results showed a significant association $(p<.01)$ where 88.4 per cent of the males disagreed with the statement 'AIDS is a disease of the poor' against 79.4 per cent of the females. No further gender differences were observed on the remaining items.

When education was adjusted for gender on all items, it was found to influence significantly the responses in respect of three items which tested beliefs. On the first item, 'AIDS is a result of our ancestors' displeasure', 79.3 per cent of the educated males disagreed $(p<.001)$ and a trend $(p=0.07)$ was observed among educated females where 72.3 per cent disagreed on the same item (Table 2).

With respect to the next item, 'AIDS is a disease of the poor', a highly significant result was recorded among educated males $(p<.001)$ and females $(p<.001)$ where more educated participants showed disagreement with the statement. With respect to the third item 'Getting AIDS is a matter of bad luck', education was 
Table 2: Variables By Gender and Education

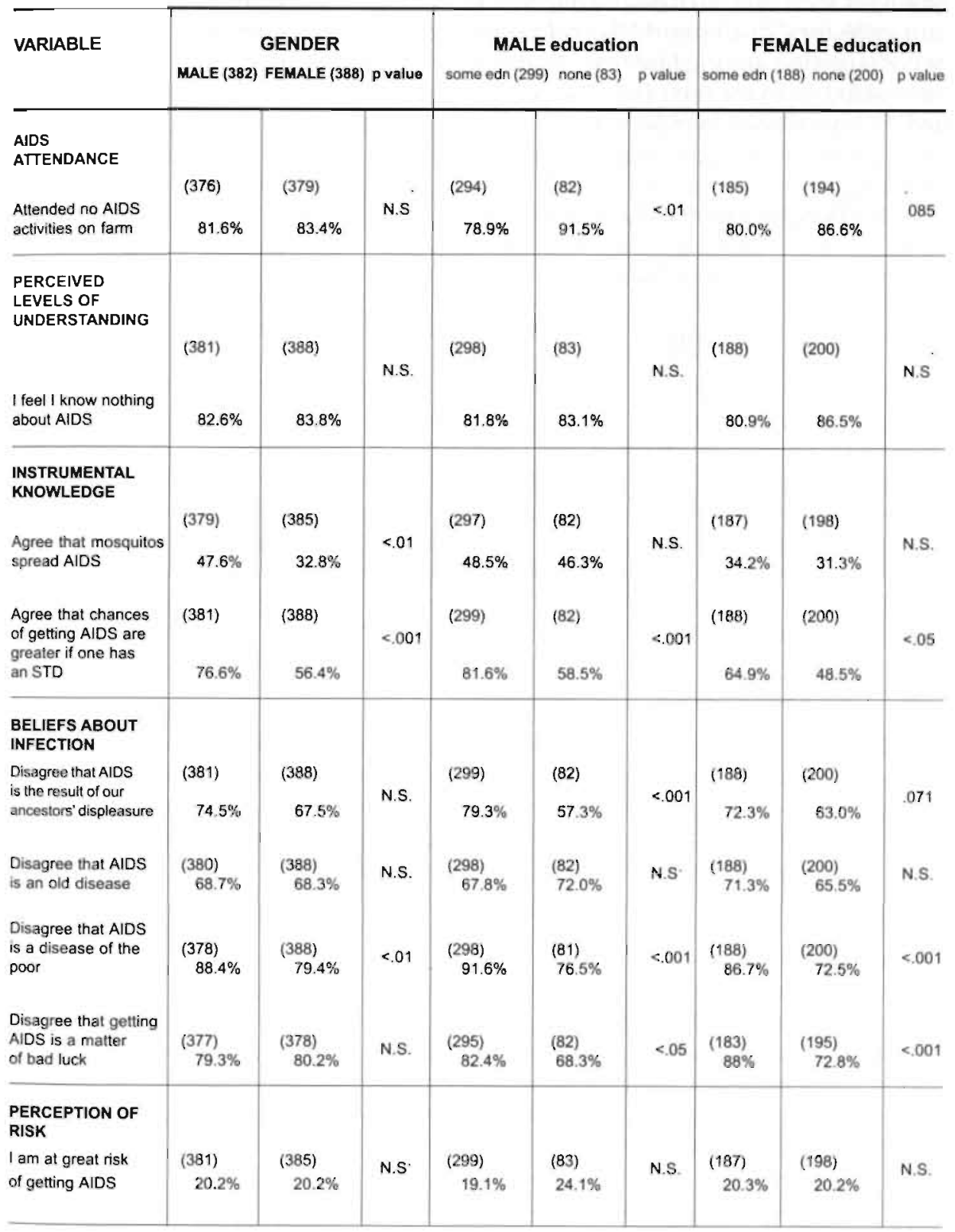

found to significantly affect responses by males $(p<.05)$ with 82.4 per cent of educated males in disagreement and in educated females $(\mathrm{p}<.001)$ where 88 per cent disagreed (Table 2). 
When age and gender were considered, we found that significantly more younger men $(81.9 \%)$ disagreed $(p<.001)$ with the statement "AIDS is a result of our ancestors' displeasure' than older men $(61 \%)$, while no significant differences were recorded among females. Significantly $(p<.01)$ more younger men $(92.0 \%)$ compared to older men $(82 \%)$ and significantly $(p<.01)$ more younger females $(83.2 \%)$ compared to older females $(68.9 \%)$ disagreed with the statement 'AIDS is a disease of the poor'. Age also had a significant effect with respect to the item 'Getting AIDS is a matter of bad luck' where 84.7 per cent of younger males $(\mathrm{p}<.01)$ disagreed with the statement compared to 70.7 per cent of the older males. A trend was observed in females $(p=0.07)$ with more women under 35 years $(82.8 \%)$ in disagreement with this statement.

\subsubsection{Perception of Risk}

No significant differences were found when gender, age and education were examined against the dimension of perceived susceptibility, as it refers to one's subjective perception of the risk of contracting HIV, as measured by the item, 'I feel at great, some or no risk of getting HIV'.

Our study revealed, however, that there was a significant association between perceived risk and self-efficacy in women (Table 4). These results will be reported shortly. Among men, a significant association $(p<.01)$ was found between risk perception and condom use, with those men who 'always use condoms' perceiving themselves to be at greatest risk of HIV infection (Table 3).

\subsubsection{Peer Influence}

Two items were used to measure the effect of peer influence in males and females.

Gender was found to significantly influence responses with respect to the item 'People will only change their ways when a close friend or relative dies of AIDS' (Table 2), where 66.4 per cent of the males agreed with the statement as opposed to 54.9 per cent of the females in agreement $(\mathrm{p}<.01)$. Education was not found to significantly influence our results with respect to this item.

The effect of gender was shown to have a significant influence $(p<.01)$ on responses to the statement 'People will find it easier to change their ways if their friends agree to do the same', where more males $(57.7 \%)$ were in agreement compared with females ( $47 \%$ ).

A trend towards significance $(p=0.07)$ was observed with respect to education where more educated males $(61.5 \%)$ agreed with the same statement compared to males with little or no education (43.9\%). However education was not found to have an effect with respect to females and the same statement.

\subsubsection{Condom Use Among Men and Attitudes to Sex and Multi- partnering}

Condom use among men was categorised 'Never use condoms, use condoms with girlfriends only and always use condoms' and measured against age, education and perception of risk (Table 3). Our results showed that older men 
$(p<01)$ and less educated men ( $p<.01)$ tend to 'never use condoms'. Those men who perceive themselves to be 'at great risk' of getting HIV reported that they 'always use condoms'. With respect to the statement that 'condoms affect my sexual pleasure', it was found that more educated men $(55.1 \%)$ disagreed $(\mathrm{p}<.05)$. We observed that among men, 82.2 per cent agreed with the statement that 'men expect to get STD sooner or later' and 77.4 per cent agreed with the statement that 'most men have more than one partner these days'.

Table 3: Condom Use by Age, Education and Perception of Risk (Men only)*

\begin{tabular}{lcccc}
\hline VARIABLE & $\begin{array}{c}\text { ALWAYS USE } \\
\text { CONDOMS }\end{array}$ & $\begin{array}{c}\text { ONLY USE CONDOMS } \\
\text { WITH GIRLFRIENDS }\end{array}$ & $\begin{array}{c}\text { NEVER USE } \\
\text { CONDOMS }\end{array}$ & P VALUE \\
\hline $\begin{array}{l}\text { AGE (YEARS) } \\
\begin{array}{l}\text { EDUCATION } \\
\text { (YEARS) }\end{array}\end{array}$ & 31.6 & 30.8 & 34.4 & $<.01$ \\
$\begin{array}{l}\text { PERCEPTION OF } \\
\text { RISK }\end{array}$ & 1.8 & 5.9 & 4.9 & $<.01$ \\
& 2.9 & 2.3 & 2.3 & $<.01$ \\
\hline
\end{tabular}

*No other associations were found when condom use was measured against other variables

\subsubsection{Self-efficacy}

Self-efficacy was measured by four items.

When education was examined against the statement 'Even if I wanted, I have no control over my sex life', there was a significant association $(p<.01)$, where uneducated women were more in agreement (Table 2$)$. Significantly $(p<.01)$ more older women agreed with the statement. A trend towards significance $(\mathrm{p}=0.06)$ was found among uneducated women who agreed with the statement 'There is nothing I can do to prevent myself from getting AIDS'. Significantly $(p<.05)$ more older women $(72.3 \%)$ agreed with this statement.

A highly significant association $(\mathrm{p}<.001)$ was found between those women who agreed $(75 \%)$ with the statement 'Even if I wanted to I have no control over my sex life' and felt that they were at were 'at some risk of getting HIV' (Table 4).

Similarly, 71.9 per cent of women who agreed with the statement 'There is nothing I can do to prevent myself getting HIV' also felt 'at some risk of getting $\mathrm{HIV}^{\prime}(\mathrm{p}<.01)$. A significant association $(\mathrm{p}<.01)$ was found among those women $(74.0 \%)$ who agreed with the statement 'I know my partner has other partners' and also felt themselves 'to be at great risk'. Women who agreed that 'most married women expect their husbands to have other partners' $(71.4 \%)$ also felt they were 'at great risk' $(\mathrm{p}<.001)$. 
Table 4: Self-efficacy By Rist Perception (Women anly)

\begin{tabular}{|c|c|c|c|c|}
\hline VARIABLE & $\begin{array}{l}\text { SREAT } \\
\text { RISK } \\
\text { Mil: }\end{array}$ & 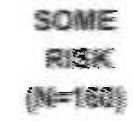 & 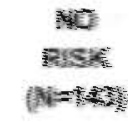 & PUALISE \\
\hline \multicolumn{5}{|l|}{ EFricacy } \\
\hline \multicolumn{5}{|c|}{$\begin{array}{l}\text { Even if I wasted I haves wet } \\
\text { control aver my sex life }\end{array}$} \\
\hline *Agree & $473 \%$ & $75.0 \% \%$ & हQसक & \\
\hline - Nat sure & $00 \%$ & $05 \%$ & $29 \%$ & $<.601$ \\
\hline - Disagree & $58 \%$ & $244 \%$ & उद.6\% & \\
\hline \multicolumn{5}{|c|}{$\begin{array}{l}\text { There is nathing l cass de to } \\
\text { grevent getting Hive }\end{array}$} \\
\hline *Agree & $57.39 \%$ & $719 \%$ & $53: 8 \%$ & \\
\hline * Not sure & $27 \%$ & $2.5 \%$ & $14 \%$ & $<\mathrm{QI}$ \\
\hline - Disagree & 40:0\% & 25: & $44.8 \%$ & \\
\hline \multicolumn{5}{|c|}{$\begin{array}{l}\text { Ifnow that } \\
\text { other sew jartuer partners }\end{array}$} \\
\hline - Agree & $74.0 \%$ & $40.7 \%$ & $51.4 \%$ & \\
\hline - Not sure & $14.3 \%$ & $44.4 \%$ & $30.7 \%$ & $<.01$ \\
\hline - Disagree & $11.7 \%$ & $14.8 \%$ & $17.9 \%$ & \\
\hline \multicolumn{5}{|c|}{$\begin{array}{l}\text { Most married women expect } \\
\text { their husbands to have other } \\
\text { sexual partners }\end{array}$} \\
\hline - Agree & $71.4 \%$ & $51.9 \%$ & $43.4 \%$ & \\
\hline - Not sure & $5.2 \%$ & $8.0 \%$ & $7.0 \%$ & $<.001$ \\
\hline - Disagree & $23.4 \%$ & $40.1 \%$ & $9.6 \%$ & \\
\hline
\end{tabular}

\subsection{Discussion}

There is little evidence from our study to suggest that the impact of the "community approach' widely promoted, but rarely implemented in Zimbabwe AIDS prevention programmes, has strengthened the capacity of poor rural farm worker communities to respond to the epidemic. In reality, decisions which require much wider reference to the community are made by land owners who show a willingness to support AIDS prevention activities providing they do not take up too much time. Our study showed that farm worker communities are loosely organized and have limited decision-making power. Seasonal workers, who at times characterise some farm worker communities, are under no obligation to comply with community norms. They play no role in decision-making and are therefore unlikely to participate actively in a community initiative which promotes the prevention of STIs. 
While these historical trends may be difficult for a community level intervention to influence, they should not be ignored. In order for AIDS prevention programmes to be 'owned' by farm worker communities, the capacity for participation by the workers must be strengthened. This implies (a) a devolution of responsibility for AIDS education and condom distribution from those in authority' to change-agents within the community; and (b) recognition that the nature of the intervention must facilitate debate and decision-making.

\section{Instrumental Knowledge of HIV/AIDS}

In sharp contrast to reports that levels of AIDS awareness are high in urban communities of Zimbabwe, our results show that farm worker communities, which are characterised by fewer educated people, particularly women, have had little exposure to AIDS prevention activities. There was high agreement among farm workers in our study that they lack information on AIDS. We found that fewer men attend educational activities and on selected items of knowledge, males showed less correct knowledge about transmission. However, we also found that educated men and women demonstrated an ability to understand the link between STIs and HIV transmission. This was possibly due to personal experience, i.e. workers with STIs would be likely to visit health centres where staff are trained to reinforce the dangers of repeated episodes of a sexually transmitted infection.

Our study also showed that beliefs that AIDS is brought about by bad luck or divine/ancestral retribution are not widely upheld by younger educated rural farm workers. We found that older, uneducated men and women in these communities were more likely to agree with the idea that factors exogenous to the individual, such as the belief that 'AIDS is an old disease', or is a result of bad luck or ancestral spirits, or that poor people are responsible for AIDS. Outsiders may be tempted to see such local beliefs as haphazard and illogical, but Mutambirwa (1991) stresses that, in fact, these beliefs often represent a coherent belief system which is defined from a local point of view. In as much as it is known that lay beliefs can act as powerful filters of AIDS prevention messages (Homans et al., 1987), we interventionists must derive their messages from a greater understanding of the socio-cultural context influencing AIDS-related beliefs and how people interpret the epidemic. Interventions must, therefore, aim to legitimise discussion around these issues and facilitate debate in a way that demonstrates an understanding of the way that 'people are socially constructed' (Taylor, 1990).

\section{Social Norms and Susceptibility to HIV Infection}

Our study revealed a significant interaction between perceived risk to HIV infection and low self-efficacy in uneducated women who articulated helplessness and an inability to protect themselves from HIV infection or to exercise control over their scxual lives. While this may be seen as an inability of women to ncgotiate protective relationships with men, the powerlessness of women in farm communities must be observed within the larger context of economic insecurity, whereby women place higher value in securing food, shelter and protection for the children than on asserting themselves sexually. Refusal to engage in sexual relations risks anger, outrage, marginalisation, eviction and survival in a harsh 
economic environment. As pointed out by other researchers (Bassett and Mhloyi, 1991; Airhihenbuwa et al., 1992) women who demand protected sex also risk suspicion arising from the implication that they are promiscuous. These responses may in no way be related to ignorance of the facts, which is often suggested; there are more critical factors which guide behaviour.

Among more educated men, we found acknowledgment of multi-partnering and an acceptance that infection with an STI is something to 'expect sooner or later'. There was also agreement among men that changes in behaviour were more likely to come about as a result of changes in normative values. Condom use, which is probably the most effective available barrier against STI transmission, was shown to be more likely among younger educated men. However, in a community which is dominated by uneducated, impoverished people with limited access to free supplies, we must understand that the failure to use condoms may have more to do with access and economics than with a lack of knowledge.

This configuration of responses would seem to indicate that social acceptance of high-risk behaviour will continue in impoverished farm communities until there is a change of social norms within dominant reference groups which are more likely, at the outset, to be men. These changes will be closely linked to the socio-economic situation of the workers and their perceptions of the advantages of change. To these barriers, we must add the influence of seasonal workers, whose transience excuses them from a personal commitment to change. While a peer-directed approach to behaviour change, which embraces free condom distribution, is likely to act as a more powerful force in shaping behaviour than one which attempts to target the individual through fear-induced messages, these issues must be considered.

\subsection{Conclusions}

Historically, most AIDS prevention programmes in Zimbabwe begin and end with efforts to persuade people to understand or do something. Little is known about the process of interventions in marginalised rural communities and few, if any, measure impact. There is little reason to believe that the inflexible nature of traditional AIDS education programmes, which rely heavily on print media as the remedy for change, will equip these communities to organise and respond to the epidemic.

The reciptivity of marginalised communities to AIDS prevention interventions is often determined by factors which are beyond the scope of even the most innovative programme. Our findings suggest, however, that there is a need to develop a comprehensive AIDS prevention intervention for farm worker communities taking into account a long history of non-participation in community issues. 'The intervention should also use a multi-level, multi-component approach to raise dialogue and address a number of interacting factors which perpetuate misund'rstanding influencing negative attitudes to women and sexuality. The intervention would also need to address the wide range of powerful social forces arrayed against behaviour change in communities which are educationally and 
economically impoverished. While the FHW is the acknowledged reference point for primary health care on commercial farms, the intervention needs to raise her self-esteem and equip her with skills and resources required to become an effective agent of change. However, this would be unlikely to occur unless the linkage system between the farm owner and the community is strengthened and a better understanding of the need to equip the community with organisational and decision-making abilities is reached.

\section{References}

Airhihenbuwa, C.O., DiClemente, R., Wingoog, G. and Lowe, A. (1992) HIV/AIDS prevention among African-Americans: A focus on culture. AIDS Education and Prevention, 4 (3), 267-276.

Bandura, A. (1986) Social Foundations of Thought and Action: a Social Cognitive Theory. Englewood Cliffs: Prentice-Hall.

Bassett, M. and Mhloyi, M. (1991) Women and AIDS in Zimbabwe: the mahing of an Epidemic. International Journal of Health Ser vices, 21, 143-156.

Caldwell, J., Caldwell, P. and Quiggin, P. (1989) Disaster in an alternate civilization. Health Transition Centre, No. 2, The Australian National University.

Chinemana, F. (1990) Report of an AIDS Knowledge Attitudes and Practices Survey in Commercial Farming Areas Marondera District. Report prepared for World Vision Zimbabwe and the Marondera District Health Team.

CSO (1992) Census Report. Central Statistics Office. Harare, Zimbabwe: Government Printers.

De May, P., Hukuimwe, H.A., Matsitukwa, L.T., Makasa, B.P. and De Colombani, P. (1992) HIV Sentinel Surveillance in Mashonaland West Province: HIV Seroprevalence Survey in the Conmercial Farming Area of Zvimba District, March-July. A Final Report: Ministry of Health, Zimbabwe.

De Vries, H., Dijkstra, M. and Kuhlman, P. (1988) Self-efficacy: The third factor besides attitude and subjective norm as predicators of behavioural intention. Health Education Research, 3, 272-282.

Denscombe, M. (1993) Personal health and the social psychology of risk taking. Health Education Research, 8 (4), 505-517.

Farag, H. (1995) Interview on Zimbabwe Television News, (ZTV) 23 January.

Frazer-Mackenzie, J.P. (1992) Report prepared for Commercial Farmers Union/AIDSTECH. Zimbabwe 15/9/90 -15/9/92.

Glanz, K., Lewis, F.M. and Rimer, B.K. (1990) Health Behaviour and Health Education. Theory and Practice. ed. Glanz, K., Lewis, F.M. and Rimer, B.K. San Fransisco: Jossey-Bass. 
Homans, H., Aggleton, P. and Warwick, I. (1987) Participatory Health Education Strategies for Health Educators with a Responsibility for Adult Education about AIDS. London: AVERT in collaboration with the Health Education Authority.

Janz, N.K. and Becker, M.H. (1984) The health belief model: A decade later. Health Education Quarterly, 11 (1), 1-48.

Laver, S. (1994) A preliminary report of a pre-intervention survey of knowledge, attitudes, beliefs of 770 Commercial Farm Workers with respect to HIVIAIDS. Unpublished monograph. Department of Community Medicine, University of Zimbabwe, Harare, Zimbabwe.

Linville, P.W. and Fischhoff, B. (1993) AIDS Risk Perceptions and Decision Biases. In The Social Psychology of HIV Infection, ed. Pryor, J.B. and Reeder, G.D., pp 5-37. Hillsdale, New Jersey: Lawrence Erlbaum Associates.

Mutambirwa, J. (1991) Aspects of sexual behaviour in local cultures and the transmission and prevention of HIV/AIDS. In Tradition and Transition: NGO's respond to AIDS, ed. Mercer and Scott, J.M. Baltimore: The Johns Hopkins University School of Hygiene and Public Health.

NACP (1994) National AIDS Co-ordination Programme. Sept-Dec Quarterly Report, Harare, Zimbabwe.

Taylor, C.C. (1990) Condoms and cosmology: The "fractal" persun and sexual risk in Rwanda. Social Scicnce and Medicine, 31, 1023-1028.

Torrey, B.B. and Way, P.O. (1991) Seroprevalence of HIV in Africa. CIR Staff Paper No. 55, Centre for International Research, U.S. Bureau of the Census, Washington D.C.

UNICEF (1994) A Situational Analysis of Women and Children in Zimbabwe, Harare, Zimbabwe.

Williams, G. and Ray, S. (1993) Work Against AIDS. Workplace-based AIDS Initiatives in Zimbabwe. Strategies for Hope Series No. 8. Kenya: Action Aid. AMREF.

ZAINET (1993) Zimbabwe AIDS Information Network News Bulletin, 4 December. 


\title{
Chapter 4
}

\section{Using Theory to Design an Intervention for HIV/AIDS Prevention in Farm Workers in Rural Zimbabwe}

\author{
Laver, S.M.L. ${ }^{1}$, Van den Borne, $B^{2}$. and Kok, $\mathrm{G}^{3}$. \\ Published in International Quarterly of Community Health Education, \\ 1994/1995, 15, (4), 349-362.
}

\begin{abstract}
Many primary prevention strategies have been used in HIV prevention programmes in Africa. Most of them developed through intuition: the theoretical basis for many interventions is limited to the knowledge/attitude model. This article illustrates how research findings from a base-line survey are combined with Paulo Freire's social change theory and the Ecological Model for Health Promotion to develop a participatory intervention for HIVIAIDS prevention in farm workers in Zimbabwe. The article addresses the need to focus attention on the process of change at the intra-personal and at organisational and policy levels of the community. Dialogue is central to the range of strategies proposed for the intervention. The effect will be measured through process and outcome evaluation.
\end{abstract}

1. Senior Lecturer, Department of Community Medicine, University of Zimbabwe Medical School, Harare, Zimbabwe.

2. Professor of Patient Education, Department of Health Education, University of Maastricht, Netherlands.

3. Professor and Scientific Director of Maastricht Health Research Institute for Prevention and Care, University of Maastricht, Netherlands. 


\subsection{Introduction}

In Africa the traditional approach to AIDS prevention has been through education. This has been on the assumption that 'people will act in their own interest once informed of the risks and benefits' (Fincham, 1992) of changing their behaviour. In recent years there has been an increasing shift away from expert-driven, individually targeted HIV / AIDS prevention programmes towards those which target social change. A variety of primary prevention strategies are used for this purpose. Not uncommonly, however, these strategies are developed through intuition and in the absence of a thorough problem analysis (Kok, 1991/2). It is also not uncommon to find that the theoretical basis for many interventions is still limited to cognitive models which stress the roles of knowledge, attitudes and beliefs in behaviour change. It follows that where the time and resources are used to develop cognitive processes within the individual, the benefits of creating change in the community through "reciprocal interaction between cognitive, behavioural and environmental determinants ...' (Fincham, 1992) may not be felt.

The advantage of integrating concepts from different theories to guide the process of behaviour change in community-based interventions, though not widely practised, is becoming more widely recognised (Amaro, 1995; Wallerstein and Sanchez-Merki, 1994). For example, interventions which, in addition to targeting cognitive skills and attitudes (Becker, 1974) at an intra-personal level, also develop networking skills and response efficacy (Rogers et al., 1978) within the target community, are of value in influencing social change. The strategies by which change is influenced have also attracted considerable debate, and, in this respect, Wallerstein and Bernstein (1988), Glanz et al. (1990), Wallerstein and Bernstein (1994) and Hope et al. (1984) draw our attention to the seminal work of Paulo Freirc (1972) and (1983), whose concept of creating critical consciousness has, according to Glanz et al. (1990), 'added an important dimension to more traditional teaching approaches'. In the Freirian model, individual and social change is brought about by developing a climate in which critical thinking, reflection and problem appraisal is facilitated through a process of listening, dialogue and action. This approach has been meaningfully adapted for use in many health education projects in first and third world countries (Minkler and Cox, 1980; Auerbach and Wallerstein, 1987; and Hope et al., 1984.) However, as Werch and DiClemente (1994) point out, it still appears that 'comprehensive programmes founded on multi-component, integrative theoretical models ...appear to be lacking... . In a similar vein, Wallerstein and Bernstein (1994) remind us that 'the challenge exists for us to look [more] objectively towards the theories' that could guide our practice.

This article describes how an HIV/AIDS prevention intervention was generated for illiterate farm workers in one district of Zimbabwe using a combination of the social ecology theory (McLeroy it al., 1988) and the structured dialogue approach proposed by Freire (1983) and later described by Wallerstein and Sanchez-Merki (1994) and Hope et al. (1984). First we provide an overview of the problem and how it is constructed in farm worker communities. We then 
show how theory was used to generate the methodology for the intervention. The paper provides a brief account of the methods that would be used to measure the process and effect of the intervention.

\subsection{The Problem}

The official estimate of HIV infection in Zimbabwe by early 1995 is estimated around one million people or approximately 10 per cent of the population (Farag, 1995). Loewenson reported recently in Harare (Loewenson, 1995) that one in five of the productive workforce has HIV. The problem is not confined to the urban areas of Zimbabwe. There is growing evidence of high sero-prevalence levels among rural farm workers who, until recently, have been marginalised in National AIDS Prevention activities (Laver, 1995). In one study, up to 48 per cent of the adults from commercial farms who presented with Sexually Transmitted Infections (STIs) were HIV positive (De May et al., 1992).

In 1993 we conducted a survey (Laver, 1995) to identify factors likely to place farm workers at risk of STI/HIV infection. Our study arose from a widespread concern that little is known about how the problem is socially produced and maintained in farm worker communities.

Using a structured questionnaire, we interviewed a random sample of 770 male and female farm workers from 17 randomly-selected, large-scale commercial farms in a district situated some $100 \mathrm{~km}$ north east of Harare where approximately 1116928 people, or 10.7 per cent of the total population of Zimbabwe, live (CSO, 1992). We also collected information through informal discussions with key informants in farm communities.

\subsection{Summary of Research Findings}

An adaptation of the Social Ecological Model for Health Promotion (McLeroy et al., 1988) guided the conceptualisation of the findings at different levels of analysis. The ecological model shows how psychological, psychosocial, organisational, cultural, social and political theories can be used to guide the targets of behaviour change at each level of intervention, i.e. the intra-personal, interpersonal, community and public policy levels. The findings are presented accordingly; at the intra-personal (individual) level characteristics such as knowledge, attitudes, perception of risk etc of the farm worker are summarised; at the socioorganisational level information related to social networks and the organisational culture of the community is presented together with information which relates directly to the community workplace. Finally, information related to regulation is summarised within the policy level.

* The Intra-Personal Level,

At this level our findings showed that farm communities in our study area were characterised by poor, marginalised workers. Most were second or third generation descendants of families which originated from Malawi, Zambia and 
Mozambique. A number of different dialects of the vernacular language were spoken. In sharp comparison to men, women were found to be educationally disadvantaged and illiteracy was correspondingly high.

Exposure to AIDS prevention activities was limited and a high percentage of men and women reported that they 'knew very little about AIDS'. On selected items of knowledge, misunderstanding about HIV transmission existed. Beliefs that AIDS is brought about by divine/ancestral retribution tended to be upheld by less educated women.

Uneducated women articulated an inability to protect themselves from HIV infection and perceived their risk of contracting HIV to be high. Among more educated men, we found acknowledgment of multi-partnering, and evidence that changes in behaviour are more likely to come about through changes in normative values. Condom use among men, which is probably the most effective barrier against STIs, was shown to be associated with younger more educated men.

\section{* The Socio-Organisational Level}

At this level, we found that although farm workers live and work together, these communities do not necessarily function as an interdependent group. They lack job tenure and tend to be loosely organised with little decision-making power. Their welfare is generally the concern of the farm owner who is the reference point for most major decisions concerning the workforce. Workers' committees had been set up on all the farms in our study sample, yet these committees lack the power to bargain or reach decisions of major importance, and prove mostly to be a useful reference point for the farm owners. A paternalistic approach to decision-making exists, and a non-participatory environment generally prevails. The workers felt that there was little that the community could do to prevent the spread of HIV.

We found that there is little recreation for these workers and social groupings tend to mobilise around 'farm football', drinking, the church and handicraft. Free time is also spent in tending to chickens and small plots of vegetables.

During times of planting, reaping and harvest there is an influx of casual or seasonal workers on many commercial farms. The transitory status of these workers tends to re-enforce their right to behave independently of community norms. They are blamed for disruptive behaviour and prostitution and it was felt that they would be unlikely to participate in a community initiative which promotes the prevention of STI/HIV.

Although no community-based AIDS prevention initiatives were identified on any of the farms in our study, primary health care (PHC) activities are carried out by Farm Health Workers (FHWs) who are normally women rather than men. Selection of FHWs is by their communities. Their role is to attend to minor health problems (with very few drugs) and deliver information (without any resources). None had recived any training in HIV/AIDS and their approach to health education is usually didactic. Although FHWs are the 'official change-agents' with respect to health matters, they lack recognition not surprisingly, and are held in poor esteem by the farm owners and the worker community. 
Farm workers are housed as family units in compounds. They do not hold any title to the land and live in dwellings which range from brick to mud and thatch. Some farms have minimum environmental standards of water and sanitation. Few farms had community halls with electricity, but all 17 farms in our study area had a beerhall which generates income for community development. Football was also a focal point for recreation. One farm had a public television set but a good number of farm workers owned or shared radios. Newspapers provide an important source of information for literate people, although access is limited and supplies are irregular.

Free primary school education was available for children of dependents on 11 farms in our study area.

\section{* The Policy Level}

At the policy level, Zimbabwe, like most other African and Western countries, has no laws specifically covering employment-related AIDS issues such as HIV screening (Williams and Ray, 1993). At the time of our study, no policy on AIDS for farm workers was in existence. Employers generally retain workers as long as they are able to perform their duties. When a worker dies the farmer helps to pay the funeral expenses. Since deceased workers are likely to be second or third generation descendants of migrants from neighbouring countries, their dependents have no traditional home to which to return. In this context, a generation of orphans, with its attendant problems, is expected to characterise farm communities. Condoms were not freely available on any of the farms in our study. Supplies tended to be erratic and cost to the farm owner was a limiting factor. No policy for accessing or distributing condoms was evident.

In summary, we concluded from these findings that unprotected sex and multipartnering were the two most important behaviours which placed farm workers at risk of HIV infection. However, we were also aware that a wide array of social, organisational and political forces influenced the problem in farm worker communities. At the intra-personal level, women in particular felt helpless, unable to control their sexuality or reduce the risk of infection with SII/HIV. At the socio-community level the people are disempowered and participate only nominally in decision-making. At the time of the study, there were no regulations which enhance accessibility of condoms or protect AIDS sufferers and their dependants in farm worker communities. In this context an intervention would need to be sensitive to these issues.

\subsection{Goal and Objectives of the Intervention}

The overall goal of the intervention was to decrease the risk of STI/ HIV through unprotected sex, and to increase farm worker participation in AIDS prevention activities. Our specific objectives included the need to develop a multi-level intervention with a phased participatory methodology which would target change within the individual and the socio-organisational context in which farm worker communities live and work. 
In keeping with community organisation principles (Bracht, 1990) we were cognisant that our intervention should be implemented by persons who were known to, and accepted by, the farm worker communities. We therefore located a cadre of health workers already working in these communities, known in Zimbabwe as Farm Health Workers (FHWs).

\subsection{Theories Guiding the Intervention}

Many authors (Amaro, 1995; Laver, 1993) draw attention to the fact that AIDS prevention interventions commonly fail to shift their focus beyond the cognitive level. McLeroy et al. (1988) point out that this incorrectly assumes that 'the proximal causes of behaviour lie within the individual... rather than in the social environment'. Amaro (1995) concurs with this position and says that 'human behaviour, especially sexual behaviour, is more complex than models suggest'. The author goes on to stress the need for researchers to locate models and theories which, in addition to cognitive change, also target the social context of sexuality and the differences which shape risk behaviour between men and women. Taking these issues into account, our attention was focused on the need to conceptualise a prevention programme for farm workers in which change could be meaningfully activated beyond a cognitive level. Two models proved appropriate for this purpose.

The first concerned the ecological model of health promotion (McLeroy et al., 1988). Although this model was not defined specifically for HIV/AIDS prevention, it is particularly relevant because it focuses attention on individual and social factors as targets for change. A variety of intervention strategies are also proposed through the model; these are specific for each level of intervention and range from skills development at the intra-personal level to mass media and regulatory changes at other levels. According to our adaptation of this model, however, the intervention would target change at the intra-personal, socioorganisational and policy levels. None of these levels was considered mutually exclusive.

The second theory of major importance to the development of the intervention was the theory for individual and social change originally developed by Freire (Freire, 1972) and used extensively in health promotion and social development programmes by Werner (Werner and Bower, 1982) and others (Auerbach and Wallerstein, 1987; Hope et al., 1984; Wallerstein and Bernstein, 1988 and Wallerstein and Sanchez-Merki, 1994). In acknowledging the need for interplay between individual and social-organisational change, Freire's work also provides a philosophical framework for the development of strategies for interventions. The model had three major advantages for our intervention: first, it encompasses a participatory orientation to learning rather than a passive mode of delivering information. In Freire's words (Freire, 1972) 'We simply cannot go to the workers... to give them knowledge or to impose upon them the model of the "good man" contained in a programme whose content we have ourselves organised'. Freire also goes on to say that 'it is not our role to speak to people about our own view 
of the world but rather to dialogue with the people about their view and ours'. This was important given the urgent need to develop and promote a culture of appraisal and dialogue around the issue of HIV/AIDS in farm worker communities. Secondly, the model incorporates a listening-dialogue-action methodology which is an ongoing cyclical process (as opposed to a linear process), appropriate for motivating critical thinking within a target group where there is a need to re-visit and re-appraise key issues such as lay beliefs throughout the intervention. Thirdly, the model, as described by Wallerstein and Sanchez-Merki (1994) integrates protection-motivation theory, which proposes that decisions to act can be initiated through a variety of information sources, thus reducing the dependency on didactics (Wallerstein and Sanchez-Merki, 1994 quoting Rogers et al., 1978; Rogers, 1984). In addition, we reviewed a number of other theories which we considered applicable for the intervention at each of the three levels.

At the intra-personal level, the theory of change is one which primarily concerns individuals. The targets of change include the characteristics of the individual such as knowledge, attitudes, skills or intentions to change (McLeroy et al., 1988). In conceptualising the targets of change for our intervention we were initially guided by the Health Belief Model (HBM) (Becker, 1974; Becker and Joseph, 1988) described by Amaro (1995) as a cognitive model of behaviour change, which attempts to explain individual behaviour according to one's perception of vulnerability, i.e. susceptibility, perceived threat, advantages and disadvantages of changing behaviour and barriers. Since lay beliefs held among people in our target group (such as 'AIDS is a result of our ancestors' displeasure; and 'Getting AIDS is a matter of bad luck'), were likely to be a barrier to cognitive and attitude change, we considered that an appraisal of HIV in terms of personal threat, vulnerability and weighing up of advantages and disadvantages of practices (such as not using a condom with girlfriends), should be an ongoing activity at the first level of intervention. The Social Learning Theory (Bandura, 1986) in which vicarious learning (modelling) is a central theme, also views behaviour as a function of a person's self-efficacy, - the belief that one can successfully execute a behaviour in order to produce the outcome, (e.g. 'In future, I will be able to ask my partner to use a condom in order to protect myself from getting STI/HIV'), was important in our study. In this respect we felt a particular need to develop coping responses among women (e.g. 'There is something I can do to prevent myself from getting STI/HIV'), who were shown through our background research to be 'helpless' and sexually disempowered.

The Theory of Reasoned Action (Fishbein and Ajzen, 1975; 1980) also had implications for conceptualising the intervention at the intra-personal level because, in addition to beliefs of behavioural outcomes, such as 'Using a condum will increase/decrease sexual pleasure' or 'Condoms will/will not reduce Sexually Transmitted Infections', it emphasises the role of personal intention and attitudes in determining whether a behaviour will occur. The theory draws attention to the influence of normative beliefs people may have, i.e. what they think other people - in particular the influential people among peers - would expect them to do in a particular situation. This was particularly important, given 
attitude's to STIS and multi-partncring by men (e.g. "Most men expect to have mure than one partner"; "These days men expect to get an STD at least once in their lifetime') which were revealed through our research.

We were aware that the models described above are based on individual conceptualisation of behaviour. We then focused on the theory of change as it would apply to the tradition of organisation in our target community. Many authors propose interesting views on the organisational aspects of community interventions (Bracht, 1990; Bracht and Kingsbury, 1990). Minkler (1990) describes community organisation as 'the process by which community groups are helped to identify common problems, mobilise resources and in other ways develop strategies and goals for reaching the goals they have set'.

Several key concepts are reported by Minkler (1990) to be central to this process. Of particular importance to this study, and central also to the Freirian philosophy, were the issues of empowerment which, according to early work of Ross (1955) and later work of Freire (1972) must increase problem-solving, participation and the development of critical consciousness. Minkler (1990) says that 'in community organisation practice, the concept of empowerment operates on two levels simultaneously. First the individual involved in a community organising effort may feel more support, and 'such social support may contribute to a more generalised sense of coherence', e.g. a response that the community can do something to prevent the spread of HIV.

In emphasising the role of change-agents (Farm Health Workers) in the diffusion process (Rogers and Shoemaker, 1971; Rogers, 1983) and the linkage approach (Havelock, 1971; Orlandi, 1986; 1987) in the social environment, the diffusion of innovations model also removes the focus somewhat away from the individual as the target for change (Graeff, et al., 1993). According to this perspective the intervention would be reinforced at each level through a linkage system made up of FHWs and land owners.

Each of the theories and models presented above is complex and multimodal. However, there were also many similarities. In examining these models we tried to keep those components which would enable the attainment of our objectives and permit the flexibility which was required in the conceptualisation of the intervention at each level of implementation.

\subsection{The Intervention}

We proposed that the intervention should be targeted at three levels viz, the intrapersonal, socio-organisational and policy levels (after McLeroy et al., 1988). The methodology would embrace the Freirian Structured Dialoguc Model described by Wallerstein and Sanchez-Merki (1994) in which a cyclical listening-appraisaldialogue-action approach is proposed. Programme inputs would incorporate user friendly, replicable and cost effective methods that could be implemented by FHWs who would be the change-agents.

Since didactic methods have been used more extensively than participatory methods to educate people about AIDS (Laver, 1993) we were aware of the need to train the FHWs to use methods which would be less teacher dependent. We 
were also aware of the need to decrease the role of the change-agent over time and increase community involvement in AIDS prevention activities. A training programme would be developed along with visual aids such as picture codes and a manual for trainers to meet these objectives.

The first objective at the intra-personal level of the intervention would be to activate recognition of and personal identification with HIV/AIDS, e.g. 'What is AIDS?'; 'How did it get to Zimbabwe?'; 'Has it reached the rural areas?'; 'Do STIs lead to the problem?' etc. Strategies such as group discussion which promote active listening and appraisal within the safety of small numbers were proposed. The value of dialogue would be stressed with an emphasis on the importance of the change-agent role in facilitation.

This stage would be followed by an appraisal of lay beliefs (e.g. "AIDS is a very old disease'; 'Getting AIDS is just a matter of bad luck' etc) using a participatory agree/disagree activity. A period of threat and susceptibility appraisal would follow ('Is AIDS really a problem?'; 'Am I at risk?'; 'Is my family at risk?' etc). Cognitive changes, for example with respect to instrumental knowledge about STI/HIV/AIDS ('Mosquitoes do not spread AIDS'; 'A person with STI is at risk of becoming infected with HIV'; 'Touching infected people does not cause a person to get HIV' etc), would be brought about through didactic sessions aided by a flip chart and pictures.

Programme inputs would then be oriented towards an appraisal of variables such as self-efficacy ('Is it possible for women to deny sex to their husbands?') and response-efficacy ('What can we do to protect ourselves?') through listening and dialogue aided by triggers such as picture codes (socially-charged pictures that illustrate problems [Laver, 1994]). Personal experience and cultural issues would be used as the basis for the appraisal of social norms ('Do men expect to have more than one partner these days?'; 'Is it true that men will only change when their friends decide to do the same?' etc).

This stage would gradually move on to an appraisal of these issues within a societal context ("What can we do to involve seasonal workers in AIDS prevention?'; 'What can men do?'; 'What can women do?'; 'What can we as a community do?'; 'What can the farm owner do?"). This phase would be accompanied by a shift in the locus of control from change-agent to the community with empowerment, social responsibility and action (i.e. shown by new initiatives such as AIDS clubs) as important objectives.

The objective of policy change would mainly target the issue of condom access and distribution within the community, whilst encouraging critical thought around the problem of AIDS orphans and dependants of sufferers ('What can the community do?'; 'What should the government do?'; "What should the landowners do?').

The locus of control for the intervention would therefore shift from the researcher at the problem definition, materials development and training stage, to a point at which the project was institutionalised within the community through the change-agents. However, given the non-participatory environment in which farm workers have historically found themselves to be, we realised 


\section{Figure 1: Summary of Intervention Plan}

\begin{tabular}{|c|c|c|c|}
\hline $\begin{array}{l}\text { Level of Intervention (after } \\
\text { McLeroy et al 1988) }\end{array}$ & Theories of Change & Targets of Change & $\begin{array}{l}\text { Strategies/Methods (after } \\
\text { Freire 1972;1983; Wallerstein } 8 \\
\text { Sanchez-Merki, 1994) }\end{array}$ \\
\hline \multirow[t]{2}{*}{ - Intra-personal level } & $\begin{array}{l}\text { - Health Belief Model } \\
\text { (Becker, 1974; 1988) }\end{array}$ & $\begin{array}{l}\text { - Personal idenlification with the } \\
\text { problem } \\
\text { - Recognition of problem } \\
\text { - Lay beliefs } \\
\text { - Vulnerability ie, appraisal of } \\
\text { susceptibility, threal, advantages v } \\
\text { disadvantages of behaviour } \\
\text { change, barriers. } \\
\text { - Cognitive change } \\
\text { - Attitude change }\end{array}$ & $\begin{array}{l}\text { - APPRAISAL } \\
\text { Agree/disagree activities } \\
\text { Poster }\end{array}$ \\
\hline & $\begin{array}{l}\text { Social Learning Theory } \\
\text { (Bandura, 1986) } \\
\text { - Theory of Planned Behaviour } \\
\text { (Ajzen, 1987) }\end{array}$ & $\begin{array}{l}\text { - Self empowerment (efficacy) } \\
\text { - Response efficacy } \\
\text { - Social norms }\end{array}$ & $\begin{array}{l}\text { DIALOGUE } \\
\text { Flip chart } \\
\text { Picture codes } \\
\text { Condom distribution } \\
\text { Drama }\end{array}$ \\
\hline - Socio-organisational level & $\begin{array}{l}\text { Community Organisation } \\
\text { Theory } \\
\text { (Minkler, 1980; 1990; Rogers \& } \\
\text { Shoemaker 1971; Rogers, 1983) }\end{array}$ & $\begin{array}{l}\text { - Community empowerment } \\
\text { - Social responsibility } \\
\text { - Social action }\end{array}$ & $\begin{array}{l}\text { ACTION } \\
\text { Formation of AIDS clubs } \\
\text { Maintenance of condom supply } \\
\text { Peer education } \\
\text { Networking }\end{array}$ \\
\hline - Policy level & - Regulations & - Improve access to STI treatment & \\
\hline
\end{tabular}


that this may be a difficult objective to achieve. Social action would depend on the support available for change; individual change could become the only possible outcome.

Figure 1 provides a summary of the intervention proposal. It shows the principal theories and models which are proposed for each level, the targets of change and the strategies to be employed (after McLeroy et al., 1988).

\subsection{Measures of Evaluation}

Although we were aware that behaviour change is likely to take place gradually, the process of the intervention would be measured throughout the period of implementation and the effect would be measured after a 12-month period.

Process information would be collected by means of:

- Process data forms to be completed by Farm Health Workers every month.

Data pertaining to the following would be collected:

* Reach, i.e.

- numbers of groups convened

- enquiries from other farms

- new initiatives within the community

- Methods of communication used

- Number of condoms distributed

* New condom distribution points

- Sexually Transmitted Infections (STT) incidence data, i.e. number of STI cases reported to FHWs and catchment clinics within the project area.

* Seasonal data, i.e. data concerning the influx of seasonal/casual workers at different times in the farming calendar, bonus months, leave periods etc

* Focus group discussions, i.e to collect data from FHWs

* Follow-up visits to farms and discussions with farm owners

The effect of the intervention would be measured using the structured interview method. Changes in knowledge, attitudes, perception of threat and vulnerability, self-esteem, social norms and empowerment would be measured. For comparative purposes, the results from our intervention farms would be compared with randomly-assigned control farms.

\subsection{Conclusion}

This paper shows how theory was used to develop an intervention for marginalised farm workers in rural Zimbabwe. It highlights the problem of HIV as revealed through a study of farm workers and goes on to explore relevant theories or models which provided a guide to the development of a methodology for the intervention. It also provides a brief account of the methods that would be used to measure the process and effect of the intervention.

In proposing the intervention we were mindful that, in addition to prevailing factors already described, the receptivity of farm worker communities to our intervention would be determined by many issues. For example, we were aware that farm workers would be at different stages of comprehension about AIDS 
and not everyone would have an equal opportunity to attend sessions. Some workers would attend some sessions and not others. It was likely that farming activities could disrupt the intervention, i.e. when workers were too busy planting or harvesting to spare limited free time for participation in intervention activities. At other times workers would need to take leave and return to their traditional homes. We also recognised the need to sustain interest among farm owners especially as it would be unlikely, at the outset, that they would see no demonstrable changes in risk-taking behaviour.

Finally, in Zimbabwe, as in many other African countries, a strong culture of didactics exists, especially with respect to education. Workers in particular expect to be told what not to do; it is unusual for them to be in a learning situation where they are invited to do the talking too. The difficulty of proposing a methodology that requires facilitators with limited experience to stand back and listen was not to be under-estimated.

\section{References}

Amaro, H. (1995) Love Sex and Power. Considering women's realities in HIV Prevention. American Psychologist, 50 (6), 437-447.

Auerbach, E.R. and Wallerstein, N. (1987) ESL for Action Problem Posing at Work Teachers Guide. Reading, Mass: Addison-Wesley.

Bandura, A. (1986) Social Foundations of Thought and Action: A Social Cognitive Theory. Englewood Cliffs: Prentice-Hall.

Becker, M.H. (1974) The Health Belief Model and Sick Role Behaviour. Henlth Eduiction Monographs, 2, 409-419.

Becker, M.H. and Joseph, J. (1988) AIDS and behavioural change to avoid risk. A review. American Journal of Public Health, 78, 384-410.

Bracht, N. (1990) Introduction. In Health promotion at the community level, ed. Bracht, N. pp 19-25. Newbury Park, CA: Sage.

Bracht, N. and Kingsbury, L. (1990) Community organisation principles in health promotion: A five stage model. In Henlth promotion at the community level, ed. Bracht, N. pp 66-88. Newbury Park, CA: Sage.

CSO (1992) Census Report Central Statistical Office. Harare, Zimbabwe: Government Printers.

De May, P., Hukuimwe, H.A., Matsitukwa, L.T., Makasa, B.P. and De Colombani, P. (1992) HIV Sentinel Surveillanc' in Mashonnland West Province: HIV Seroprevalcnce Survey in the Comme'rial Farming Area of Zuimba District, March-July. A Final Report: Ministry of Hcalth, Zimbabwe.

Farag, H. (1995) Interview on Zimbabwe Television News, (ZTV) 23 January 1945. 
Fincham, S. (1992) Community Health Promotion Programs. Social Science and Medicine, 35 (3), $239-249$.

Fishbein, M. and Ajzen, I. (1975) Beliefs, attitudes, intention and behaviour: An introduction to theory and research. Reading, MA: Addison-Wesley.

Fishbein, M. and Ajzen, 1. (1980) Understanding attitudes and predicting social behaviour. Englewood Cliffs, NJ: Prentice Hall.

Freire, P. (1972) Pedagogy of the Oppressed. New York: Seabury Press.

Freire, P. (1983) Education for Critical Consciousness. New York: Seabury Press/ Continuum Press.

Glanz, K., Lewis, F.M. and Rimer, B.K. (1990) In Health Behaviour and Health Education, Theory and Practice, ed. Glanz, K., Lewis, F.M. and Rimer, B.K. San Francisco: Jossey-Bass.

Graeff, J.A., Elder, J.P. and Booth, E.M. (1993) Communication for health and behaviour change. A developing country perspective. San Francisco: Jossey-Bass.

Havelock, R. (1971) Planning for Innovation Through Dissemination and Utilisation of Knowledge. Ann Arbor, Mich.: Institute for Social Research.

Hope, A., Timmel, S. and Hodzi, C. (1984) Training for Transformation: A handbook for Community Workers. Gweru, Zimbabwe: Mambo Press.

Kok, G. (1991/2) Health Education and Research for AIDS Prevention. Hygie, X, 32-39.

Laver, S. (1993) AIDS education is more than telling people what not to do. Tropical Doctor, 23, 156-160.

Laver, S. (1994) Picture Codes in AIDS education. World Health Forum, 15, 39-41.

Laver, S. (1995) A pre-interventiun survey to determine understanding of HIV / AIDS in farm worker communities of Zimbabwe. In Press, AIDS Education and Prevention, (Accepted for publication 1995).

Loewenson, R. (1995) Sunday Mail Newspaper, Harare Zimbabwe.

McLeroy, K.R., Bibeau, D., Steckler, A. and Glanz, K. (1988) An Ecological Perspective on Health Promotion Programs. Health Education Quarterly, 15 (4), 351-377.

Minkler, M. (1990) Group Intervention Models of Health Behaviour Change. In Health Behaviour and Health Education. Theory and Research, ed. Glanz, K., Lewis, F.M. and Rimer, B.K. pp 253-287. San Francisco: Jossey-Bass Health series.

Minkler, M. and Cox, K. (1980) Creating Critical Consciousness in Health: Applications of Freire's Philosophy and Methods to the Health-care Setting. International Journal of Health Services, 311-322. 
Orlandi, M.A. (1986) The Diffusion and Adoption of Worksite Health Promotion Innovations: An Analysis of Barriers. Preventive Medicine, 15, 522-536.

Orlandi, M.A. (1987) Promoting Health and Preventing Disease in Health-care Settings: An Analysis of Barriers. Preventive Medicine, 16, 199-130.

Rogers, E. (1983) Diffusion of Innovations. New York: Free Press.

Rogers, E. and Shoemaker, F. (1971) Communication of Innovations, 2nd ed. New York: Free Press.

Rogers, R.W. (1984) Changing health-related attitudes and behaviour: the role of preventive health psychology. In Interfaces in Psychology, ed. McGlyn, R., Maddox, J., Stoltenbury, C. and Harvey, R.J. Lubbock, T.X.: Texas Tech University Press.

Rogers, R.W., Deckner, C.W. and Mewborn, C.R. (1978) An expectancy-value theory approach to the long-term modification of smoking behaviour. Journal of Clinical Psychology, 34, 562-566.

Ross, M. (1955) Community Organisation: Theory and Principles. New York: Harper and Row.

Wallerstein, N. and Bernstein, E. (1988) Empowerment Education: Freire's Ideas Adapted to Health Education. Health Education Quarterly, 15, 379-394.

Wallerstein, N. and Bernstein, E. (1994) Introduction to Community Empowerment, Participatory Education, and Health. Health Education Quarterly, 21 (2), 141148.

Wallerstein, N. and Sanchez-Merki, V. (1994) Freirian Praxis in health education: research results from an adolescent prevention programme. Health Education Research. Theory and Practice, 9 (1), 105-118.

Werch, C.E. and DiClimente, C.C. (1994) A Multi-component stage model for matching drug prevention strategies and messages to youth stage of use. Health Education Research. Theory and Practice, 9 (1), 37-46.

Werner, D. and Bower, B. (1982) Helping Health Workers Learn. Palo Alto, CA: The Hesperian Foundation.

Williams, G. and Ray, S. (1993) Workplace Against AIDS. Workplace-based AIDS Initiatives in Zimbabwe. Strategies for Hope Series No. 8. Kenya: Action Aid. AMREF. 


\title{
Chapter 5
}

\section{Was the Intervention Implemented as Intended? A Process Evaluation of an AIDS Prevention Intervention in Rural Zimbabwe.}

\author{
Laver, S.M.L.', Van den Borne, B. ${ }^{2}$, Kok, G. ${ }^{3}$ and Woelk, G. ${ }^{4}$ \\ Published in International Quarterly of Health Education, \\ 16 (1), 25-46 1996/1997
}

\begin{abstract}
End-point evaluations are still the most commonly used method of assessing the success or failure of interventions. In this article we describe how a process evaluation was used to measure 'what happened' during an HIVIAIDS prevention programme for farm workers in Zimbabwe. The intervention was developed according to the Paulo Freirian theory of Social Change and the Ecological Model for health promotion.

The stages of the intervention were cyclical; in the first stage innovative methods were used to encourage appraisal of vulnerability to HIV/AIDS through activities which raised critical thinking and dialogue. In the next phase, emphasis was placed on developing cognitive and attitude change in the target group. Self-protective behaviour was encouraged through condom use and an increase in self-efficacy with respect to negotiating safe sex, especially among women. In the last stage of the intervention, efforts were made to create a climate for maintenance of behaviour and socially responsible action within the community.

The process evaluation gave us valuable insight to factors which, when aggregated, provided an overview of a programme whose successes and failures may well have been determined by issues outside the scope of the intervention. The effect of seasonal fluctuations of labour, income and farming activity on programme activity, patterns of STI and condom demand were marked. This led us back to our initial question 'Was the intervention implemented as planned?' and the answer: 'Only partially'.
\end{abstract}

1. Senior Lecturer, Department of Community Medicine, University of Zimbabwe Medical School, Harare, Zimbabwe.

2. Professor of Patient Education, Department of Health Education, University of Maastricht, Netherlands.

3. Professor and Scientific Director of Maastricht Health Research Institute for Prevention and Care, University of Maastricht, Netherlands.

4. Senior Lecturer, Department of Community Medicine, University of Zimbabwe Medical School, Harare, Zimbabwe 


\subsection{Introduction}

'Outsiders' views of the poor are distorted in many ways... when they are met they often do not speak; when they speak they are often cautious and deferential; and often what they said is not listened to.., interpreted in a bad light'.

(Chambers, 1983)

End-point evaluations are still the most common method of assessing the success or failure of interventions. In this respect the questionnaire is very uften used to gather information. However, Chambers (1983) reminds us that although questionnaires 'can be aggregated to give an overall view... their penctration is usually shallow, concentrating on what is measurable, answerable and acceptable as a question rather than probing less tangible and more qualitative aspects of society'. The author goes further to say that 'conventional questionnaires have many drawbacks if the aim is to gain insight into the lives and conditions of poorer rural people... other methods are required, either alone, or together with surveys'. Many evaluation theorists, such as Cook and Campbell (1979) and Reichart and Cook (1979) among others, support this vicw and advocate the inclusion of quantitative and qualitative methods in the data collection repertoire.

Increasingly we have come to notice that, in addition to the measurement of outcome or effect of an intervention through quantitative research methods, other methods are recommended for assessing the effectiveness of long-term intervention programmes (Nutbeam et al., 1993).

In this respect, Glanz et al.(1990), Van Assema (1993) and Ingersoll et al. (1993), advocate the use of well-structured and comprehensive process evaluation approaches as a means of strengthening assumptions about causality by clarifying the relationships between interventions and outcome. In describing process evaluation McGraw et al. (1994) say that it "compliments outcome evaluation by providing data to describe how a programme was implemented, how well the activities delivered fit the original design, to whom the services were delivered, the extent to which the target population was reached and factors external to that programme that may compete with the programme effects'. Green and Lewis (1986) say that 'process analyses are useful in large diffuse programmes where the source of programme effects is unclear'. They go on to say that 'process analysis helps us to learn as much as possible about how, why, and under what conditions a programme brings about certain outcomes [including no effect]. It encompasses', they say, 'more than the functioning of the programme. It answers the question "what happened" and permits the analysis of unusual failures, successes, or dropouts; close observation of especially effective aspects of the programme... and [it] presents a better picture of how the programme really works'.

Recent studies (Flora et al., 1993; Lytle et al., 1994; McGraw et al., 1994; Johnson et al., 1994; McKenzie et al., 1994) show how process evaluation is used to complement outcome evaluation in interventions carried out in the United States. The literature also reveals reports of a process evaluation study in Canada where Gliksman et al. (1993) evaluated the role of alcohol servers in a prevention 
programme; in Holland where the method was used in a school-based smoking prevention project by Dijkstra $e t$ al. (1993) and an interesting account of a process evaluation of a community intervention project in Bergeyk (Van Assema, 1993). Although the search can by no means be regarded as exhaustive, there appears to be little documented evidence of process evaluation studies in developing country situations, particularly in respect of community outcomes.

In this paper we describe how an STI/HIV/AIDS prevention intervention was generated for farm workers. We show how process evaluation was used to describe the events which took place during the intervention period. In particular, we report on factors such as seasonal farming activity which affected the process of implementation. We report on the reach of the intervention and methods used. We also report on condom demand during the intervention period, possible effects of labour fluctuation on project implementation, disposable income and patterns of STI.

The generation of our process evaluation plan was guided by the expcricnce of McGraw et al. (1994) and Van Assema (1993).

\subsection{Background Research}

Our intervention was planned against a background of concern about rising HIV infection in workers who live and work on large-scale commercial farms in Zimbabwe. For example, a study conducted by De May et al. (1992) showed that up to 49 per cent of farm workers presenting with STIs at a district hospital in one catchment area were HIV positive.

In an effort to examine behavioural factors likely to place workers at risk of STI/HIV infection in farm communities, we conducted a survey by interview (Laver et al., 1995). 770 farm workers from 17 randomly-selected commercial farms participated in the study.

The survey showed that at an intra-personal level, farm worker communities, which are characterised by women who are more educationally disadvantaged than men, have had little exposure to AIDS prevention activities. Our study showed that beliefs that AIDS is brought about by divine/ancestral retribution were upheld by less-educated women. A significant association was found with respect to perceived risk to HIV and low self-efficacy among uneducated women, who articulated helplessness and an inability to protect themselves from HIV infection. Among more educated men, we found acknowledgment of multipartnering and also that changes in behaviour are more likely to come about through changes in normative values. Condom use, which is probably the most effective barrier against STIs, was shown to be very low and associated with younger, better educated men.

At a socio-organisational level, our findings showed that farm worker communities are loosely organised, they lack decision-making power and are characterised by extreme poverty. There were no policies or laws in place covering employment-related AIDS issues and condoms were usually unavailable. 
We concluded from these findings that a replicable, low cost STI/HIV/AIDS prevention programme should be designed, implemented and evaluated in one farming district. A process and impact evaluation would be conducted to measure the effect of the intervention.

\subsection{Intervention Goal and Objectives}

The overall goal of the intervention was to decrease the risk of STI/HIV infection through unprotected sex and increase farm worker participation in AIDS prevention activities (Laver et al., 1994/1995). Our specific objectives included the need to develop a multi-level intervention with a phased, participatory methodology in which dialogue would play a central role. We aimed to target changes such as self-efficacy, social norms and perceived susceptibility to STI/ HIV infection at an intra-personal level. Within the socio-organisational context of the farm worker community, we aimed to create an enabling climate which would encourage the development of community-based initiatives against AIDS. A further objective concerned policy change with respect to condom distribution and care of AIDS sufferers on farms (Laver et al., 1994/1995).

\subsection{Change-agents}

In keeping with community organisation principles (Bracht, 1990) we were aware that our intervention should be implemented by persons who were known to, and accepted by, the farm worker communities. We therefore located a cadre of health workers (known in Zimbabwe as Farm Health Workers [FHWs]) already active in these communities,

\subsection{Theoretical Implications for the Development of the Intervention}

Several theories were reviewed for the purposes of intervention design. Of these, two were especially pertinent to the study. The first concerned the ecological model of health promotion (McLeroy et al., 1988). Although this model was not defined specifically for HIV / AIDS prevention, it was relevant because it focused attention on individual and social factors as targets for change.

The second theory of major importance to the development of the intervention was the theory for individual and social change originally developed by Freire (1972) and used extensively in health promotion and social development programmes by Werner (Werner and Bower, 1982) and others (Auerbach and Wallerstein, 1987; Hope et al., 1984; Wallerstein and Bernstein, 1988; Wallerstein and Sanchez-Merki, 1994). In acknowledging the need for interplay between individual and socio-organisational change, Freire's work also provides a philosophical framework for the development of strategies for interventions. The model had three major advantages for our intervention. Firstly it encompasses a participatory orientation to learning rather than a passive mode of delivering information. Secondly, it incorporates a listening-dialogue-action methodology 
which is an on-going cyclical process (as opposed to a linear process) appropriate for motivating change within a target group where there was a need to re-visit and re-appraise key issues such as lay beliefs throughout the intervention. Thirdly, the model as described by Wallerstein and Sanchez-Merki (1994), integrates protection-motivation theory which proposes that decisions to act can be initiated through a variety of informational sources (Wallerstien and Sanchez-Merki, 1994 quoting Rogers et al., 1978; Rogers, 1983; Rogers, 1984), thus reducing the dependency on didactics. Our intervention also combined the constructs of a number of other theories, i.e. the Health Belief Model (Becker, 1974), the Social Learning Theory (Bandura, 1977), the Theory of Reasoned Action (Fishbein and Azjen, 1975; 1980), Community Organisation Theory (Minkler, 1990; Bracht, 1990) and Diffusion of Innovations Theory (Rogers and Shoemaker, 1971).

\subsection{The Intervention}

\subsubsection{Selection of Farm Health Workers}

In order for the intervention to have the best chance of success, 40 of the "best" FHWs in the district were selected as change-agents. The criteria for selection included their Primary Health Care (PHC) training record, records of attendance at monthly FHW meetings, performance within the community, functional literacy and a willingness to participate. None of the FHWs had received previous training in AIDS prevention; all $40 \mathrm{FHWs}$ were female. We then randomly assigned 20 FHWs to an intervention group for training in our methodology, and assigned 20 to a control. As it was impractical to follow up 20 FHWs in the intervention group, nine farms were randomly selected from the intervention group for this purpose; eight were selected from the control. Each FHW represented a community of around 300 permanent workers and their dependents.

\subsubsection{Materials Development and Training}

The FHWs in the intervention group received intensive training which was carried over a period of 10 days at a FHW training centre, situated at a rural district hospital. Resources were extremely limited; the FHWs cooked their meals on an open fire and slept on the floor during the training period. Their training was conducted in the vernacular by persons who had already received training in the listening-appraisal-dialogue-action method.

In particular the advantages of a participatory approach versus a didactic approach in information-delivery were stressed. FHWs were trained to become the sharers instead of the givers of information. They learned the importance of listening versus telling people what was known already. Group work rather than lectures was encouraged. At the conclusion of the training, each FHW was equipped with pre-tested resource materials which would be used during the intervention. These included posters, picture codes (which are socially-charged pictures that illustrate problems), hand-outs which showed colour photographs of STIs and an AIDS flipchart. Our FHWs were also trained in the compilation of 
process data sheets (Appendix A) which would be submitted monthly to the research co-ordinator. Additional training was provided at monthly meetings which were held throughout the intervention.

A post-training survey indicated that the FHWs had grasped the basic concepts of the listening-appraisal-dialogue-action approach. Their ability to handle small groups and training aids such as picture codes with confidence, was measured through practical sessions during and subsequent to their training. They emerged enthusiastic and confident about their new role in HIV/AIDS communication, yet they were also realistic about the barriers which may prevent an attainment of their objectives. These included a lack of 'protected' time for education at the workplace and apathy and disruption by contract workers. There was also a clear recognition by FHWs that social action would depend on widespread support for change. Individual change would become the only possible outcome.

\subsubsection{Description and Implementation of the Intervention}

The intervention was carried out according to the phases in our listeningappraisal-dialogue-action model (after Wallerstein and Sanchez-Merki, 1994; Laver et al., 1994/1995). The process was cyclical and no single phase was discrete.

\section{The Listening Phase}

The listening phase targeted active versus passive listening. The issue of AIDS was raised in the farm community by the FHW who encouraged workers to discuss, and listen to others discuss, the problem. In this stage the FHWs especially aimed to activate recognition of, and personal identification with HIV/AIDS. Questions such as 'What is AIDS?'; 'How did it get to Zimbabwe?'; 'Has it reached the rural areas?'; 'Has the problem reached our community, our families our friends?' etc were raised. Group discussion which promotes active listening and dialogue within the safety of small numbers was used to facilitate this process. This phase lasted about two months.

\section{Appraisal Phase}

Since misconceptions and lay beliefs about AIDS were identified as possible barriers to behaviour change in farm workers (Laver et al., 1995), the intervention graduated towards a process of critical appraisal around the issue of vulnerability, i.e. susceptibility to infection, perceived threat, the disadvantages and advantages of changing behaviour and barriers to action. For the initial phase of appraisal, FHWs pooled a number of 'trigger statements' which reflected lay beliefs and misunderstandings commonly cited by farm workers. such as: "AIDS is a very old disease'; 'Getting AIDS is just a matter of bad luck' etc. The community was invited to participate in 'agree/disagree' activities to appraise these beliefs.

This phase was followed by a further period of appraisal which dealt more specifically with the issues of personal threat and susceptibility, e.g. 'Is AIDS really a problem to me?'; Am I personally at risk?'; 'Is my family at risk?'; 'Are farm workers at more risk than other people in Zimbabwe?', etc. Active listening skills were promoted and empathy, shown to be an important variable for 
behaviour change (Millar and Rollinick, 1990; Wallerstein and Sanchez-Merki, 1994), was encouraged through anecdotes which helped to create and sustain an openness about these issues.

A free, monthly condom supply was offered to FHWs working on intervention farms and in control farms during this phase. Many of the control farms did not respond. Supplies were calculated at 15 condoms per person per month, according to the approximate number of males and females permanently resident on the farm and aged between 17 and 55. Additional supplies were made available to FHWs on request and especially during periods when there was an influx of seasonal/casual workers. FHWs were encouraged to ensure regular condom supplies at high access points such as beer-halls during peak periods of farming activity. The number of condoms distributed each month was recorded on the process data form (Appendix A). This phase of the intervention merged with the dialogue phase, although appraisal methods were used throughout the intervention.

\section{Dialogue Phase}

In this phase we aimed especially to increasc instrumental knowledge about STI/ HIV / AIDS (e.g. 'Mosquitoes do not spread AIDS'; 'A person with STD is at risk of becoming infected with HIV'; 'Touching infected people does not cause a person to get HIV' etc), and develop critical thought about the social context of the problem ('Women are at risk'; 'Old people and young children will be affected when wage earners die'). Teaching resources included a flip chart and colour photographs showing STIs. Regular, free supplies of condoms were maintained through FHWs and volunteer 'community-based' distributors.

We also aimed to encourage the belief that the sense of vulnerability and helplessness was heightened by low self-efficacy among women. Dialogue and debate was encouraged through discussion and triggers such as picture codes which depicted problems of local relevance. Among men, anecdotes provided the catalyst for discussion around social norms which were known to be prevalent (e.g. 'Is it true that most men expect to have more than one partner these days?'; 'Is it true that men only change their ways when their friends decide to do the same?'etc).

\section{Action Phase}

The dialogue phase gradually progressed in the last months of the intervention to an appraisal of resources available to deal with the problem of HIV / AIDS in a societal context ("What can we do to involve seasonal workers in AIDS prevention?'; 'What can men do?'; 'What can women do?'; 'What can we as a community do?'; 'What can the farm owner do about the problem?'). In this phase we expected a shift in the locus of control from change-agent to the community with empowerment, social responsibility and action (shown by new initiatives, such as AIDS clubs) as important objectives. Drama was used to promote the concept of change and community-focused action. 
Figure 1:

STIS AND CONDOM DISTRIBUTION v SEASON, LABOUR FLUCTUATION AND DISPOSABLE INCOME ON INTERVENTION FARMS

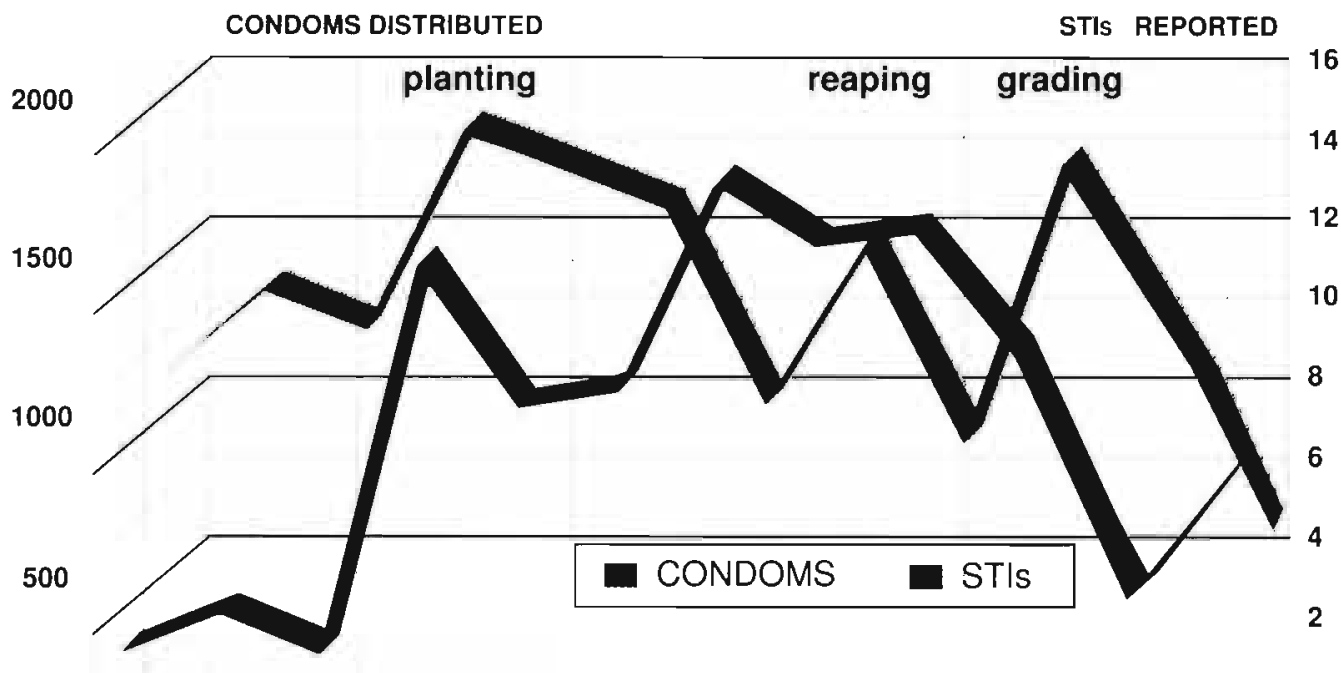

0

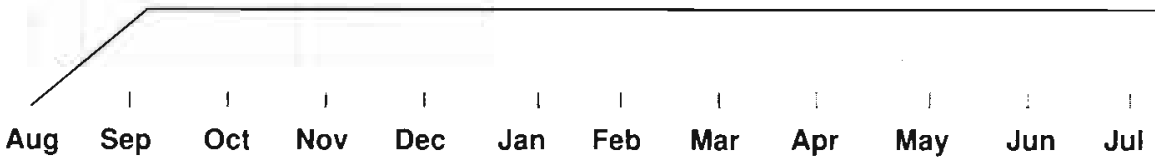


The objective of policy change in this phase concerned the need to remove stigma and increase access by workers to STI treatment, in addition to increasing access to condoms. Critical appraisal of the growing problem of AIDS orphans was also encouraged, ('How do children perceive the problem?'; 'What can the community do?'; 'What should the government do?'; 'What should the land owners do?').

\subsection{Process Evaluation Measures}

We were aware of the fact that post-intervention community-level changes are difficult to detect within a one-year time frame. In addition to a quasiexperimental, post-test study design to measure the effects of the intervention, our process evaluation was designed to answer the question 'What happened over time?'.

Information was collected through:

* Process data forms completed by Farm Health Workers every month (Appendix A). Data pertaining to the following was collected:

* Methods of communication used

* Reach, i.e.

- numbers of groups convened

- enquiries from other farms

- new initiatives within the community

* Condom demand

- STIs reported to FHWs

- Clinic records, i.e. STD cases reported to catchment clinics within the project area. Cases were identified by farm name, disease type, gender and age

* Seasonal activities on farms, i.e. data concerning the influx of seasonal/casual workers at different times in the farming calendar, bonus months, leave periods etc

* Focus Group Discussions, i.e. to collect mid-point data from FHWs

- Follow-up visits to farms, i.e. discussions with farm owners

\subsubsection{Data Analysis}

Qualitative and quantitative data was collected for the process evaluation. The qualitative data was analysed through content analysis; quantitative data was analysed using Lotus 1-2-3.

\subsection{Findings}

Process data were collected over 12 months. Figure 1 provides a graphic representation of epidemiological data and condom demand for intervention farms. It is also annotated with information pertaining to seasonal patterns of farming activity, seasonal fluctuation of labour and disposable income patterns observed during the intervention period. 
None of the FHWs $(n=9)$ from our intervention farms submitted process data forms (Appendix A) every month as planned. Four FHWs cumpleted data forms for 11 months, two FHWs had between four and six months missing. Reasons given for this included illness, leave, forgetfulness and a bereavement. At the outset of the intervention it was noted that FHWs inflated their process data and unrealistic records concerning 'reach' were received. This problem diminished as trust was established within the FHW group. Process data was also collected through monthly group discussions with FHWs and a real picture of intervention activity was revealed in a way that we could not derive from written reports. With respect to condom demand (Figure 1), we could not say with any certainty to whom they were issued, i.e. seasonal/casual workers, workers from neighbouring farms or workers from the intervention community. Re-supplies were calculated on a monthly basis according to stock in hand.

\subsubsection{Factors Affecting the Process of Implementation}

The intervention was set against a background of farming activity which closely influenced the implementation process in terms of reach and participation.

\section{Off-season Farming Activities}

The off-scason on large-scale tobacco farms, which occurs approximately between July and September, coincided with the 'listening phase' of our intervention. Wo learned from process data collected during this period that many farm workers were on leave and seasonal workers had moved away from most farms. In theory, fewer people would participate in intervention activities. In contrast to what we expected, however, process data submitted by FHWs for this period showed inflated levels of activity and reach. FHWs later confirmed that this happened because of an anxiety 'to please and to show that a good start on the project had been made'.

\section{Mid - High Season Farming Activities}

The appraisal-dialogue phase of the intervention coincided with a period of intensive farming activity from October through April. With the advent of the tobacco planting season came also an increase in opportunities for seasonal worker employment (Figure 1) and an influx of male and some female casual workers from surrounding farms and communal areas was noted. Wives of permanent workers were employed; school children engaged in after-school activities such as weeding. It became evident that limited time was available for intervention activities.

On some farms, protected time for the intervention was arranged through the farm owner during working hours. However, this time was limited and FHWs reported that activity was mainly restricted to didactic sessions. As expected, men and women preferred to separate for intervention activities. Sessions with males only were more frequent, and their exposure to intervention activities during this period was reported to be greater than that of women, who tended to be less visible and harder to reach. In addition to working long hours, women were also committed to domestic chores which precluded the possibility of after 
hours sessions. We also learned that men, and more especially seasonal workers, did not participate in AIDS prevention activities voluntarily during their timeoff; this was said to interfere with social drinking and womanising at the local beer-halls. One FHW recorded:

'People want to learn but they do not want to spend time learning'

Abstracts from FHW process data during this period revealed the following:

'This month I have not had any meetings because people are too busy reaping tobacco' (December)

'Due to many hours of working, it is difficult to have meetings. Some do not attend because they are exhausted' (April)

'Women who work do not have equal chance for education activities because they are busy with household duties'

Participation in the intervention by seasonal workers in the high season was described as disruptive. Process data yielded the following comments from FHWs:

'They, [referring to seasonal workers] attend when they have nothing else to do; sometimes they are noisy and mostly drunk'

'The female seasonal workers are prostituting on our farm'

'They care little for the problem of AIDS'

Disposable income on farms increased with the influx of seasonal workers. In the absence of other recreational activities, binge drinking provided a major source of entertainment for men; sex workers were reported to be particularly visible on pay days and interest in AIDS prevention activities was reported to be low.

\section{The Slow Season}

A season of low activity, during which tobacco is graded, characterised the period between May and July (Figure 1). This period was marked by the pay-off and a gradual departure of seasonal workers. During this period two major public holidays occurred and an influx of people from urban areas was noted. Our records also showed that the cold weather had an effect on participation in intervention activities at this time;

'I am unable to meet people after work this month. The sun sits very early...' (June)

'People want to go straight home after work: it is getting very cold now' (June)

' $I$ ' $m$ behind in "lessons". People are still very busy grading tobacco' (May)

'This month I did not teach many people because they are away now' (June)

\subsection{Methods Used}

\section{Listening}

During the first phase of the intervention process data showed that FHWs were anxious to proceed from the listening phase to the dialogue phase of the project. One FHW reported: 
'The workers had high expectations that I would return from my AIDS training to "teach" not to waste time motivating people to "listen" to others talking about their fears and worries about HIV"

FHWs expressed a fear that unless they moved ahead quickly with other activities in which visual aids were used, farm workers would soon become disinterested. Key to this phase was the ability of the facilitator to promote listening skills and discussion; clearly there was a conflict between training needs and community expectations.

In spite of these drawbacks, the listening phase yielded much information about lay beliefs. Among those commonly recorded were:

'People are still saying that AIDS is the same as rukawo'

'It is said that guilty people get AIDS'

'AIDS is thought to be a disease of prostitutes'

'Some men say that they expect to get STDs sometime'

'Women are afraid that they carnot prevent themselves getting HIV'

These statements were collected and used as triggers in the next stage for threat and susceptibility appraisal.

\section{Appraisal-Dialogue}

The agree/ disagree activity in which lay beliefs about HIV / AIDS were debated, proved popular and aroused interest and participation during this phase. Abstracts from records by FHWs during this period included:

'The people like this activity, it makes them think about another point of view'

'My people ask for agree/disagree all the time'

'Men are now attending my sessions - I never saw this before when I talked about health matters'

'People ask for this activity over weekends'

'At times there is much debate about the truth of these beliefs'

'The agree/disagree activity makes people participate very zell'

In the dialogue phase, a flip chart was used to reinforce instrumental knowledge of HIV/AIDS and picture codes were introduced to encourage problem appraisal and problem solving. The latter was reported to be particularly popular among groups of women. Comments received from FHWs included:

'The women especially like the picture codes'

'Picture codes help people to talk about real problems and discuss ways of finding asolution'

'The picture codes show problems which we were quict about before this project'

However, FHWs reported that farm workers quickly tired of the same codes; there was a need to develop new codes rapidly as the problem of AIDS was realised in a much wider social context. We responded, but not quickly enough, as the need for supplementary codes was greater than we expected.

Laminated photographs of STIs were used to convey information in this phase. The pictures aroused much interest, particularly among men. Our records revealed that FHWs and resident traditional healers recorded an increase in requests by farm workers for private consultations about STIs around the time 
that these were first introduced; an increase in condom demand was also recorded. Interestingly, in group discussions with FHWs during this period, we also learned that the pictures also seemed to arouse fear and denial about the problem of STIs.

\section{According to one FHW:}

'These pictures make some people frightened: they do not want to touch them'

Other FHWs recorded:

"Men say that they do not want to think about such things when they see these pictures'

'Men ask me privately for these pictures - they prefer to study them alone'

Requests for videos which showed the 'real problem' of AIDS were frequently received during this phase of the intervention and farm owners were co-operative in helping to organise public viewing sessions. However, the only locally available videos at that time did not apparently satiate the demand for information about the epidemic as it occurs in Zimbabwe. FHWs frequently reported that the people 'wanted to see the real thing'.

\section{The Action Phase}

This phase was mainly characterised by a move to recruit volunteer farm workers to participate in condom distribution and educational activities. This phase took place at the end of the high season and was reported to be extremely difficult. Little progress was achieved and a number of arguments were put forward by farm workers, i.e.:

'We should be paid for our effort'

'Nothing is for free these days'

'What reward can I expect?'

'People in this community have their own ideas about AIDS'

'This problem should be dealt with by the Government'

'Seasonal workers will spoil our effort'

'There is nothing we can do about this problem'

'We have little time for such things'

\subsection{Effects of Labour Fluctuation and Availability of Disposable Income on Condom Demand}

The pattern of condom demand is shown in Figure 1 together with annotations which refer to seasonal fluctuation in labour supply and disposable income.

The peak in condom demand during October 1993 appeared to correspond with an influx of seasonal workers and the return of permanent farm workers from home leave on most farms. A further peak was observed in February 1994 during the high season. However we could not be sure that these results reflect an increase in condom demand by workers from our intervention farms. One FHW reported:

'People from other farms are coming across to take our condoms because they have none of their own' 
Further observations included:

'People should pay for condoms; they are wasted if they are free'

'Free condoms are now being sold in our community'

Bonus pay outs and pay days during the high season (Figure 1), which were reported to be marked by binge drinking and an influx of commercial sex workers on many farms, were also thought to influence condom demand from high access points such as beer-halls. Careless disposal of condoms in these areas was also reported. FHWs noted that condom demand tended to decline significantly with the departure of seasonal workers at the end of the season.

\subsection{Patterns of Sexually Transmitted Infection During the Process Evaluation Period}

STI-incidence data collected from catchment clinics during the intervention period was lower than expected. FHWs reported that people with STIs tended to seek treatment either at centres where they would not be recognised, or they gave false names and addresses at catchment clinics. During the period January to April, i.e. the busiest time on most farms, a decline in STI reports to catchment clinics was noted. Our process data suggested that it was difficult for workers to take time off during working hours to attend clinics and reports confirmed that farm workers either delayed seeking treatment or consulted traditional healers for STI treatment in this period. One FHW recorded,

'Many people are using herbs from the bush for STIs at this time; they only go to the clinic later when the sores erupt'.

Our findings showed that the most significant peak in STI incidence occurred in November, following bonus payouts and an influx of seasonal/ casual workers on our intervention farms (Figure 1). This trend also occurred at district and provincial level.

The rise in the incidence of STIs around May coincided with a decline in seasonal farming activity and the departure of seasonal workers on most farms.

\subsection{Discussion}

A process evaluation was used to describe the events which took place over one year in an intervention where a listening-appraisal-dialogue-action model was used to raise awareness about STI/HIV/AIDS and stimulate action in farm worker communities of rural Zimbabwe.

The extensive nature of the information yielded by the study permitted an insight into the programme which may not have been obtained had we relied on an endpoint evaluation. Firstly, it helped to explain how the intervention was synthesised over time by the farm worker communities. Secondly, and importantly, it assisted us to respond more readily to the need for additional resources and moral support for our change-agents than would have otherwise been impossible.

It also helped us to recognise the limitations imposed by our measurement procedures. We learned, for example, that data related to condom distribution (Table 1) on our intervention farms may not have been representative of actual 
demand in those communities, since our prevention activities also attracted workers from neighbouring farms. Similarly, had we not linked our epidemiological findings to seasonal information we may have erroneously concluded that the decline in STI incidence during the busiest months on our intervention farms was due to the intervention and not - as we learned from the process evaluation - due to a lack of time which limited access to health care during that period (Figure 1). We also learned that while we were cognisant of the need to involve our FHWs in the data collection process, we failed to make the significance of this activity apparent during training, and as a result, records were inflated at the beginning of the study. These findings led us to believe, therefore, that the concept of process evaluation should not merely be regarded as an academic activity, but something that is part of training and implementation in every project.

Our study also led us to question the nature of HIV / AIDS prevention programmes in farm worker communities, where reaching a threshold necessary for change lies clearly beyond the intervention. We found, for example, that in addition to the perspectives held aboutSTI/HIV / AIDS and the ways in which the problem interfaces with culture, fear and stigma among workers, the calibre of the change-agent and the social and environmental milieu in which the people live and work seem to be equally important in influencing participation and action.

At an organisational level, our data showed that worker communities demonstrated difficulty in responding to the challenge of change even in the face of an epidemic which will place further burdens upon them in the future. While it was hoped that our intervention would encourage people to become organised around an issue as important as HIV / AIDS, it is possible that the lack of previous experience in collective action was a disabling factor in achieving this objective. We also concluded from our observations that, in the face of other problems such as poverty and drought, it was not without reason that workers perceived little sense of purpose in dealing with an 'external' threat which will only impact their lives in the future.

We therefore questioned the extent to which participation or otherwise in a community intervention should be used as a valid index of success. In this context we ask whether the desire for participation carries more significance for programme implementors than for the farm workers themselves? For example, did the intervention uphold and synthesise the perspectives articulated by the community about their inability to participate and their lack of capacity to change? What should the intervention look like the second time around?

Although not fully answered by our process evaluation, these questions led us to believe that while HIV / AIDS prevention programmes have a role in generating cognitive and attitude change in farm worker communities, the motivation to confront seriously and re-pattern risk behaviour may best evolve from the people themselves over a much longer period than one year.

We also discovered the issue of timing - the impact of the farming calendar for example - to be an unexpectedly important factor in influencing programme implementation in these communities. In particular, we observed that it was 
difficult to involve farm workers during the off-season and the peak season on farms. When more time was available for intervention activities, fewer people were available because a large number of farm workers took their leave. Conversely, in the high season when more people were available, long working hours precluded intervention activities and fewer farm workers participated. Intervention activities were not ranked as a priority during recreation time. Men preferred binge drinking; women on the other hand were busy with domestic chores after work. In addition to this, we found that seasonal workers were disruptive and non-participative during peak periods.

The evaluation assisted in highlighting difficulties experienced by our change-agents in using a methodology where people are not the objects of an educational project, but participants in a process of change. In particular, we noted that the culture of didactics, which still characterises health education activities in Zimbabwe, prevailed in spite of intensive training which promoted a participatory approach. Nonetheless, we also noted that great difficulty was experienced by our FHWs in creating an environment for dialogue and active participation during sessions which were arranged in protected time offered by the farm owner during working hours in the high season. In spite of our implementation plan, we learned that the cyclical nature of the intervention was disrupted throughout the year, and our FHWs proceeded during difficult periods with those methods which they enjoyed using most. On a related issue we also learned that although FHWs were cognisant of the need to promote the concept of self-efficacy, particularly in women, they also acknowledged the real difficulties of influencing cultural norms known to militate against the attainment of this concept. We therefore question an approach which is dependent on a single change-agent, and suggest that greater support for the intervention may be generated by a peer group, i.e. men and women who are elected by the farm worker communities for training in the listening-appraisaldialogue-action method.

\subsection{Conclusion}

Process evaluation receives little serious attention in community interventions. This study demonstrates, however, that process evaluation is as important in measuring 'what actually happened' as single, end-point measurements which are often used to measure the impact of multi-dimensional interventions. It provided a valuable insight into factors which, when aggregated, gave us an overview of a programme whose success or failure may well have been determined by issues outside the scope of the intervention.

This leads us back to our initial question: 'Was the intervention implemented as planned?' and the answer must be: 'Only partially'. 


\section{References}

Auerbach, E.R. and Wallerstein, N. (1987) ESL for Action Problem Posing at Work, Teachers Guide. Reading, Mass: Addison Wesley.

Bandura, A. (1977) Social Foundations of Thought and Action: A Social Cognitive Theory. Englewood Cliffs: Prentice-Hall.

Becker, M.H. (1974) The Health Belief Model and Sick Role Behaviour. Health Education Monographs, 2, 409-419.

Bracht, N. (1990) Introduction. In Health Promotion at the Community Level, ed. Bracht, N. pp 19-25. Newbury Park, CA: Sage.

Chambers, R. (1983) Putting the Last First. UK: Longman Group Ltd.

Cook, T.D. and Campbell, D.T. (1979) Quasi-experimentation: Design and Analysis Issues in Field Settings. Boston, MA: Houghton Mifflin.

De May, P., Hukuimwe, H.A., Matsitukwa, L., Makasa, B.P. and De Colombani, P. (1992) HIV Sentinel Surveillance in Mashonaland West Province: HIV Seroprevalence Survey in the Commercial Farming Area of Zvimba District, March-July. A Final Report. PMD, Mashonaland West Province, Zimbabwe.

Dijkstra, M., De Vries, H. and Parcel, G.S. (1993) The Linkage Approach Applied to a School-Based Smoking Prevention Program in The Netherlands. Journal of School Health, 63 (8), 339-42.

Fishbein, M. and Ajzen, I. (1975) Beliefs, Attitudes, Intention and Behaviour: An Introduction to Theory and Research. Reading, MA: Addison-Wesley.

Fishbein, M. and Ajzen, I. (1980) Understanding Attitudes and Predicting Social Behaviour. Englewood Cliffs, NJ: Prentice Hall.

Flora, J. R., Lefevre, C., Murray, D., Stone, E. J., Assaf, A., Mittelmark, M. and Finnegan, J. Jr. (1993) A Community Education Monitoring System: Methods from Stanford Five-City Project, the Minnesota Health Heart Programme and the Pawtucket Heart Health Programme. Health Education Research. Theory and Practice, 8 (1), 81-95.

Freire, P. (1972) Pedagogy of the Oppressed. New York: Seabury Press.

Glanz, K., Lewis, F.M. and Rimer, B.K. (1990) In Health Behaviour and Health Education. Theory and Practice. ed. Glanz, K., Lewis, F.M. and Rimer, B.K. San Irancisco: Jossey-Bass.

Gliksman, L., McKenzie, D., Douglas, R., Brunet, S. and Moffatt, K. (1993) The Rule of Alcohol Providers in Prevention: An Evaluation of a Server Intervention Programme. Addiction, 88 (9), 1195-1203.

Green, L.W. and Lewis, M.M. (1986) Measurement and Eraluation in Health Education and Health Promotion. Palo Alto, California: Mayfield Publishing Company . 
Hope, A., Timmel, S. and Hodzi, C. (1984) Training for Transformation: A handbook for Community Workers. Gweru, Zimbabwe: Mambo Press.

Ingersoll, G.L., Bazar, M.T. and Zenter, J.B. (1993) Monitoring Unit-Based Innovations: A Process Evaluation Approach. Nursing Economics, 11 (3), 137-143.

Johnson, C.J., Osganian, V., Elder, J., Luepker, R.V., Johnson, C.J., Parcel, G.S., Perry, C.L. and Webber, L.S. (1994) CATCH: Family Process Evaluation in a Multicenter Trial. Health Education Quarterly, Suppl 2, S91-S106.

Laver, S., Van den Borne, B., Kok, G. and Woelk, G. (In press) A Pre-intervention Survey to Determine Understanding of HIV / AIDS in Farm Worker Communities of Zimbabwe. Awaiting publication by AIDS Education and Precention. (Accepted November, 1995).

Laver, S., Van den Borne, B. and Kok, G. (1994/1995) Using Theory to Design an Intervention for HIV/AIDS Prevention in Farm Workcrs in Rural Zimbabwe. International Quarterly of Community Health Education, 15 (4), 349-362.

Lytle, I..A., Davidann, B.Z., Bachman, K., Johnson, C.C., Reeds, J.N., Wambsgans, K.C. and Budman, S. (1994) CATCH: Challenges of Conducting Process Evaluation in a Multicenter Trial. Heilth Ellucation Quarterly, Suppl 2, S129$\$ 142$.

McCiraw, S.A., Stone, E.J., Osganian, S.K., Elder, J.P., Perry, C.L., Johnson, C.C., Parcel, G.S., Webber, L.S. and Luepker, R.V. (1994) Design of Process Evaluation within the child and Adolescent Trail for Cardiovascular Health (CATCH). Health Eutucution Quartirly, Supplement 2, S5-S26.

McKenzie, T.L., Strikmillar, P.K., Stone, E.J., Woods, S.E., Ehlinger, S.S., Romero, K.A. and Budman, S.T. (1994) CATCH: Physical activity process evaluation in a multicenter trial. Health Education Quarterly, Suppl 2, S73-S89.

McLeroy, K.R., Bibeau, D., Steckler, A. and Glanz, K. (1988) An Ecological Perspective on Health Promotion Programs. Health Education Quarterly, 15 (4), 351-377.

Millar, W.R. and Rollinick, S. (1990) Motivational Interviewing: Preparing People to Change Addictive Behaviour. New York: Guilford Press.

Minkler, M. (1990) Group Intervention Models of Health Behaviour Change. In Health Belhiriur and Hialth Education. Theory and Research, ed. Glanz, K., Lewis, F.M. and Rimer, B.K. pp 253-287. San Francisco: Jossey-Bass.

Nutbeam, D., Smith, C., Murphy, S. and Catford, J. (1993) Maintaining Evaluation Designs in Long Term Community Based Health Promotion Programmes: Heartbeat Wales case study. Journal of Epidemiology \& Community Health, 47 (2), 127-133.

Reichart, C.S. and Cook, T.D. (1979) Beyond Qualitative vs Quantitative methods. In Qualitative and Quantitative Methods in Evaluation Research, ed. Cook, T.D. and Reichart, G.S. Beverley Hills, CA.: Sage. 
Rogers, E. and Shoemaker, F. (1971) Communication of Innovations. 2nd ed. New York: Free Press.

Rogers, E. (1983) Diffusion of Innovations. 3rd ed. New York: Free Press.

Rogers, R.W., Deckner, C.W. and Mewborn, C.R. (1978) An expectancy -value theory approach to the long term modification of smoking behaviour. Journal of Clinical Psychology, 34, 562-566.

Rogers, R.W. (1984) Changing Health-Related Attitudes and Behaviour: The Role of Preventive Health Psychology. In Interfaces in Psychology, ed. McGlyn, R., Maddox, J., Stoltenbury, C. and Harvey, R.J. Lubbock, TX: Texas Tech University Press.

Van Assema, P. (1993) The Process Evaluation of a Dutch Community Health Project. In The development, implementation and evaluation of a community' health project. Proefschrift: Universitaire Pers Maastricht.

Wallerstein, N. and Bernstein, E. (1988) Empowerment Education: Freire's Ideas Adapted to Health Education. Health Education Quarterly, 15, 379-394.

Wallerstein, N. and Sanchez-Merki, V. (1994) Freirian Praxis in Health Education: Research Results from an Adolescent Prevention Programme. Health Education Research. Theory and Practice, 9 (1), 105-118.

Werner, D. and Bower, B. (1982) Helping Health Workers Learn. Palo Alto, CA: The Hesperian Foundation. 
PROCESS DATA COLLECTION FORM FOR FARM HEALTH WORKERS

NAME: FARM:

DATE:

NUMBER OF CONDOMS DISTRIBUTED BY YOU THIS MONTH

\begin{tabular}{l}
\hline AIDS ACTIVITIES THIS MONTH \\
LARGE GROUPS \\
men only ..................................... TOTAL \\
mixed - men \& women ................
\end{tabular}

SMALL GROUPS

men only.

women only

mixed - men \& women

\section{PRIVATE - FACE-TO-FACE}

men only

women only

\section{METHODS USED}

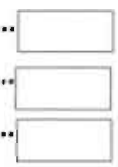

listening survey

board

picture code

story

drama

talking only

films/video

agree/disagree

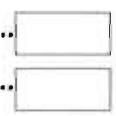

NUMBER OF STIS REPORTED TO

YOU THIS MONTH

COUNT MEN
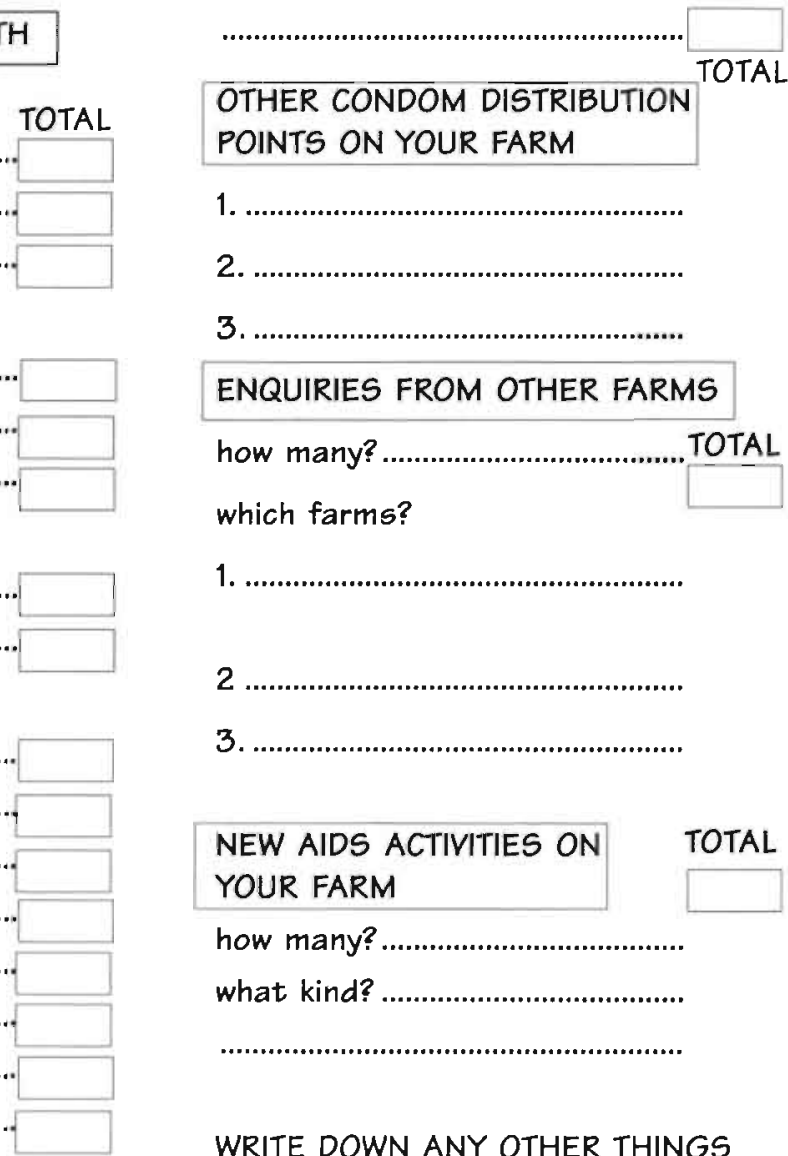

1.

2.

3.

\section{ENQUIRIES FROM OTHER FARMS}

how many? TOTAL

which farms?

1.

2

3.

NEW AIDS ACTIVITIES ON TOTAL YOUR FARM

how many?

what kind?

WRITE DOWN ANY OTHER THINGS YOU WISH TO MENTION.

COUNT WOMEN 


\title{
Chapter 6
}

\section{Was the Intervention Effective? \\ The Results of a Post-intervention Study on HIV Prevention in Rural Zimbabwe}

\author{
Laver, S.M.L. ${ }^{1}$, Van den Borne, B. ${ }^{2}$, Kok, G ${ }^{3}$. and Suleman, G. ${ }^{4}$ \\ Submitted for publication 1996
}

\begin{abstract}
This paper describes an end-point evaluation which was conducted one year after an HIV/AIDS prevention intervention was implemented in nine farm worker communities in one district of Zimbabwe. The results were compared with a control group where no intervention had taken place. The intervention, which was carried out between 1993 and 1994, was designed using a combination of Freire's Social Change Theory and the Ecological Model for Health Promotion (Laver et al., 1994/1995). A participatory methodology was developed to provoke critical thought about the problem of HIVIAIDS, to encourage self-protective behaviour especially among women, and to create a climate for preventive action within farm worker communities. During the intervention, a process evaluation (Laver et al., 1996/1997) was carried out.

At an intra-personal level, knowledge in educationally disadvantaged women was significantly increased in the intervention group. However, we noted a striking differince in self-efficacy between men and women, with females articulating concern about their risk of HIV infection, helplessness and an inability to protect themselves. At an organisational level, women also expressed an inability to change the situation. Condom use was found to be low, although demand for condoms in the interoention farms was high.

We concluded that there is an urgent need to recognise the gender power differences which exist in farm worker communitios and that interoention strategies must: (a) address the gender imbalances by reinforcing, from an early age, the need for males to take responsibility for their health and for the health of their female partners, as well as the need to practise safe sex; (b) create a climate which de-emphasises the need for females to take primary responsibility for safer sex practices and vigorously explores every possibility to strengthen women's ability for self-protection; (c) increase the range of technical options for self-protective behaviour among women; (d) acknowledge that interventions which control the information flow through didactics lack empirical support in terms of creating effective HIV/AIDS prevention behaviour. Finally we draw attention to the impact of economic reform programmes which exacerbate the effect of HIVIAIDS in vulnerable communities and we call for policies to decentralise STI programmes.
\end{abstract}

1. Senior Lecturer, Department of Community Medicine, University of Zimbabwe Medical School, Harare, Zimbabwe.

2. Professor of Patient Education, Department of Health Education, University of Maastricht, Netherlands.

3. Professor and Scientific Director of Maastricht Health Research Institute for Prevention and Care, University of Maastricht, Netherlands.

4. Project Rescarch Assistant 


\subsection{Introduction}

"Policy analysis, educational diagnosis and evaluation breed institutional anxiety ... and institutional anxiety ...stems from program visibility and exposure, nonparticipation by key personnel and groups, the political climate underlying the measurement efforts, and the stakes various parties may have in the program's success or failure or in the study's implications for policy" (Green and Lewis, 1986).

It is not uncommon for AIDS prevention programmes to begin and end with efforts to persuade people to understand or do something through a method with which the educator is comfortable. There is also evidence of 'tidy assessments' which expose the positive qualities of programmes (Green and Lewis, 1986) while programme visibility, which exposes weaknesses or negative qualities of the process of an intervention and even unquestionable failure in the outcome, is not so common. Added to which is the problem that the practice of monitoring the effects of community interventions is perceived to be methodologically difficult (Renton and Whitikar, 1994). It is evident that questions used to measure outcome are often limited to knowledge gain (Bijlmakers, 1993) and short-term changes in behaviour (Knepp et al., 1994; Govender et al., 1992).

Although much has been learned about the efficacy of AIDS prevention strategies which use programmes to focus on a single risk population, Janz and colleagues point out that few researchers have assessed multiple interventions which use a variety of health education strategies and target diverse populations. The authors go further to say that 'few researchers have focused attention on the problems and barriers that arise in conducting community-based AIDS prevention' (Janz et al., 1996).

In this paper, we answer the question 'Was the intervention effective in promoting interest in HIV prevention and intent to change behaviour among farm workers on selected farms?' after a planned intervention (Laver, in press) was carried out in Zvimba District of Mashonaland West Province, Zimbabwe.

We describe an end-point evaluation which was conducted one year after an HIV/AIDS prevention intervention was implemented between 1993 and 1994 in nine farm worker communities. Our intervention combined Freire's Social Change Theory and the Ecological Model for Health Promotion (Laver et al., 1994/ 1995). A participatory methodology was developed to provoke critical thought about the problem of HIV/AIDS, to encourage self-protective behaviour, especially among women, and to create a climate for preventive action within farm worker communities. During the intervention, a process evaluation was carried out (Laver, 1996/1997). This showed 'what happened' and in particular demonstrated how factors outside the intervention design can affect the process of programme implementation. 


\subsection{Background to the Study}

The true extent of the HIV / AIDS epidemic in Zimbabwe is unknown but it is estimated that upwards of one million people are now infected with the virus $(\mathrm{MoH}, 1995)$. A cumulative figure of 48882 AIDS cases was reported by the end of September, $1995(\mathrm{MoH}, 1995)$. The distribution of cases is bimodal (Munodawafa and Gwede, 1996) with 14.8 per cent (6885) cases reported to be in children under five years and 71 per cent (34 797) cases reported in the economically productive group, i.e. from 20 to 49 years. Farm workers constitute between 17 to 20 per cent of the total population of Zimbabwe (Frazer-Mackenzie, 1992; Amanor-Wilks, 1995). Although there are no data which specifically indicate sero-prevalence in this population there are indications that the trend of infection is probably similar to other rural communities. For example, the risk of infection is known to be higher in unskilled labour, low-income women and women under the age of 30 years who are single, divorced or co-habiting (Loewenson and Chisvo, 1994 quoting Mohamed et al., 1991).

According to Gregson et al. (1993) and Gregson and Foster (1994), 'the AIDS epidemic has already caused a dramatic increase in deaths among adults and children and it is known that, irrespective of any successes which night now be achieved in checking its spread, the death rate will steadily climb until well into first decade of the next century'.

Rural communities, hitherto neglected in AIDS prevention initiatives, are increasingly being called upon to care for the terminally ill. Another tragedy is also unfolding as the survivors, i.e. the elderly and orphans, previously not perceived as a problem in traditional African society (SAFAIIDS and ('FU, 1996), turn to the community for assistance. This is occurring at a time when government has failed to protect the health sector from budgetary cut-backs and when the maintenance of primary health care (PHC) is becoming more difficult within the context of the economic structural adjustment program (ESAP). The epidemic is therefore imposing a 'disproportionate burden of care on rural communities' (Anderson, 1994) and, in particular, on women who lack the resources to cope. While decentralised approaches in AIDS prevention may be reasoned to be most efficacious (Livingstone, 1992), community interventions pose a special challenge to the programme implementor.

\subsubsection{The Farm Worker Environment and Social Networks Operating Within the Community}

The environment in which farm worker communities live and work on largescale commercial farms in Zimbabwe was outlined in an earlier paper (Lavere et. al., in press). Isolated from large towns and often situated some distance from rural grow th points and health facilities, farm communities are characterised by extended family units who do not own the land on which they live and work. Tenure is often uncertain and the majority of farm workers and their dependents exist on an income which falls below the average real earnings in the formal sector. 
In the commercial farming sector, the welfare of the farm worker is traditionally the concern of the farm owner. A paternalistic approach has been historically adopted in dealing with labour. Decision-making in the community is therefore diffuse, and a collective approach to problem-solving is not widely practised (Laver et al.,in press). Women, and more especially older women, tend to be educationally and socially disadvantaged with little opportunity for selfactualisation, and apart from seasonal work, opportunities for income-generation are limited to informal activities such as gardening. On some farms public television is available but our study showed that recreation facilities in the community are largely confined to farm beer-halls. Drinking is the most common pastime and alcohol abuse is widespread. With the influx of seasonal workers during peak periods of farming activity, come the attendant problems of prostitution and STIs (Laver et al., 1996/1997).

\subsubsection{Description of the Intervention}

The intervention, which is described in an earlier paper (Laver et al., 1994/1995), was targeted at three levels, viz the intra-personal, socio-organizational and policy levels (after McLeroy et al., 1988). The methodology embraced the Freirian Structured Dialogue Model described by Wallerstein and Sanchez-Merki (1994) in which a cyclical listening-appraisal-dialogue-action approach is proposed.

Didactic methods of health education are traditionally used more extensively than participatory methods to educate people about AIDS in Zimbabwe (Laver, 1993). For the purposes of this intervention we trained Farm Health Workers (FHWs), who are front-line PHC workers living and working in farm communities, to use methods which were lesis teacher dependent. A manual for trainers of FHWs was developed a long with materials such as picture codes which formed part of the resource package given to FHWs after their training. In summary, we aimed to decrease the role of the change-agent over time and increase community involvement in AIDS prevention activities on our randomlyselected intervention farms.

At the intra personal level of the intervention, we aimed to activate recognition of, and personal identification with, HIV/AIDS, asking, for example: 'What is AIDS?'; 'How did it get to Zimbabwe?'; 'Has it reached the rural areas?'; 'Do STIs lead to the problem?' etc. Strategies such as group discussions, which promote active listening and appraisal within the safety of small numbers, were used. This stage was followed by an appraisal of lay beliefs, examining statements such as: 'AIDS is a very old disease'; 'Getting AIDS is just a matter of luck'. These were done using a participatory 'agree/disagree' activity. A period of threat and susceptibility appraisal followed, asking: 'Is AIDS really a problem?'; 'Am I at risk?'; 'Is my family at risk?' etc. Cognitive changes (with respect to instrumental knowledge about STI/HIV / AIDS) were assessed using statements such as: 'Mosquitoes do not spread AIDS'; 'A person with STI is at risk of becoming infected with HIV'; 'Touching infected people does not cause a person to get HIV' etc. This would be achieved through didactic sessions reinforced by visual aids. 
The intervention then targeted the appraisal of constructs such as self-efficacy ('Is it possible for women to deny sex to their husbands?') and response efficacy ('What can we do to protect ourselves?'). Dialogue and triggers such as picture codes (socially charged pictures that illustrate problems) were used. Personal experience and cultural issues were also used as the basis for the appraisal of social norms ("Do men expect to have more than one partner these days?; 'Is it true that men will only change when their friends decide to do the same?' etc). Condom use was promoted for sex with girlfriends and wives.

At a socio-organisational level, the intervention progressed to an appraisal of issues within a broader societal context ('What can we do to involve seasonal workers in AIDS prevention?'; 'What can men do?'; 'What can women do?'; 'What can we as a community do?'; 'What can the farm owner do?'). This phase was accompanied by a shift in the locus of control from change-agent to the community, with empowerment, social responsibility and action (e.g. new initiatives such as AIDS clubs) as important objectives.

At a policy level we set up a system where free condoms were supplied monthly to intervention farms, and we encouraged FHWs to set up new points for condom distribution within the community. The intervention encouraged critical thought around the problem of AIDS orphans and dependents of sufferers, asking: 'What can the community do'; 'What should the government do?'; 'What should the land owners do?'.

The locus of control for the intervention therefore shifted from the researcher at the problem definition, materials development and training stage, to a point at which the project was institutionalised within the community through the changeagents. The process of the intervention was measured (Laver et al., 1996/1997) and the effect evaluation took place exactly 12 months after the intervention began.

Figure 3 in Chapter 1 provides a summary of the intervention. It shows the principal theories/models which are proposed for each level of intervention, the targets of change and the strategies employed (after Freire, 1983; McLeroy et al., 1988; Wallerstein and Sanchez-Merki, 1994).

\subsection{Aim of the Study}

The aim of the study was to measure the effects of an HIV/AIDS prevention intervention in a randomly-assigned study population of farm workers permanently living and working on commercial farms in one district of Zimbabwe.

\subsubsection{Study Objectives}

At an intra-personal level, we hypothesised that our intervention would have a significant effect in raising cognitive understanding of HIV / AIDS, increasing condom use and increasing self-efficacy in women with respect to self-protective behaviour.

At a socio-organisational level, we hypothesised that the intervention would improve support by authority (farm owners and farmers' organisations) for AIDS prevention activities, and lead to a change in policy for condom distribution and improve access of farm workers to STI treatment. 


\subsection{Method}

\subsubsection{The Study Site}

The study took place in the Zvimba district of a large commercial farming area in the north west of Zimbabwe. The district, which has a population of 1116928 people or approximately 10 per cent of the total population of Zimbabwe (CSO, 1992), is situated some $100 \mathrm{~km}$ north of the capital city, Harare.

\subsubsection{Study Design}

A quasi-experimental, post-test-only design with non-equivalent groups was used to measure the effect of the intervention after 12 months (Cook and Campbell, 1979).

\subsubsection{Participants}

The study participants were full-time, adult, male and female farm workers who permanently resided and worked on commercial farms in the Zvimba District of Mashonaland West Province in Zimbabwe. Seasonal workers were excluded because they did not meet the criteria for residency or permanency.

\subsubsection{Sampling}

Participants were selected from 17 farms randomly assigned in the preintervention phase of the project, i.e. nine farms to an 'intervention' group and a further eight farms to a control group. For the purposes of our analysis, however, four farms from the control group were re-assigned to an 'unplanned intervention' group. This change was made because, during the process evaluation (Laver et al., 1996/1997), it became evident that when (a) workers from a farm adjacently situated to one intervention farm had been attending intervention activities and (b) on the other three control farms, HIV / AIDS projects had been implemented by a non-governmental organisation. In their intervention we found the change-agents were men, with peer education and condom distribution as the main focus in those farm worker communities.

The criteria for including farms in the study were a willingness of the owner and the community to participate. Not surprisingly, in an environment where workers have historically lacked the opportunity to make choices, the participation rate in the data collection was 100 percent, although some respondents did not answer all the questions. A further requirement was that each farm should have in residence a trained FHW who was functionally literate and actively engaged in PHC activities within the farm worker community but who had not received training in AIDS prevention (l aver et al., in press).

( ) each of the $17 \mathrm{farms}$, a random number table and a numbered employment register were used to select $50 \mathrm{farm}$ workers for interview. In order to ensure equal representation of men and women in the sample, where possible we also interviewed the wives of men randomly selected from the employment register. 
The total sample size was 853 farm workers, of whom 452 ( 229 male, 223 female) were drawn from the 'intervention' group. In the control group our sample size was 199 (101 male and 98 female). In the 'unplanned intervention' group the total sample was 202 workers ( 100 male and 102 female).

The intervention groups and the control groups of farm workers were similar in respect of gender, marital status, nationality and wage (see Table 1). However, significant differences were found between groups in respect of education $(p=<.01)$, age $(\mathrm{p}<.05)$ and religion $(\mathrm{p}=<0.01)$

\subsubsection{Procedures}

Data were collected over a period of six weeks and exactly 12 months after the intervention was implemented. The interview method was used to administer a pre-tested questionnaire. Three male and three female research assistants with previous research experience in farm worker communities conducted the interviews in Shona (the vernacular language) which took no longer than 20 minutes per respondent. In order to obviate bias which may have resulted through shyness, female researchers interviewed female workers and male research assistants interviewed male farm workers. The experimental status of the farms surveyed in the study was unknown to the interviewing team. Interviews were conducted in a comfortable, secluded place. To ensure further privacy, respondents were invited to indicate their responses to sensitive statements or questions by pointing to a coloured board where the colour green denoted a positive response, orange denoted 'unsure' and red denoted a negative response.

\subsection{Measures}

\subsubsection{Checklist}

A checklist was used to make background observations about the social and environmental context in which farm workers live and work. For example, we were interested in collecting information about recreational facilities, housing conditions, ownership of radios, etc.

\subsubsection{Demographic Differences Between Farm Groups}

Demographic differences between farm groups were measured by seven questions concerning gender, age, education, religion, wage, nationality and marital status (Table 2).

\subsubsection{Scales to Measure Intervention Effects}

There being no validated instruments to measure reliably and validly the intervention effects in farm worker communities where literacy and education is known to be low, we formed a data set from a pool of statements and short questions collected from the farm worker community during the pre-intervention phase of the study. 
Test items were drawn from the data set and converted into scales to test different constructs of knowledge, such as condom use, self-efficacy and perceived support by authority for HIV prevention. Scale construction was performed by selecting groups of variables, determining the number of items to be considered, extracting a set of factors from the correlation matrix and rotating the factors to increase interpretation. In this way items were factor analysed and refined until a reliable and sensitive research instrument with an internal consistency (Cronbach's alpha) $a ́$ >.50) was reached (Tabachnick and Fidell, 1983). Table 1 provides a summary of information relating to the scale analysis.

Table 1: Overview of Scales

\begin{tabular}{|c|c|c|c|c|c|c|c|c|}
\hline \multirow{2}{*}{ Scale } & \multirow{2}{*}{$\begin{array}{l}\begin{array}{l}\text { Number } \\
\text { of items }\end{array} \\
7\end{array}$} & \multirow{2}{*}{$\begin{array}{l}\text { Range } \\
0-6\end{array}$} & \multicolumn{2}{|c|}{$\begin{array}{l}\text { Mean score } \\
\text { and (SD) }\end{array}$} & \multirow{2}{*}{$\begin{array}{l}\text { Alpha } \\
0.59\end{array}$} & \multirow{2}{*}{$\begin{array}{c}\begin{array}{c}U \\
N=202 \\
(S D)\end{array} \\
\\
4.95 \\
(1.21)\end{array}$} & \multirow{2}{*}{$\begin{array}{c}\begin{array}{c}\mathrm{I} \\
\mathrm{N}=\mathbf{4 5 2} \\
(\mathrm{SD})\end{array} \\
\\
4.74 \\
(1.34)\end{array}$} & \multirow{2}{*}{$\begin{array}{c}C \\
N=199 \\
(S D)\end{array}$} \\
\hline & & & 4.69 & $(1.35)$ & & & & \\
\hline \multicolumn{9}{|l|}{ Condoms } \\
\hline $\begin{array}{l}\text { - Stages of behaviour } \\
\text { change }\end{array}$ & 4 & $0-4$ & 2.08 & $(1.03)$ & - & $\begin{array}{c}2.23 \\
(1.01)\end{array}$ & $\begin{array}{c}2.02 \\
(1.02)\end{array}$ & $\begin{array}{c}2.05 \\
(1.04)\end{array}$ \\
\hline $\begin{array}{l}\text { - Men's attitudes to condom } \\
\text { use by women for } \\
\text { contraception and self- } \\
\text { protection }\end{array}$ & 5 & $5-15$ & 12.45 & $(1.08)$ & 0.80 & $\begin{array}{l}12.63 \\
(2.71)\end{array}$ & $\begin{array}{l}12.48 \\
(2.79)\end{array}$ & $\begin{array}{l}12.20 \\
(2.93)\end{array}$ \\
\hline $\begin{array}{l}\text { - Advantages and } \\
\text { disadvantages of condom use }\end{array}$ & 7 & $7-14$ & 12.05 & $(2.07)$ & 0.79 & $\begin{array}{l}12.24 \\
(1.96)\end{array}$ & $\begin{array}{l}12.09 \\
(2.04)\end{array}$ & $\begin{array}{l}11.77 \\
(2.32)\end{array}$ \\
\hline Perceived efficacy & 4 & $0-4$ & 2.00 & $(1.43)$ & 0.73 & $\begin{array}{c}1.95 \\
(1.43)\end{array}$ & $\begin{array}{c}2.06 \\
(1.45)\end{array}$ & $\begin{array}{c}1.91 \\
(1.39)\end{array}$ \\
\hline $\begin{array}{l}\text { Perceived support by } \\
\text { authority for AIDS } \\
\text { preventlon activities }\end{array}$ & 2 & 0.2 & 1.56 & $(0.6)$ & 0.56 & $\begin{array}{c}1.54 \\
(0.73)\end{array}$ & $\begin{array}{c}1.63 \\
(0.66)\end{array}$ & $\begin{array}{c}1.50 \\
(0.78)\end{array}$ \\
\hline
\end{tabular}

$\mathrm{U}=$ Unplanned intervention group

$\mathrm{I}=$ Intervention group

$\mathrm{C}=$ Control group

* The higher the score, the more positive the result. 


\section{Instrumental Knowledge Scale}

A scale $(\alpha=.59)$ of 7 items was constructed to measure instrumental knowledge about HIV/AIDS, such as: 'Do you think that: ...mosquitoes spread AIDS?; ... that AIDS can be cured if treated early?; ...that you can get AIDS by shaking hands with an infected partner?; ... that AIDS is the same as Rukawo?'.

Item values were coded as follows: $0=$ Yes, $1=$ No.

Also included on this scale were the statements: 'In your opinion do you think that: ...the chances of getting AIDS are greater if one already has STI (Sexually Transmitted Infection)?; ..... pregnant woman can pass AIDS on to the unborn child?; ... a person who takes many different partners is more likely to get AIDS?'.

Item values were coded: $0=$ No, $1=$ Yes.

A higher score on the scale represented more knowledge with fewer incorrect beliefs (Table 2).

An additional item (not on the scale) was used to measured whether respondents had questions about AIDS, where None $=1$, Some $=2$ and Many $=$ 3.

\section{Condom Scale}

Three scales were developed: (a) to measure stages of change with respect to condom use; (b) to measure attitudes to condom use by women for contraception and self-protection; and (c) to measure perceived advantages and disadvantages of condom use as shown below.

\section{Stages of Behaviour Change With Respect To Condom Use}

The Stages of Change Model (Prochaska and DiClemente, 1984) which operates on the assumption that behaviour change occurs within four stages, namely precontemplation, contemplation, action and maintenance, was used as the framework for analysing questions regarding condom use. A scale (á not calculated) of four items, scored 1-4 with 4 as the highest score, was used as follows:

Pre-contemplation

If, 'I have not tried to use a condom and I do not think about using condoms', then score $=1$.

Contemplation

If, 'I have not tried using condoms but I think about using them', then score $=2$. Use

If, 'I only use condoms from time to time', then score $=3$.

Maintenance

If, 'I use condoms for sex every time', then score $=4$

\section{Attitudes Towards Condom Use for Contraception and Self-protection}

A scale $(a=.80)$ with five items was constructed to measure perceived attitudes to condom use by women for contraception and self-protection as follows: 
'Men have the right to be angry if their wives ask them to use a condom; ... for family planning; ...for STI; ...for menstruation; .....all the time'.

Items in the scale were coded: $1=$ Yes; 2 = Not Sure and $3=$ No. A higher score represented a more positive attitude towards women using condoms for contraception and self-protection.

\section{Perceived Advantages and Disadvantages of Condom Use}

A scale $(\hat{a}=.79)$ with seven items measured, perceived advantages and disadvantages of condom use by farm workers as follows:

'Do you think that condoms are: ... affordable?; ... easy to use?; ... protect against STI?' Item value $1=\mathrm{No} ; 2=$ Yes.

On the items 'Do you think condoms spoil your sexual pleasure?'; 'Do you believe your partner will be angered if you suggested using condoms?'; 'Do you think condoms are inconvenient to use?'; 'Is it a problem to discuss using condoms with your partner?'. Item values: $1=$ Yes; $2=$ No. A higher score indicated more perceived advantages to condom use.

\section{Efficacy Scale with Respect to Self-protection Against HIV}

A scale $(\hat{a}=.73)$ with four items was used to measure perceived efficacy with respect to self-protection against HIV (where self-efficacy is defined as 'the conviction that one can successfully execute the behaviour to produce the outcomes' [Bandura, 1986]) as follows: 'Do you feel you have the right to choose about your sex life?"; 'Would you be afraid to deny sex to your partner?'; 'Do you think there is something that the people on this farm can do to prevent AIDS?' and 'Do you think that there is something the farm community can do to prevent AIDS?'.

The scoring was: $0=$ no; $1=$ Yes. A higher score represented higher perceived efficacy.

\section{Perceived Susceptibility to HIV/AIDS}

Two items measured perceived susceptibility to HIV/AIDS:

'Do you worry about getting AIDS yourself?'; 'Do you do anything to put yourself at risk of infection?' Yes; Not sure; No).

At the socio-organizational level: perceived support by authority for AIDS prevention activities was measured by a scale (á.56) with two items:

'Do you think that the farm owner shows support for AIDS prevention on this farm?' and 'Do you think that the farm owner assists people to get condoms?'.

Item value: $0=\mathrm{No} ; 1=$ Yes. A higher score represented better perceived support by authorities.

One item measured attendance at AIDS prevention activities organised by the FHW. Item values: 1 = Yes; $2=$ Not sure; $3=$ No. A further item measured condom availability. 
Table 2: Demographic Differences Between Farm Groups

\begin{tabular}{|c|c|c|c|c|c|c|c|c|}
\hline \multirow{2}{*}{$\begin{array}{l}\text { Demographic } \\
\text { Profile }\end{array}$} & \multirow[b]{2}{*}{$\mathbf{N}$} & \multicolumn{2}{|c|}{ Intervention } & \multicolumn{2}{|c|}{ Control } & \multicolumn{2}{|c|}{$\begin{array}{l}\text { Unplanned } \\
\text { Intervention }\end{array}$} & \multirow{2}{*}{$\begin{array}{l}P \\
\text { Value }\end{array}$} \\
\hline & & $\mathbf{N}$ & $\%$ & $\mathbf{N}$ & $\%$ & $\mathbf{N}$ & $\%$ & \\
\hline & 853 & 452 & $(53.0)$ & 199 & $(23.3)$ & 202 & (23.7) & \\
\hline
\end{tabular}

Gender

- Male

- Female

$\begin{array}{rrrrrrrr}430 & 229 & (50.7) & 101 & (50.8) & 100 & (49.5) & \text { NS } \\ 423 & 223 & (49.3) & 98 & (49.2) & 102 & 50.5) & \end{array}$

\section{Marital Status}

- Married

- Single

- Divorced

- Widowed

$\begin{array}{rrrrrrrr}815 & 430 & (95.1) & 195 & (98.0) & 190 & (94.1) & \\ 26 & 14 & (3.1) & 1 & (0.5) & 11 & (5.4) & \text { NS } \\ 8 & 5 & (1.1) & 2 & 1.0) & 1 & (0.5) & \\ 4 & 3 & (0.7) & 1 & (0.5) & 0 & & \end{array}$

\section{Nationality}

- Zimbabwean

$\begin{array}{rr}703 & 377 \\ 81 & 50 \\ 47 & 13 \\ 20 & 11 \\ 2 & 1\end{array}$

$(83.4)$
$(11.1)$
$(2.9)$
$(2.4)$
$(0.2)$

143

(71.9)

$183 \quad(90.6)$

- Mozambique

- Malawi

- Zambia

- Tanzania

\section{Formal}

Education

- None

-Some

$\begin{array}{lll}399 & 225 & (49 \\ 454 & 227 & (50\end{array}$

$\begin{array}{lrr}(49.8) & 99 & (49.7) \\ (50.2) & 100 & (50.3)\end{array}$

(13.6)

(2.0)

\section{Age}

Mean (years)

35.6

37.31

33.1

Range (years)

$16-79$

$17-77$

$15-76$

$<35$ years

464

246

(54.4)

95

(45.6)

104

(47.7)

(52.3)

123
79

(60.9)

(39.1)

\subsubsection{Data Analysis}

The data were analysed using Epi-Info Version 5 and SPSS.PC+ (SPSS Inc, 1988) Reliability of data coding was estimated by independently re-entering data from $85(10 \%)$ randomly-selected questionnaires. A 95\% agreement level was reached. Analysis of Variance was applied to test differences in means of variables between 
the intervention, unplanned intervention and the control group as well as differences in effects for both sexes. The students' $t$-test was used for comparing two means where appropriate.

In order to minimise the confounding effect of age, education, religion and gender in the study, these variables were used as co-variates throughout the analysis. Significance was examined through the p-values at the $99.9^{1 \%}(\mathrm{p}<.001)$, $99 \%(\mathrm{p}<.01)$ and $95 \%(\mathrm{p}<.05)$ levels of confidence.

\subsection{Findings}

\subsubsection{Demographic Differences Between Farm Groups}

The demographic characteristics of the farm workers are presented in Table 2.

Significant differences were noted in education, age and religion between farm groups in the study population. With respect to education, the 'intervention' and control groups were similar, but in the 'unplanned intervention' group, farm workers had significantly more education. No differences between the 'intervention' and the control group were found in age. However, we found that there was a significantly younger female population in the unplanned intervention' group and an older male population in the control group.

With respect to religion we noted that significantly more farm workers in the intervention group reported no religious affiliation when compared with the control and the unplanned intervention group. Significantly $(\mathrm{p}<.01)$ more females $(66 \%)$ reported a religious affiliation when compared with males $(33 \%)$.

Our analysis showed further that there was a significant $(\mathrm{p}<.001)$ difference between males and females in respect of education with 62.2 per cent of the females having not attended school compared to 32 per cent of males.

Of further interest was that older workers, ( 35 years and over), who comprised 45.6 per cent of our population, were found to be significantly $(p<.001)$ less educated when compared with younger workers ( $<35$ years). Females were found to be significantly younger than males across the sample $(p<.001)$.

The differences which were found to exist between gender, age, education and religion in our study sample were therefore used as co-variates in further analysis.

\subsubsection{Comparison of Farm Groups}

Table 3 provides a summary of post-test differences by farm group and gender.

\section{Intra-personal Level Changes}

\section{* Instrumental Knowledge about AIDS}

Table 3 presents the mean scores for each group of farms in respect of the scale which measured instrumental knowledge about HIV/AIDS. The 'intervention" group showed a significantly higher mean score on knowledge when compared with the control group. No significant differences were found when the 
'intervention' group and the 'unplanned intervention' group were compared. The 'unplanned intervention' group also scored significantly higher than the control group on the knowledge scale.

In the overall sample of farm workers, it was noted that there was an interaction between gender and farm, with females scoring significantly better on the knowledge scale than males.

When items on the knowledge scale were examined separately, we found, for example, that although there were no differences between farm groups on the item 'Do you think mosquitoes spread AIDS?', females across the sample scored significantly ( $\mathrm{p} .<001)$ fewer incorrect responses $(7.8 \%)$ when compared with males $(20 \%)$. Similarly, although there were no significant differences between farm groups on the item 'Do you think that the chances of getting AIDS are greater if one has an STI?' significantly $(\mathrm{p}<.001)$ more females $(86.8 \%)$ correctly agreed when compared with males $(68.1 \%)$. Farm workers in the 'intervention' group had significantly fewer questions $(p<.05)$ about AIDS when compared with the other groups.

\section{* Condoms}

\section{Stages of Behaviour Change}

No significant differences were found between the three farm groups with respect to condom use. A closer examination of the results showed that 43.5 per cent (where $\mathbf{n}=371$ ) of the sample were in the pre-contemplation phase, i.e. they had not tried to use a condom and did not think about using condoms. The findings showed that 10.7 per cent $(n=91)$ of the sample were in the contemplation phase, i.e. they said that they had not tried to use condoms but sometimes think ahout using condoms' and 40.4 per cent $(n=345)$ of the sample said they were 'in use' but only from 'time to time'. Only 5.4 per cent $(n=46)$ of farm workers werc in a maintenance phase, i.e. they said they 'always used condoms'. "This finding is similar to the findings of a study carried out by Moyo et al. (1993) in an urban setting in Zimbabwe where condom use was also reported to be low with only 9.2 per cent 'always using a condom' for sex.

We observed that females scored significantly lower $(p<.001)$ than males on the scale which measured condom use.

Perceived Attitudes to Condom Use for Contraception and Self-Protection against HIV No significant differences were found between farm group means on the scale which measured perceived attitudes to condom use by women for contraception and self-protection. When we examined scale items separately, we found no significant differences between males and females on the question 'In your opinion, do you believe that men have the right to be angry if their wives ask them to use a condom?', and that the majority $(70 \%)$ of respondents said 'no'. On the item 'In your opinion, do you believe men have a right to be angry if asked to use a condom all the time for sex?', we found that significantly $(p<.001)$ more females $(60.8 \%)$ said yes when compared with males $(38 \%)$.

On one further statement which was not on the scale, 'Condoms should be used by married couples', we found significantly $(p<.001)$ more women $(70.7 \%)$ agreed when compared with men (20.5\%). 
Table 3: Post-test Differences on Scales by Gender and Farm Group

\begin{tabular}{|c|c|c|c|c|c|c|c|c|c|c|c|c|c|}
\hline \multirow[b]{3}{*}{ Scale } & \multicolumn{2}{|c|}{$\begin{array}{c}\text { Overall Gender } \\
\text { Means }\end{array}$} & \multirow{3}{*}{$\begin{array}{l}\text { p values } \\
\text { for } \\
\text { gender } \\
\text { differ- } \\
\text { ence }\end{array}$} & \multicolumn{6}{|c|}{ Gender Means by Farm Group } & \multirow{3}{*}{$\begin{array}{c}\text { p value for } \\
\text { gender by farm } \\
\text { group }\end{array}$} & \multicolumn{3}{|c|}{$\begin{array}{l}\text { p values for farm } \\
\text { comparisons }\end{array}$} \\
\hline & \multirow{2}{*}{$\begin{array}{c}\text { Male } \\
(n=430)\end{array}$} & \multirow{2}{*}{$\begin{array}{l}\text { Female } \\
(n=423)\end{array}$} & & \multicolumn{2}{|c|}{ Unplanned Interventio } & \multicolumn{2}{|c|}{ on Intervention } & \multicolumn{2}{|c|}{ Control } & & \multirow{2}{*}{$\mathrm{I} / \mathrm{C}$} & \multirow{2}{*}{$\mathrm{I} / \mathrm{U}$} & \multirow{2}{*}{$U / C$} \\
\hline & & & & $\begin{array}{c}M \\
(n=100)\end{array}$ & $\begin{array}{c}F \\
\langle n=102)\end{array}$ & $\begin{array}{c}M \\
(n=229\end{array}$ & $\begin{array}{c}F \\
(n=223)\end{array}$ & $\begin{array}{c}M \\
(n=101)\end{array}$ & $\begin{array}{c}F \\
(n=98)\end{array}$ & & & & \\
\hline $\begin{array}{l}\text { Instrumental } \\
\text { knowledge }\end{array}$ & 4.45 & 4.93 & $<.001$ & 4.81 & 5.08 & 4,42 & 5.06 & 4.17 & 4.47 & .033 & $<.001$ & .299 & $<.001$ \\
\hline \multicolumn{14}{|l|}{ Condoms } \\
\hline - Behaviour change & 2.34 & 1.81 & $<.001$ & 2.43 & 2.03 & 2.35 & 1.69 & 2.22 & 1.87 & .230 & .307 & .902 & .261 \\
\hline $\begin{array}{l}\text { - Attitudes to condor } \\
\text { use by women for } \\
\text { contraception and } \\
\text { self-protection }\end{array}$ & 12.95 & 11.94 & $<.001$ & 13.24 & 12.03 & 12.82 & 12.97 & 12.97 & 11.41 & .109 & .098 & .947 & .114 \\
\hline $\begin{array}{l}\text { - Advantages and } \\
\text { disadvantages of } \\
\text { condom use }\end{array}$ & 12.03 & 12.15 & .503 & 12.20 & 12.32 & 12.02 & 12.37 & 11.89 & 11.69 & .320 & .098 & .947 & .114 \\
\hline Perceived efficacy & 3.06 & 0.92 & $<.001$ & 2.91 & 1.00 & 3.17 & 0.92 & 2.95 & 0.86 & .176 & .290 & .080 & .642 \\
\hline $\begin{array}{l}\text { Perceived support } \\
\text { authority for AIDS } \\
\text { prevention activitie }\end{array}$ & 1.69 & 1.44 & $<.001$ & 1.52 & 1.48 & 1.78 & 1.47 & 1.66 & 1.35 & .036 & .049 & .031 & .753 \\
\hline
\end{tabular}




\section{Table 4: Item Analysis : Efficacy Scale by Gender}

\begin{tabular}{|c|c|c|c|}
\hline Item & $\underset{(n=430)}{\text { Male }}$ & $\begin{array}{l}\text { Female } \\
(n=423)\end{array}$ & $\mathrm{p}$-value \\
\hline $\begin{array}{l}\text { Agree that you have the right to choose about } \\
\text { your sex life }\end{array}$ & $\begin{array}{l}395 \\
(92.3 \%)\end{array}$ & $\begin{array}{l}36 \\
(8.5 \%)\end{array}$ & $<.001$ \\
\hline $\begin{array}{l}\text { Agree that I would be afraid to deny sex to my } \\
\text { partner }\end{array}$ & $\begin{array}{l}41 \\
(9.4 \%)\end{array}$ & $\begin{array}{l}184 \\
(44.1 \%)\end{array}$ & $<.001$ \\
\hline $\begin{array}{l}\text { Agree that there is something the people on } \\
\text { this farm can do to prevent HIV }\end{array}$ & $\begin{array}{l}262 \\
(60.9 \%)\end{array}$ & $\begin{array}{l}46 \\
(10.9 \%)\end{array}$ & $<.001$ \\
\hline $\begin{array}{l}\text { Agree there is something the community can } \\
\text { do to prevent HIV }\end{array}$ & $\begin{array}{l}265 \\
(61.6 \%)\end{array}$ & $\begin{array}{l}75 \\
(17.7 \%)\end{array}$ & $<.001$ \\
\hline
\end{tabular}

\section{Perceived Advantages and Disadvantages of Condom Use}

Our results showed that, on the scale which measured the advantages and disadvantages of condom use, no significant differences were noted between farm groups. An overall mean score of 12.05 on a scale of 7 to 14 indicated that farm workers across the sample perceived more advantages than disadvantages of condom use.

\section{- Perceived Efficacy with Respect to Self-Protection Against HIV}

No significant differences were observed between farm groups on the scale which measured perceived efficacy with respect to self-protection against HIV (Table 3). However, attention is drawn to the striking gender differences on the efficacy scale which showed that females scored significantly lower than males on the efficacy scale. We also examined items on the scale separately and the results are presented in Table 4. The most common reasons that women cited for not withholding sex were: the fear of violence; fear of abandonment; and distrust by their partner.

On the issue of community empowerment significantly $(p<01)$ more farm workers in the 'intervention' group agreed that 'there was something the people on their farm could do to prevent the spread of HIV' when compared with the other two groups.

However, it was noted that across all three groups, significantly $(p<.001)$ fewer females agreed on this item when compared with their male counterparts.

Although there were no significant differences between farm groups on the item, 'Do you think there that there is something the community can do to prevent AIDS', we noted again that significantly $(p<.001)$ fewer females were in agreement when compared with males. 


\section{* Perceived Susceptibility to HIV/AIDS}

There being no reliable scale available to measure perceived susceptibility to HIV / AIDS, on the item 'Do you worry about getting AIDS?', we found that significantly $(\mathrm{p}<.01)$ more farm workers in the 'intervention' groups worried about getting AIDS when compared with the control group. We also found that people who worry have better knowledge than those who do not worry $(p<.05)$. In particular, significantly $(\mathrm{p}<.001)$ more women $(96.7 \%)$ than men $(56.3 \%)$ across all three farm groups said they 'worried about getting AIDS'.

We also found that farm workers who perceived the advantages of condom use also worried more about contracting HIV ( $p<.01)$. When the item 'Do you worry about getting AIDS?' was examined against the efficacy scale, people who scored higher on the efficacy scale worried less, whereas those who scored lower on the efficacy scale worried more $(\mathrm{p}<.05)$.

\section{Socio-organizational Level Changes}

\section{Perceived Support by Authorities for AIDS Prevention Activities}

On the scale which measured perceived support for AIDS prevention activities by farm owners we found that significantly more farm workers in the intervention group acknowledged support $(\mathrm{p}=<.05)$ when compared with the control group (Table 3 ). There was a significant ( $\mathrm{p} .<001$ ) difference between males and females, with males across the sample perceiving support by authority more positively than females.

Of those workers $(n=564)$ who said that they had attended activities organised by the Farm Health Worker during the last six months, significantly $(p<.05)$ more workers said 'yes' from the 'intervention' group $(68 \%)$ when compared with the control group (10.1\%)and the 'unplanned intervention' group (22\%). We noted that of the workers from the 'intervention' group $(n=383)$ a higher percentage of males (72.6) attended when compared with females (67.9). This links with the findings of the process evaluation (Laver et al., 1996/1997) which show that women in the 'intervention' group had cited lack of time as a major factor in preventing them from attending activities.

On increasing condom availability, the intervention had a significant $(\mathrm{p}<.001)$ effect on increasing availability of condoms on the 'intervention' farm with 60 per cent workers saying that condoms were 'always available' compared with 18 per cent workers in the control farm group and 22 per cent in the 'unplanned intervention' group.

\subsection{Discussion}

A community-based intervention in itself does not guarantee a reduction in morbidity of disease or a change in behaviour; there are a number of factors which may be difficult to control and may therefore influence the outcome. However, because of the gravity of the epidemic and the urgent need to respond with prevention interventions, few programmes build in components which enable the objective evaluation of projects. In this discussion we make observations about the difficulties in measuring change in a community-based HIV/AIDS 
prevention initiative in farm worker communities. We set out the limitations of our study and deliberate the findings. We conclude with suggestions for future community-based HIV prevention interventions.

\subsubsection{Limitations of the Study}

\section{Study Measures}

Although theory guided the development of the intervention approach and the selection of constructs for the end-point evaluation, we were aware of the limitations imposed by (a) measuring change where the time frame of the intervention was limited to one year and (b) the difficultics of constructing a reliable research instrument to measure end-point change in an educationally disadvantaged community.

Notwithstanding the drawbacks of conducting the end-point evaluation after one year, we draw attention to the advantage of incorporating a process evaluation in studies which are conducted within a limited time frame (Laver et al., 1995/ 1996). Process evaluations provide a valuable insight into 'what actually happens' during an intervention period and help to illustrate that end-point results are often determined by a number of factors which lie beyond the scope of an intervention. We learned from our study, for example, that high levels of condom demand recorded by change-agents during the intervention period (Laver et al., 1995/1996) could be attributed to factors which were outside the immediate goals of the intervention. Firstly, condom demand rapidly increased as it became known that condoms were freely available on intervention farms. Secondly, condoms had a re-sale value which increased their demand, i.e. they were sold to "outsiders" during the intervention period - a factor not to be underestimated in poor communities. Thirdly, we discovered that the increase in the number of nonpermanent workers during the peak season coincided with an increase in condom demand on intervention farms. This would have escaped our attention in the end-point evaluation and it is possible that we may have erroneously concluded that increased demand was due to the effect of the intervention.

We also discovered that we may have incorrectly concluded that a decline in STI incidence during peak periods of work on farms was due to an intervention effect and not - as we learned from the process evaluation - because farm workers were too busy to take time off to attend clinics for treatment.

The second important issue which we wish to raise with respect to study measures is that, although we were able to develop scales with acceptable levels of reliability to address the major research questions for the study, we are also aware of the weaknesses in the end-point evaluation design. We failed, for example, to measure changes in the problem-solving ability within the community. The research would have benefited from a less superficial analysis of intrapersonal and organisational change which would have led to a deeper understanding of barriers to behaviour change in farm worker communities. The problem of developing indicators and methods for evaluating a community-based intervention remains a challenge. 


\section{Change-agents and the Contextual Environment of the Intervention}

Our change-agents (the FHWs) experienced difficulty in using a method where people are not the objects of an educational project, but participants in a process of change. In particular we noted that the culture of didactics, which still characterises health education activities in Zimbabwe, prevailed in spite of intensive training which promoted the use of participatory methods. A further issue of concern was that although the FHWs were keen to facilitate dialogue around issues concerning individual perceptions of risk avoidance, they would encounter extreme difficulty in influencing cultural norms known to militate against the attainment of this objective. Being women, they personally identified with and expressed helplessness about overcoming this problem. We therefore question our approach, which was mostly dependent on single female changeagents, and suggest that greater support for the intervention would be generated by a peer group of men and women who would be more likely to pre-suppose a 'community organising' approach. In this respect, perhaps, the intervention would have been more successful in assisting the community to articulate and synthesise their feelings about their capacity to change. We therefore agree with Schulz et al. (1995) who say that 'for health educators and others engaged in community-based approaches to foster individual and collective change, gaining an increased understanding of the correlates of empowerment is important'.

The contextual environment - social and physical - in which an intervention in farm worker communities takes place is complex. In addition to the perspectives held about STI/HIV/AIDS and the ways in which the problem interfaces with culture among farm workers, the social and environmental milieu in which the people live and work are important factors which influence participation and action in a community-based intervention. While it was hoped that our intervention would encourage people to become organised around an issue as important as HIV / AIDS, their lack of experience in collective action was a disabling factor. We also concluded from our observations that, in the face of other problems such as poverty and drought, it was not without reason that workers felt little sense of purpose in dealing with an 'external' threat which may only influence their lives in the future. Attention is also drawn to the unanticipated effect of seasonal farming activities which disrupted the carefully planned, reiterative nature of our intervention. In addition to which, the influx of seasonal workers attracted problems of alcohol abuse and prostitution.

These factors, when aggregated, provided us with a perspective of a programme whose success or failure was partially determined by issues beyond the scope of the intervention.

\subsubsection{Intervention Effects}

At an intra-personal level we found significant differences in knowledge about HIV/AIDS between the 'intervention' and control group. In particular, the intervention was successful in increasing knowledge in educationally disadvantaged women. Interestingly, FHWs reported that women participatcd in fewer intervention activities than men. Women voluntarily participated in 
their free time which was limited because of their need to attend to household chores. Men, on the other hand, mainly attended activities during working hours in time specifically allocated for that purpose.

With respect to our findings concerning perceived susceptibility to HIV we found that, particularly among women, the intervention had a significant effect in raising concern about, and perceived vulnerability to, HIV. It was striking, however, that even when armed with information and concern about HIV / AIDS, our efforts to increase self-esteem and self-efficacy in females failed, with a significant number of women articulating helplessness, powerlessness and an inability to transform their risk status. In our opinion, achieving a threshold necessary for increasing self-efficacy in interventions is beyond cognitive gain, and far more dependent on developing skills which will reduce the sexual inequality which currently exists between men and women. We also agree with Levine et al. (1993) who point out that self-esteem variables correlate highly to positive behaviour changes and that "if we are to increase the self-worth of women they must be [encouraged] to feel that they have something to contribute instead of being perceived as inadequate'.

On the issue of condom use at an intra-personal level, our study showed that male and female farm workers across all three farm groups perceived the advantages of using condoms. However, "Use always for sex" was low (5.4\%) with no significant differences between farm groups. Under half $(43 \%)$ of respondents said they 'had not tried using condoms but do sometimes think about' using condoms, i.e. they were still in the pre-contemplation stage of use. Males strongly disagreed $(p<.001)$ that condoms should be used by married couples. We noted that on the behaviour change scale for condom use, the score for 'use' among women (of whom at least 95\% in this study were married) was significantly $(p<.001)$ lower than men. We concluded that if men use condoms, use is with girlfriends rather than wives. Attention is drawn to the considerable risk of HIV infection at which women are placed in relationships where their husbands multi-partner, but refuse to use condoms with their wives (Bassett and Mhloyi, 1991; Chin, 1990; Campbell, 1990; de Bruyn, 1992). While the issue of condom use continues to be closely tied to matters of male dominance in the sexual arena, it will be difficult to promote use within marriage. The challenge of motivating the sexually active from a stage of ambivalence about condom use to a stage of use which requires overt modification of behaviour should not be underestimated. In acknowledging the difficulties in creating change in this sphere, wc agree with Campbell (1995) in her important discourse on male gender roles and the implications for women's AIDS risk and prevention. She argues that there is an important need to build on the existing culture of association between 'masculinity' and 'sexual power' in men by teaching that they too can [and should] take responsibility for protected sex.

At socio-organizational/policy level we found initially that difficulty was experienced in setting an agenda for the intervention. This was resolved over time as the change-agents recognised the importance of generating formal and informal networks so that a local agenda could be developed to address issues concerning intervention activities and condom distribution. As a result, the 
intervention was successful in significantly increasing perceived support by authorities (i.e. farm owners) for HIV prevention activities on our 'intervention' farms. Condom availability was also significantly increased on these farms, with a high percentage of workers acknowledging that condoms were "always available' (as opposed to 'sometimes' or 'never').

In the one year period of the intervention we did not succeed in creating an enabling climate for the development of community-based initiatives on AIDS. In this respect it is felt that insufficient attention was given to establishing groups through which the intervention objectives might have been fostered. This may to some extent have accounted for the striking gender differences we observed in response to the issue of community empowerment. It was possible that FHWs showed greater empathy with female farm workers and were therefore able to communicate more effectively at an intra-personal level. However our studs showed that, in the face of an epidemic which is poised to place high demands on women, they feel irresolute about their personal ability or the ability of the community to bring about change. Although their high levels of knowledge about HIV / AIDS appeared to have sharpened their understanding of the problem, their perception of a solution is clearly defined within socio-cultural-gender issues. Among men, however, our study showed that gender socialisation appears to contribute to high levels of self-efficacy and a powerful perception of sexual identity and control at individual and community level. Interestingly, when invited to become involved in peer group activities our FHWs reported that men in particular declined on the basis that they expected rewards and said they had 'no time for such things' (Laver et al., 1996/7). The intervention was therefore clearly unsuccessful in assisting men to define their role in responding to the epidemic.

\subsection{Conclusion - Implications for Future Interventions}

What have we learned from this intervention which will transform our approach to AIDS prevention in commercial farm workers in the future? It is clear that historical and political events have conspired over time to create differences in these communities which make their needs unique. We concede that the dynamics of change are complex in individuals and communities who have been traditionally denied access to decision-making, and we believe that there are certain imperatives which are crucial to the transformation of community-based interventions.

Firstly we recognize the gender power differences which militate against change, and we concur strongly with Campbell (1995) that there is an urgent need for interventions to target men directly, rather than through women. This calls for a clear recognition that intervention strategies must be constructed in a way that allows time and expands the opportunity for men to participate in dialogue about gender imbalances and appraise their role in this epidemic. They need to acknowledge independently that they too have a responsibility to protect themselves and their female partners. 
Secondly, in creating opportunities for men to assume greater responsibility in inhibiting transmission of HIV, interventions must seek to create a climate which de-emphasizes the need for females to take primary responsibility for safer sex practices. There is a need to expand the dialogue about the imbalances in power relations between men and women, and we believe that male and female constituents of the community must work together to achieve this objective. We also need to explore vigorously 'every means possible to strengthen women's immediate ability to protect themselves in the face of current economic and cultural forces allied against them' (Heise and Elias, 1995). Because of the difficulties inherent in achieving regular condom use, other cost-effective methods such as spermicides, which enable protection without the risk of confrontation, must be examined further.

Thirdly, we must acknowledge that interventions which control the flow of information and utilise a didactic approach lack empirical support in terms of creating effective HIV/AIDS prevention behaviour (Carballo et al., 1989; Des Jarlais and Friedman, 1990; Green, 1992a; 1992b; Krieger and Margo, 1991; Laver et al., 1995; Miotti et al., 1992; Pela and Platt, 1989; Wasserheit, 1992). This calls for transformation in the construction of interventions within a setting that (a) clearly acknowledges that change rests within the community and (b) increases perceptions of learned hopefulness and proactive behaviour through modelling, skills training and reinforcement. In this context, the work of Werner and Bower (1982), Freire (1972; 1983), Wallerstein and Sanchez-Merki (1994), Wallerstein and Bernstein (1988) and Hope et al. (1984) provides outstanding examples of how the theory of praxis, i.e. reflection (appraisal), dialogue and action (praxis) can be integrated with the principles of community organisation (Bracht, 1990). In this approach, involvement of the community is maximized relative to the 'expert' who facilitates change through activities which heighten debate, maximise the opportunity for self-learning (Ankrah, 1991; Prual et al., 1991) and increase the opportunity for networking at every level.

Fourthly, there is an urgent need to reverse the trend of government's inability to protect the poor from the effects of economic reform which is having a marked impact on service delivery in the health sector and which will, over time, serve to exacerbate the impact of AIDS on poor and vulnerable communities. In this context, Bijlmakers et al. (1996) recommend, and we agree, that ...'more resources [should] be made for primary health care facilities and no fees should be charged for services provided at this level, so as to make them accessible to all'.

\section{Implications for Future Interventions}

In the words of Loewenson (1993), "the AIDS epidemic has the contradictory features of being one of the most devastating blows that we have experienced in Africa, while at the same time teaching us new lessons about health actions'. Programmes which neglect the policies and discourses which shape the AIDS agenda and fail to address the cultural and sub-cultural differences inherent in the beliefs, attitudes and values of individuals or communities, run the risk of joining the long list of failures (Adamchack et al., 1990; Ankrah, 1989; Bassett and Mhloyi, 1991; Earickson, 1990; 
Green, 1992a; 1992b; Packard and Epstein, 1991; Schoepf et al., 1992). On the basis of our findings we ask the question: 'What would we change and how would we plan the next intervention?' In summary we would:

- continue to use the empirically-tested social change approach proposed by Wallerstein and Sanchez-Merki (1994) which was tested in our intervention. We would continue to actively promote the concept that community members are not the objects of an educational project, but participants in a process of change.

* foster the process of appraisal, reflection, decision-making and, more importantly, dialogue through methods and resources such as picture codes which were shown to be effective in this study

* strengthen the capacity for building self-efficacy in women. This does not imply that our future interventions should be targeted at women - or at men through women. On the contrary, the intervention would pay close attention to illuminating gender power differentials, and would invest time in helping men to acknowledge that they are stakeholders and not merely passive bystanders in AIDS prevention. They too have an important role to play in fighting the epidemic.

* generate support for the intervention through a peer group, i.e. men and women, which would pre-suppose a 'community organising' approach. In this respect, we would promote the need for a wider community response, which includes seasonal workers and facilitates the synthesis of perspectives articulated by members of the community about their inability/ability to participate and their capacity to change.

$\therefore \quad$ work towards the development of an integrated plan for social development on farms where workers could network more closely with key partners such as farm owners and other organisations who are already working towards change in farm worker communities

* explore policy concerning condom access and condom distribution within farm worker communities and actively target the need to increase access to STI treatment in the current climate of economic decline. In this respect we would critically explore the possibility of, for example, devolving responsibility for treatment to a level at which local people can become more actively involved

- recognise the seasonal effect of farming on intervention activities and strengthen efforts to promote group consensus and a unified sense of purpose within the farm worker community with respect to HIV prevention at an organisational level.

Finally we would continue to promote the process of developing appropriate measures to test and amend community-based interventions on the basis of empirical research which includes process and end-point evaluations. 


\section{References}

Adamchak, D.J., Mbizvo, M.T. and Tawanda, M. (1990) Male knowledge of and attitudes and practices towards AIDS in Zimbabwe. AIDS Education and Prevention, 4, 245-250.

Anderson, S. (1994) Community responses to AIDS. International Nursing Review, 41 (2), 57-60.

Ankrah, E.M. (1989) AIDS. Methodological problems in studying it's prevention and spread. Social Science and Medicine, 29, 265-276.

Ankrah, E.M. (1991) AIDS and the social side of health. Social Science and Medicine, 32, 967-980.

Amanor-Wilks, D.E. (1995) In Search of Hope for Zimbabwe's Farm Workers. London: Date Line Southern Africa and Panos.

Bandura, A. (1986) Social Foundations of Thought and Action.: A Social Cognitive Theory. Englewood Cliffs, NJ: Prentice-hall.

Bassett, M.T. and Mhloyi, M. (1991) Women and AIDS in Zimbabwe: The making of an epidemic. International Journal of Health Serrices, 21, 143-56.

Bijlmakers, L.A. (1993) Directory of socio-behavioural research on HIV infection and AIDS in Zimbabwe. Central African Journal of Medicine, 39 (2), 37-39.

Bijlmakers, L., Bassett, M.T. and Sanders, D. (1996) Health and Structual Adjustment in Rural and Urban Zimbabwe. Research Report No. 101. Uppsala, Sweden: The Scandinavian Institute of African Studies.

Bracht, N. (1990) Introduction. In Health Promotion at the community level. ed. Bracht. N. pp 19-25. Newbury Park, CA: Sage.

CSO (1992) Census Report. Central Statistical Office. Harare, Zimbabwe: Government Printers.

Cook, T.D. and Campbell, D.T. (1979) Quasi-experimentation: Design and Analysis Issues in Field Settings. Boston, MA: Houghton Mifflin.

Campbell, C.A. (1990) Women and AIDS. Social Science and Medicine, 30, 407.

Campbell, C.A. (1995) Male gender roles and sexuality: implications for women's AIDS risk and prevention. Social Science and Medicine, 41 (2), 197-210.

Carballo, M., Cleland, J., Caracl, M. and Albrecht, G. (1989) Research Agenda: A Cross National Study of Patterns of Sexual Behavior. The Journal of Sex Research, 26, 287-299.

Chin, J. (1990) Current and Future dimensions of the HIV / AIDS pandemic in women and children. The Lancet, 336, 221. 
Des Jarlais, D.C. and Friedman, S.R. (1990) Target groups for preventing AIDS among intravenous drug users. In Psychosocial perspectives on AIDS: Etiology, prevention and treatment. ed. Temoshok, L. and Baum, A. pp 35-50. Hillsdale NJ: Lawrence Earlbaum Associates Inc.

De Bruyn, M. (1992) Women and AIDS in developing countrie's. Social Science and Medicine, 249.

Earickson, R.J. (1990) International behavioral responses to a health hazard: AIDS. Social Science and Medicine, 31, 951-962.

Frazer-Mackenzie, J.P. (1992) Commercial Farmers Union/AIDSTECH Report. Zimbabwe $15 / 9 / 90-15 / 9 / 92$.

Freire, P. (1972) Pedagogy of the Oppressed. New York: Seabury Press.

Freire, P. (1983) Education for Critical Consciousness. New York: Seabury Press/ Continuum Press.

Govneder, V., Bhana, R., Pillay, A., Panchia, R., Padayachee, G.N. and De Beer, M. (1992) Perceptions and knowledge about AIDS among family planning clinic attenders in Johannesburg. South African Journal of Medicine, 81 (2), 71-74.

Green, L.W. and Lewis, M.M. (1986) Measurement and Evaluation in Health Education and Health Promotion. Palo Alto, California: Mayfield Publishing Company.

Green, E.C. (1992a) Sexually transmitted disease, ethnomedicine and health policy in Africa. Social Science and Medicine, 35, 121-130.

Green, E.C. (1992b) The anthropology of sexually transmitted disease in Liberia. Social Science and Medicine, 35, 1457-1468.

Gregson, S., Garnett, G.P., Shakespeare, R., Foster, G. and Anderson, R.M. (1993) "Mathematical model simulations and empirical estimates of HIV-1 on orphanhood in sub-Saharan Africa. Paper presented at the Seminar on AIDS Prevention in Developing Countries; the Role of Demograply and Social Science, Annecy, France, December 5-9.

Gregson, S. and Foster, G. (1994) "Orphans in Zimbabwe - A Descriptive and Enumerative Study". Abstract POD 5158, VIII International Conference on AIDS, Amsterdam.

Heise, L.L. and Elias, C. (1995) Transforming AIDS prevention to meet women's needs; a focus on developing countries. Social Science and Medicine, 40 (7), 931-943.

Hope, A, Timmel, S. and Hodzi, C. (1984) Training for Transformation: A handbook for Community Workers. Gweru, Zimbabwe: Mambo Press.

Janz, N.K., Zimmerman, M.A., Wren, P.A., Israel, B.A., Freudenberg, N. and Carter, R.J. (1996) Evaluation of 37 AIDS prevention projects: Successful Approaches and Barriers to Program Effectiveness. Health Educatim Quarterly, 23 (1), 80-97. 
Krieger, N. and Margo, G. (1991) Women and AIDS: Introduction. International Journal of Health Services, 21, 127-130.

Knepp, K.I., Ndeki, S.S., Seha, A.M., Hannan, P., Lyimo, B.A., Msuya, M.H., Irema, M.N. and Schriener, A. (1994) AIDS education for primary school children in Tanzania: an evaluation study. AIDS. 8 (8), 1157-1162.

Laver, S. (1993) AIDS education is more than telling people what not to do. Tropical Doctor. 23, 156-160.

Laver, S., Van den Borne, B., Kok, G. and Woelk, G. (in press). A Pre-intervention Survey to Determine Understanding of HIV / AIDS in Farm Worker Conmunities of Zimbabwe. Awaiting publication by AIDS Education and Prevention. (Accepted November, 1995).

Laver, S., Van den Borne, B. and Kok, G. (1994/1995). Using Theory to Design an Intervention for HIV/AIDS Prevention in Farm Workers in Rural Zimbabwe. Intermational Quarterly of Community Health Education, 15 (4), $349-362$.

Laver, S., Van den Burne, B. and Kok, G. (1996/1997). Was the Intervention implemented as intended?: A Process Evaluation of an AIDS Prevention Intervention in Rural Zimbabwe. International Quarterly of Community Health Education, 16 (1), 25-46.

Levine, O., Britton, H., James, T.T., Jackson, A.P. and Hobfall, S.E. (1993) The Empowerment of Women: A Key to HIV Prevention. Journal of Social Psychology, $21,320-330$

Livingstone, 1.L. (1992) AIDS/ HIV Crisis in developing countries: the need for greater understanding and innovative health promotion approaches. (Review) journal of the National Medical Associntion, 84 (91), 755-770.

Loewenson, R.L. (1993) Potentials and Constraints to Trade Union Action on AIDS: Lessons from Zimbabwe. Paper presented to SENASO, Namibia, May.

Loewenson, R. and Chisvo, M. (1994) Transforming Social development: The Experience of Zimbabwe. Report prepared for UNICEF, Harare, Zimbabwe.

Miotti, P.G., Chiphangwi, J.D. and Dallabetta, G.A. (1992) The situation in Africa. Baillieres Clinical Obstetrics and Ginnaecology, 6, 165-186.

MoH (1995) HIV and STl Surveillance Zimbabwe Quarterly Report April - June. Health Information Unit and National AIDS Co-ordination Programme.

McLeroy, K.R., Bibeau, D., Steckler, A. and Glanz, K. (1988) An Ecological Perspective on Health Promotion Programs. Health Education Quarterly, 15 (4), 351-377.

Moyo, I.M., Ray, C.S., Chisvo, D., Gumbo, N., Low, A., Katsumbe, T.M. and Mbengeranwa, O.L. (1993) Behaviour patterns which may predispose to HIV infection or further transmission and possible intervention strategy in the city of Harare. Part 11 Central African Journal of Medicine, 39 (11), 217-221.

Munodawafa, D. and Gwede, C. (1996) Patterns of HIV/AIDS in Zimbabwe: Implications for Health Education. AIDS Education and Prevention, 8 (1), 1-10. 
Packard, R.M. and Epstein, P. (1991) Epidemiologists, social scientists, and the structure of medical research on AIDS in Africa. Social Science and Medicine, 33, 771-794.

Prochaska, J.O., and DiClemente, C.C. (1984) Self-change processes, self efficacy and decisional balance across five stages of smoking cessation. Advances in cancer Control. Epidemiology and Research, 131-140.

Pela, A.O. and Platt, J.J. (1989) AIDS in Africa: Emerging trends [Comment]. Social Science and Medicine, 28, 1-8.

Prual, A., Chacko, S. and Koch-Wezer, D. (1991) Sexual behaviour, AIDS and poverty in Sub-Sahara Africa [Editorial]. International Journal of Sexually Transmitted Diseases and AIDS, 2, 1-9.

Renton, A.M. and Whitikar, L. (1994) Using STD occurrence to monitor AIDS prevention. Social Science and Medicine, 38 (8), 1153-1165.

SAFAIDS and CFU. (March 1996) Orphans on Farms: Who Cares? An Exploratory Study into Fostering Orphan Children on commercial farms in Zimbabwe. Report prepared by Southern Africa AIDS Information Service and Commercial Farmers Union.

Schoepf, B.G. (1992) Sex, gender and society in Zaire. In Sexual behaviour and networking: Anthropological and socio-cultural studies on the transmission of HIV. ed. T. Dyson. pp 366. Liege, Belgium: Derouaux-Ordina.

Schulz, A.J., Israel, B.A., Zimmerman, M.A. and Checkoway, B.N. (1995) Empowerment as a multi-level construct: perceived control at the individual, organisational and community levels. Health Education Research. 10 (3), 309-327.

SPSS Inc. (1988) SPSS-X User's Guide. Chicago, Ill: SPSS inc.

Tabachnick, B.G. and Fidell, L.S. (1983) Using Multioariate Statistics. Harper and Row.

Wallerstein, N. and Bernstein, E. (1988) Empowerment Education: Freire's Ideas Adapted to Health Education. Health Education Quarterly, 15, 379-394.

Wallerstein, N. and Sanchez-Merki, V. (1994) Freirian Praxis in health education: research results from an adolescent prevention programme. Health Education Research. Theory and Practice, 9 (1), 105-118.

Wasserheit, J.N. (1992) Epidemiological synergy: Inter-relationships between human immunodeficiency virus infection and other sexually transmitted diseases. Sexually Transmitted Diseases, 19 (2), 61-77.

Werner, D. and Bower, B. (1982) Helping Health Workers Learn. Palo Alto, CA: The Hesperian Foundation. 


\section{Summary}

The AIDS epidemic erupted in Africa when the leadership and the people - who like much of the world - were not ready to confront such a threat. Zimbabwe was no different. After independence from colonial rule in 1980, the newly-elected government was responding decisively and effectively to a combination of demands and the expectations of an independent nation. A public health threat with an unknown face could not have come at a more inauspicious time.

By mid-1995, it was estimated that around one million people or 10 per cent of the total population were infected with HIV in Zimbabwe. Almost all infection is transmitted through sexual intercourse or mothers passing the infection to the unborn or newborn; there is little evidence of transmission through the intravenous drug route or through blood transfusion. The relationship between Sexually Transmitted Infections (STIs) and HIV infection is widely recognised with STIs known to play a potentiating role in HIV transmission. It is estimated that $14.1 \%$ cases are in children under five years and approximately $71 \%$ fall within the economically productive group. The male to female ratio is nearly 1:1 among adults. Among adolescents (15 to 19 years) the incidence in females has been estimated to be six times greater than their male counterparts. The tragedy of orphanhood, previously not perceived as a problem in traditional African culture is now also unfolding. Exacerbated by the increase in premature deaths of women, who customarily assume most responsibility for child rearing, the vulnerable position of orphans in Zimbabwe is a matter of deep concern.

It is against this background that the HIV prevention intervention described in this thesis was developed, implemented and evaluated among farm workers in a district of one of Zimbabwe's eight provinces. The overall goal of the intervention was to decrease the risk of STI/HIV in farm workers through unprotected sex and to increase farm worker participation in AIDS prevention activities. The specific objectives of the study included the need to develop a multi-level intervention with a phased participatory methodology which would target change within the individual and the socioorganisational context in which farm worker communities live and work. In keeping with community organisation principles, the intervention was implemented by changeagents i.e. Farm Health Workers (FHWs) who, apart from being trained in participatory methods for HIV prevention, were known to and accepted by the communities in which they lived and worked.

The development of the intervention and the execution of the research in the present study was carried out in six phases. Phase 1 involved a needs assessment; in phase 2, empirically tested theory was examined and adapted for the development of the intervention. A training phase followed in phase 3 , and in phase 4 the intervention was carried out over a period of 12 months. Phase 5 concerned a process evaluation and in phase 6 an impact evaluation was carried out to measure the effects of the intervention.

Chapter 1 provides the historical and social background against which the intervention took place. In this chapter, attention is drawn to the increasing prevalence of HIV in the rural communities of Zimbabwe, who comprise about 73 per cent of the total population. In addition to presenting an overview of the research findings and 
recommendations for future interventions, attention is also drawn in this chapter to the limitations of the study design and those imposed by the contextual environment in which the intervention took place.

In Chapter 2, a range of discourses or dialogues which have shaped the AIDS prevention agenda in Zimbabwe over the past decade are reviewed. According to the analysis made in this chapter, these discourses have fallen within four distinctive eras, i.e. an era of non-confrontation, an era of moral confrontation, an era of realisation and an era of re-assessment. The conclusions call for a transformation of the AIDS discourse to address imbalances in health care caused by budgetary cutbacks which marginalise poor communities upon whom the major burden of the AIDS epidemic is falling. Attention is drawn to the need to confront the gender inequities which increase the risk of HIV transmission in women and a call is made for intervention strategies which reinforce the role of males in taking responsibility for protected sex. The importance of pursuing every means possible to strengthen women's ability to protect themselves against infection is stressed. Lastly, a call is made for a change in the construction of interventions within settings which pay attention to empirical research and which use methods that increase learned hopefulness, proactive behaviour and compassion.

Chapter 3 describes the pre-intervention survey. The findings showed variability in living conditions for farm workers with some farms having only minimal standards of housing, water and sanitation. Women, who bear the burden of a double workload in farm communities with little time for leisure, were shown to be socially, economically and educationally disadvantaged when compared with men, and reported only marginal exposure to AIDS prevention activities. Alcohol abuse is reportedly high among men; beerhalls are the focal point for recreation on most farms. Seasonal workers commonly boost the labour supply during the peak periods of farming activity; they are perceived by permanent workers to be 'disruptive and act outside' community norms.

With respect to HIV/AIDS, the pre-intervention study findings showed that less educated women on farms believe that AIDS is brought about by divine/ancestral retribution. A significant number of women perceived themselves to be at high risk of HIV infection; conversely the findings showed that a significant number of women had low self-efficacy with respect to their ability to protect themselves from infection. Among more educated men, widespread acknowledgement of multi-partnering was found and condom use was shown be closely associated with age and education. The study concluded with recommendations to generate an appropriate intervention which would take into account the long history of non-participation of farm workers in decision-making. Attention was drawn to factors which often determine the outcome of community-based interventions which lie beyond the scope of even the most innovative programmes. The need to train and equip Farm Health Workers with skills and resources to become effective agents of change in the farm worker community was recognised and attention was drawn to the need to improve the linkage system between the farm owner and the community.

Chapter 4 focuses on the theory which was used to generate the intervention. It highlights the problem of developing interventions through intuition alone and illustrates how research findings from the pre-intervention survey were combined with Paulo Freire's social change theory and the Ecological Model of Health Promotion to develop a participatory intervention for prevention in farm workers. The chapter 
addresses the need to focus on change at the intra-personal level, organisational and policy level through an intervention which was re-iterative. It was proposed that in the first stage of the intervention, innovative methods would be used to encourage personal appraisal of vulnerability to HIV/AIDS through activities designed to raise critical thinking and dialogue. In the next phase, emphasis would be placed on developing cognitive and attitude change in the target group. Self-protective behaviour would be encouraged through condom use and an increase in self-efficacy with respect to negotiating sex, especially among women. In the last stages of the intervention, efforts would be made to move from an approach which targeted the interpersonal level and create a climate for decision-making and socially responsible action within the community. Dialogue as opposed to didactics would be central to the proposed intervention and recommendations were made to measure the intervention through a process and an outcome evaluation.

The process evaluation is described in Chapter 5. This provided a description of 'what happened' during the one-year intervention period. The process evaluation also provided valuable insight into factors which, when aggregated, gave an overview of a programme whose successes and failures were determined outside the scope of the intervention. During peak periods of farming activity, for example, there was an influx of seasonal workers which, when coupled with an increase in disposable income, was reported to lead to an increase in prostitution and alcohol abuse in farm worker communities. Interestingly, STI incidence data collected from catchment clinics showed a decline in the number of reports during this period. However, as was observed later, the decrease occurred because farm workers lacked time to seek treatment - not because of the effects of the intervention or an increase in condom availability as may have been concluded had the process evaluation not been carried out. The seasonal effect of farming activities was also observed to have an effect on intervention activities which FHW's found difficult to co-ordinate during this period. Women in particular were disadvantaged because of a lack of time to participate in activities, while men regarded the problem of HIV/AIDS prevention to be outside their control. Commitment to the intervention by FHW's was also found to be variable and difficulty was experienced in mobilising a community response to AIDS prevention.

This led back to the initial question 'Was the intervention implemented as planned?' and the answer was 'only partially'.

The final chapter describes the end-point evaluation which was conducted one year after the intervention had been implemented in nine randomly-assigned farm worker communities. Data were collected by trained research assistants through the interview method using a pre-tested questionnaire. The findings were compared with a control group where no intervention had taken place. With respect to intervention effects at the intra-personal level, the intervention group showed a significantly higher mean score on knowledge when compared with the control group. In the overall sample of farm workers, it was noted that there was a significant interaction between gender and farm, with educationally disadvantaged women scoring significantly better on knowledge than their male counterparts. Despite free access to condoms throughout the intervention, regular use of condoms for self-protection was reported to be low and no significant differences were found between farm groups. Although the advantages of condom use were positively perceived across all groups, significantly fewer males than females agreed that condoms should be used between married couples. 
The intervention failed to increase efficacy with respect to self-protection against HIV - especially in wornen whose scores on the efficacy scale were strikingly low when compared with males. The most common reasons that women cited for withholding sex, even when at risk of HIV, was fear of violence, fear of abandonment and distrust by their partners. The study showed that, in the face of an epidemic which is poised to place high demands on women, they felt irresolute about their personal ability or the ability of the community to bring about change. Although high levels of knowledge about HIV / AIDS appeared to have sharpened their understanding of the problem, their perception of a solution is clearly defined within socio-cultural-gender issues. Among men, however, the study showed that gender socialisation appears to contribute to high levels of self-efficacy and a powerful perception of sexual identity and control at individual and community level. The intervention was therefore clearly unsuccessful in assisting men to define their role in responding to the epidemic.

Significantly more farm workers in the intervention group agreed that they could do 'something' to prevent HIV when compared with the control group and the intervention had the effect of increasing perceived support by authorities for AIDS prevention activities. It was strikingly evident, however, that women across all groups felt significantly less able to do anything to prevent the spread of AIDS than men. No new community-based initiatives concerning HIV prevention were started by the farm worker community on any of the intervention farms.

On the basis of these findings, the question was asked, 'What would we change and how would we plan the next intervention?" A number of important issues would be considered.

Firstly, it is recognised that although theory guided the development of the intervention approach and the selection of constructs for the end-point evaluation, the limitations imposed by (a) measuring change where the time frame of the intervention was limited to one year and (b) the difficulties of constructing a valid and reliable method to measure end-point change in an educationally disadvantaged community, were evident. It is felt that the research would have benefitted from a less superficial approach to measuring change. Furthermore, the ethnographic approach adopted for the process evaluation could have been further evolved in order to reach a deeper understanding of the barriers to organisational change in farm worker communities. This, in turn, might have led to the generation of more sensitive recommendations for the way forward. The issue of developing relevant indicators and methods for evaluating a community-based intervention remains a challenge.

Secondly, this study and many studies before this, clearly demonstrate that improving behaviour change with respect to HIV prevention lies beyond raising cognitive understanding in the individual. There is an urgent need to develop multiple avenues to behavioural change which not only reverse misperceptions about HIV/ AIDS, but also promote self-protection through mastery learning and skills training. It is particularly important to develop behavioural capability among women whose self-esteem and self-efficacy with respect to prevention of HIV was shown to be so low. Men, on the other hand, should be assisted to identify behaviours which have negative consequences and to learn that they too have an important role to play in initiating, practising and maintaining change.

Thirdly, if the locus of control for change is to shift from the individual to the community, it is important that change is fostered within the wider context of the social environment. A mechanism for operationalising future interventions through an 
integrated policy for social development in farm worker communities is considered essential if efforts to enhance interaction among community stakeholders and create a unified sense of purpose with respect to HIV prevention are to succeed.

Fourthly, given the findings which clearly illustrate (a) the negative impact of poverty and peak-season farming activities on health-seeking behaviour among farm workers and (b) the current decline in the delivery of health services in Zimbabwe, every effort would be made to provide free access to STI treatment through a policy which recognises the need to devolve treatment to a local level on farms.

Finally, the perception that people are not the 'objects' of a didactic process, but 'participants' in a process of change would be re-emphasised in future training programmes for community-based change agents. The notion that innovation can, and should, emerge through an interactive approach in which stakeholders play the key role, would be reinforced. Furthermore, the potential for strengthening networks with key partners who are already working towards change in farm worker communities would be more vigorously explored.

This study demonstrated the difficulties of developing an appropriate intervention to foster a climate with respect to HIV/AIDS prevention at individual, socioorganisational and policy levels in farm worker communities. The process evaluation provided valuable insight into 'what actually happened' during the intervention period. The end-point results showed that the intervention was determined by a number of factors which lay beyond the scope of 'what was planned'.

In an ideal world, community interventions should bring about change. In reality, such events are uncommon. It is therefore important to place an intervention in its real context, extract that which is successful and build on changes however small, which will hopefully lead to a better understanding of the larger picture. 


\section{Samenvatting}

Evenmin als elders in de wereld waren de leiders en de bevolking van de Afrikaanse landen voorbereid, toen de AIDS epidemie uitbrak. In Zimbabwe was het niet anders. $\mathrm{Na}$ de onafhankelijkheid van de koloniale overheersing in 1980, reageerde de pas gekozen regering doortastend en effectief op de vele behoeften en verwachtingen van een onafhankelijke natie - een bedreiging voor de volksgezondheid met een onbekend gezicht zou niet op een ongunstiger tijdstip hebben kunnen komen.

Medio 1995 schatte men dat in Zimbabwe ongeveer 1 miljoen mensen of 10 procent van de totale bevolking geïnfecteerd was met HIV. Bïna alle infectie word tovergedragen door sexuele gemeenschap of door moeders die de infectie doorgeven aan het ongeboren- of pasgeboren kind; er is weinig bewijs van overdracht via intraveneuze toediening van drugs of via bloedtransfusie. De relatie tussen sexueel overdraagbare infecties (STIs) en HIV-besmetting wordt algemeen erkend; sexueel overdraagbare infecties spelen een potentiele rol in HIV-overdracht. De spreiding van HIV-infecties in Zimbabwe vormt geen normaalverdeling maar kent twee pieken. Volgens rapportages bevindt $14.1 \%$ van de HIV-geïnfecteerden zich in de leeftijdsgroep van 0 tot 5 jaar terwijl naar schatting $71 \%$ van de geïnfecteerden valt binnen de economisch produktieve groep. De man-vrouw verhouding is bij volwassenen ongeveer 1:1. Alarmerend is de schatting dat bij adolescenten (15-19 jaar) de incidentie onder jonge vrouwen 6 keer hoger is dan bij jonge mannen. De tragedie van 'verwezing', hetgeen voorheen in de traditionele Afrikaanse cultuur niet als een probleem werd ervaren, openbaart zich nu.

Door de toename van het vroegtijdige sterven van vrouwen, die gewoonlijk de meeste verantwoordelijkheid dragen voor het grootbrengen van kinderen, is de verslechterde kwetsbare positie van wezen in Zimbabwe een zaak van grote zorg. Het is tegen deze achtergrond dat de HIV-preventie interventie, zoals beschreven in dezc studie, werd ontwikkeld, geïmplementeerd en geëvalueerd. Deze interventie was gericht op relatief geïsoleerde agrarische gemeenschappen in een district van één van de 8 provincies van Zimbabwe. Het algemene doel van de interventie was het verlagen van het risico op STI/HTV infecties door onveilig vrijen bij "farm workers" en het bevorderen van de cleelname van "farm workers" aan AIDS-preventie activiteiten.

De specifieke streefdoelen waren gericht op het tot stand brengen van individuele en sociaal-organisatorische veranderingen door de ontwikkeling van een multi-leve] interventie waarbij een gefaseerde participatieve methode werd toegepast. In overeenstemming met de organisatie principes van de gemeenschap werd de interventie geimplementeerd door "change agents" die, behalve dat zij getraind war en in het gebruik van participatieve methoden voor HIV-preventie, bekend waren bij-en geaccepteerd door de mensen in de gemeenschap.

De ontwikkeling van de interventie en het onderzoek werden uitgevoerd in zes fases. In de eerste fase werden een probleem-analyse en een behoefte-onderzoek uitgevoerd; in de tweede fase werd op basis van de probleem-analyse en theorieën een interventie ontwikkeld. In de derde fase werden de "change agents" getraind, terwijl in de vierde fase gedurende een periode van 12 maanden de interventie werd uitgevoerd. De vijfde fase betrof een proces-evaluatie en in de laatste fase werden de effecten van de interventie nagegaan.

In hoofdstuk 1 wordt een algemene beschrijving gegeven van de historische- en sociale achtergrond waartegen de interventie plaatsvond. Ook wordt in dit hoofdstuk ingegaan op de toenemende prevalentie van HIV in agrarische gemeenschappen. Deze 
omvatten ongeveer $73 \%$ van de totale bevolking van Zimbabwe. Behalve een samenvatting van de onderzoeksresultaten wordt in dit hoofdstuk aandacht besteed aan de moeilijkheden en beperkingen die, mede als gevolg van de sociale context, waren verbonden aan de onderzoeksopzet en de interventie. Verder worden aanbevelingen voor toekomstige interventies gedaan.

In hoofdstuk 2 wordt een overzicht gegeven van de discussies die gedurende de afgelopen 10 jaar de Aidspreventie-agenda in Zimbabwe hebben bepaald. Hierbij worden een viertal tijdvakken onderscheiden, te weten, een periode van nonconfrontatie, een periode van morele confrontatie, een periode van bewustwording en een periode van herbezinning. In dit hoofdstuk wordt geconcludeerd dat in de discussie over AIDS meer aandacht zou moeten worden besteed aan de onevenwichtigheden in de gezondheidszorg die een gevolg zijn van bezuinigingen. Deze bezuinigingen treffen vooral de arme gemeenschappen, die al het meeste lijden onder de AIDS-epidemie, waardoor deze verder gemarginaliseerd worden. Er wordt gewezen op de noodzaak aandacht te besteden aan de ongelijkheden in de verhoudingen tussen mannen en vrouwen, die de risico's van besmetting met het HIV-virus bij vrouwen verhogen. In het bijzonder wordt aandacht gevraagd voor interventie strategieën waarbij de rol van de mannen met betrekking tot het nemen van verantwoordelijkheid voor veilig vrijen, wordt versterkt. Het belang van het toepassen van elk haalbaar middel dat de mogelijkheden van vrouwen om zich te beschermen tegen infectie versterkt, wordt benadrukt. Als laatste wordt ingegaan op het belang van het ontwikkelen van interventies die op empirisch onderzoek worden gebaseerd en waarbij methoden worden toegepast waardoor vertrouwen in de toekomst, proactief gedrag en medeleven met slachtoffers wordt versterkt.

In hoofdstuk 3 wordt het pre-interventie onderzoek beschreven. Uit de resultaten bleek onder andere dat vrouwen in agrarische gemeenschappen een onderwijsachterstand hebben vergeleken met mannen en dat zijop het moment van het onderzoek nog weinig waren blootgesteld aan AIDSpreventie-activiteiten. Het geloof dat AIDS teweeg wordt gebracht door goddelijke bestemming of voorouderlijke vergelding, werd vooral door sommige lager opgeleide vrouwen nog gehandhaafd. Ook bleek duidelijk dat bij vrouwen de waameming van een hoog risico op HIV-infectie samenging met een lage eigen-effectiviteit ten aanzien van het voorkomen van infectie. Een groot aantal vrouwen waren van mening dat ze een hoog risiko liepen op infectie met het HIV-virus. Omgekeerd bleek dat een betrekkelijk groot aantal vrouwen een lage eigeneffectiviteit had ten aanzien van hun mogelijkheden om zichzelf tegen infectie te beschermen. Met name hoger opgeleide mannen erkenden sexuele relaties te onderhouden met meerdere vrouwen. Hoger opgeleide en jongere personen gaven vaker te kennen condooms te gebruiken. I let pre-interventie onderzoek leidde tot aanbevelingen om een interventie te ontwikkelen waarbij speciaal rekening zou moeten worden gehouden met de lange geschiedenis van het niet deelnemen aan besluitvormingsprocessen door de werknemers in de gemeenschap. In het onderzoek werden factoren geidentificeerd die vaak de uitkomst van community interventies lijken te bepalen doch die buiten het bereik vallen van de meeste vernieuwingsprogramma's. De noodzaak om de reguliere "Farm Health Workers" uit te rusten met vaardigheden en hulpmiddelen om effectieve AIDS-preventiewerkers in de gemeenschap te worden, werd onderkend. Eveneens werd het belang onderkend van het ontwikkelen van een "linkage system" tussen de eigenaren van de agrarische bedrijven en de gemeenschappen van hun werknemers. 
In hoofdstuk 4 wordt ingegaan op de theorie die gebruikt werd om de interventie te ontwikkelen. In het hoofdstuk wordt het probleem belicht van het enkel ontwikkelen van interventies op basis van intuïtie. Het laat zien hoe de onderzoeksresultaten van het pre-interventie onderzoek werden gecombineerd met de sociale veranderingstheorie van Paulo Freire en het Ecological Model of Health Promotion ten einde een participatieve interventie op te stellen die door de "Farm Health Worker" zou kunnen worden toegepast.

Ten einde veranderingen te bewerkstelligen op het intra-persoonlijke niveau, op het organisatie niveau en op het sociale niveau van de gemeenschap, zou een interventie ontwikkeld moeten worden die in belangrijke mate zou bestaan uit een interactief proces tussen de "Farm Health Worker" en de gemeenschap. Er werd voorgesteld dat in het eerste stadium van de interventie methoden zouden worden gebruikt die aanzetten tot een persoonlijke inschatting van de eigen kwetsbaarheid met betrekking tot HIV-infectie, door activiteiten die een kritisch denken in een onderlinge dialoog te bevorderen. In de volgende fase zou nadruk moeten worden gelegd op het ontwikkelen van cognitieve en houdingsveranderingen in de doelgroep. Zelfbeschermend gedrag door condoomgebruik zou moeten worden aangemoedigd en de eigen effectiviteit met betrekking tot het onderhandelen over seks zou, speciaal bij vrouwen, moeten worden versterkt. In het laatste stadium van de interventie zouden er pogingen moeten worden gedaan om een klimaat te creëren voor de handhaving van preventief gedrag en van sociaal verantwoordelijk handelen binnen de gemeenschap. Dialoog zou centraal moeten staan in de voorgestelde interventie en er werden aanbevelingen gedaan voor een proces - en een effect evaluatie.

De proces-evaluatie wordt beschreven in hoofdstuk 5. Daarin wordt een beschrijving gegeven van "wat er gebeurde" tijdens de interventie-periode van een jaar. De procesevaluatie gaf ook bruikbare inzichten in een aantal factoren die, bij elkaar genomen, een overzicht gaven van een programma waarvan het succes en het falen mede bepaald werden door factoren die buiten het bestek van de interventie vielen. Gedurende perioden van grote drukte op de landbouwbedrijven was er bijvoorbeeld vaak sprake van een grote toevloed van seizoenarbeiders en een verhoging van besteedbaar inkomen uit het werk, hetgeen leidde tot een toename van prostitutie en gebruik van alcohol.

Tevens werd in deze periode, waarin ook interventies plaatsvonden, een afname geconstateerd in sexueel overdraagbare aandoeningen. Uit de procesanalyse bleek dat deze afname in sexueel overdraagbare aandoeningen niet kon worden toegeschreven aan een interventie-effect en toename van condoomgebruik, maar een gevolg was van het feit dat de werkers minder tijd hadden om voor behandeling naar een gezondheidscentrum te gaan. Seizoensgebonden schommelingen in agrarische werkzaamheden bleken eveneens een effect te hebben op interventie-activiteiten die in die perioden dan moeilijk te coördineren waren. Dit voerde terug naar de vraagstelling voor de procesevaluatie, namelijk: "Werd de interventie geimplementeerd zoals gepland?". Het antwoord: "Slechts gedeeltelijk".

Het laatste hoofdstuk beschrijft de effect-evaluatie, een jaar na aanvang van de interventie. Hiertoe werd een quasi-experimenteel, interventie- en controlegroep onderzoek met eenmalige nameting uitgevoerd. De experimentele groep werd gevormd door 9 willekeurig voor de interventie geselecteerde commerciële agrarische gemeenschappen. De controlegroep werd gevormd door 8 eveneens willekeurig gekozen gemeenschappen in het zelfde district. Binnen de gemeenschappen werden participanten voor het onderzoek eveneens willekeurig gekozen. Data werden 
verzameld door getrainde onderzoek-assistenten door middel van interviews waarbij gebruik gemaakt werd van een tevoren geteste vragenlijst. Daarbij werden hulpmiddelen gebruikt speciaal bestemd voor het interviewen van participanten met weinig of geen scholing.

Met betrekking tot de effecten van de interventie op het intra-persoonlijke vlak, liet de interventiegroep een significant hogere gemiddelde score zien op kennis, vergeleken met de controlegroep. In de hele onderzoeksgroep van werknemers bleek dat zelfs vrouwen met weinig schoolopleiding, significant beter op kennis scoorden dan hun mannen.

De interventie slaagde er niet in het condoomgebruik, dat zoals vermeld laag was, te doen toenemen. Hoewel de voordelen van het condoomgebruik werden onderkend door zowel de participanten in de experimentele als in de controlegroep, waren significant minder mannen dan vrouwen het ermee eens, dat condooms gebruikt zouden moeten worden door getrouwde paren.

De interventie slaagde er evenmin in om de eigen-effectiviteit ten aanzien van zelfbescherming tegen HIV te versterken. De meest genoemde redenen die vrouwen noemden voor geen onthouding van seks, zelfs bij risico op HIV-infectie, waren angst voor geweld, vrees om verlaten te worden en wantrouwen bij hun partners. Uit het onderzoek blijkt dat de vrouwen, ook wanneer zij worden geconfronteerd met een epidemie die veel van hen vraagt, zich machteloos voelen over hun eigen vermogen om veranderingen te bewerkstelligen. Dit gold eveneens voor hun inschatting van het vermogen van de gemeenschap om veranderingen in positieve zin te bewerkstelligen. Oischoon hun betere kennis van HIV / AIDS hun begrip van het probleem scheen te hebben vergroot, werd hun perceptie van een oplossing duidelijk bepaald door de sociaal-cultureel bepaalde verhoudingen tussen mannen en vrouwen.

Mannen, echter, blijken een hoge inschatting te hebben van hun eigen-effectiviteit, een sterke sexuele identiteit te hebben en controle te ervaren zowel ten aanzien van hun eigen sexuele gedrag als ten aanzien van het vermogen van de gemeenschap op dit gebied problemen te voorkomen, hetgeen door specifieke socialisatieprocessen kan zijn bepaald. Echter, het bleek dat hun gedrag ook na de interventie hiermee in het geheel niet in overeenstemming was. De interventie was daarom duidelijk niet succesvol in het helpen van mannen om hun rol te bepalen met betrekking tot hun reactie op de epidemie.

Met betrekking tot het versterken van de perceptie dat de gemeenschap in staat is bij te dragen tot de preventie van besmetting, bleek dat "farm workers" uit de interventiegroep in vergelijking met de controlegroep, significant vaker van mening waren dat door hen iets gedaan kon worden aan preventie van infectie. De interventie had een positief effect op de waargenomen steun van autoriteiten (bedrijfseigenaren) bij Aids-preventie activiteiten. Echter, het was opvallend duidelijk dat vrouwen zich minder dan mannen in staat voelden om iets te kunnen doen on de verspreiding van AIDS te voorkomen. Op grond van deze bevindingen werd de vraag gesteld "Wat zouden we willen veranderen en hoe willen we een volgende interventie plannen?". Een aantal aspecten zouden dan nader moeten worden bekeken.

Ten eerste, ofschoon de ontwikkeling van de interventie en de opzet van de eindevaluatie werden gestuurd op basis van veranderingstheorieën, kan gewezen worden op een aantal beperkingen in het onderzoek. Zo werd slechts een eenmalige nameting uitgevoerd, een jaar na aanvang van de interventie. Ook bleek het niet eenvoudig om voor het adequaat meten van interventie effecten bij een doelgroep met 
geen of weinig onderwijs, valide en betrouwbare onderzoeksinstrumenten te ontwikkelen. Een meer diepgaande benadering bij het meten van veranderingen was wenselijk geweest. Eveneens had de ethnografische benadering die werd toegepast bij de procesevaluatie verder ontwikkeld kunnen worden, om zodoende de hinderpalen voor organisatie-verandering in agrarische gemeenschappen beter te begrijpen. Mogelijk zou dit hebben geleid tot meer specifieke anbevelingen voor toekomstige preventie initiatieven. Het ontwikkelen van relevante indicatoren en methoden voor het evalueren van een "cummunity based" interventie, zou daarom een belangrijke uitdaging moeten blijven.

Ten tweede blijkt uit dit onderzoek, evenals uit veel voorgaande studies, dat voor het bevorderen van gedrag ter voorkoming van HIV-infectie, meer nodig is dan het verhogen van het cognitief begrip van het individu. Er is een dringende behoefte aan het ontwikkelen van samengestelde benaderingen voor gedragsverandering waarbij niet alleen mispercepties over HIV/AIDS worden gecorrigeerd, maar waarbij ook zelfbescherming wordt bevorderd door het leren van vaardigheden en vaardigheidstraining. Het is van bijzonder belang om met name de gedragsmogelijkheden en bekwaamheid van vrouwen te versterken, omdat juist hun gevoel van eigenwaarde en eigen-effectiviteit ten aancien van het uitvoeren van gedrag gericht op HIV-preventie zo laag blijkt te zijn. Mannen zouden geholpen moeten worden bij het onderkennen van gedrag dat negatieve gevolgen heeft en bij het leren dat ook zij een belangrijke rol te spelen hebben in het initiëren, uitvoeren en volhouden van verandering.

Ten derde, bij een verschuiving van de aandacht voor verandering in het individu naar verandering in de gemeenschap, is het van belang dat die verandering wordt ingebed in de bredere context van de sociale omgeving. Om succes te verkrijgen van pogingen om de interactie tussen belanghebbenden in de gemeenschap te versterken en van pogingen om een gemeenschappelijk doelbewustzijn ten aanzien van HIVpreventie te creëren, wordt een mechanisme voor het operationaliseren van toekomstige interventies van bijzonder belang geacht. Dit zou met name moeten gebeuren op basis van een geïntegreerd sociaal beleid voor de agrarische gemeenschappen.

Ten vierde, gezien de huidige terugval in het aanbod van gezondheidsvoorzieningen in Zimbabwe en op basis van de resultaten van dit onderzoek, die duidelijk laten zien dat armoede en piektijden van drukke seizoenarbeid op de bedrijven een negatieve invloed hebben op de toegang tot hulp en op het hulpzoekend gedrag van werknemers, zou alles in het werk gesteld moeten worden om een vrije toegang tot behandeling voor sexueel overdraagbare aandoeningen te bieden. Dit op basis van een beleid waarin de behoefte aan een aanbod voor behandeling op lokaal bedrijfsniveau wordt erkend.

Tenslotte omdat was gebleken dat de "change agents" (hier Farm Health Workers) moeilijkheden hadden met het toepassen van een methode waarbij mensen niet zozeer het doel zijn van een onderwijsproject maar meer deelnemers zijn in een veranderingsproces, zou in toekomstige trainingsprogramma's meer aandacht moeten worden besteed aan het aanleren van de toepassing van participatieve methoden voor gedragsverandering. Het idee dat innovatie kan en zou moeten voortkomen uit een interactieve benadering waarbij belanghebbenden een sleutelrol vervullen, moet worden versterkt. Verder zou veel energie moeten worden gestoken in het verkennen van mogelijkheden om netwerken te ontwikkelen waarin sleutelfiguren, zoals de eigenaren van boerderijen en andere organisaties die al werken aan veranderingen in agrarische gemeenschappen, zijn opgenomen. 
Deze studie heeft de moeilijkheden laten zien die zich kunnen voordoen bij het ontwikkelen van een interventie gericht op het creëren van een geschikt klimaat met betrekking tot HIV / AIDS-preventie op individueel-, socio-organisationeel-en politiek niveau in agrarische gemeenschappen. De procesevaluatie gaf een waardevol inzicht in "wat werkelijk gebeurde" gedurende de interventieperiode. De eindresultaten laten zien dat de interventie werd bepaald door een aantal factoren die buiten het bestek liggen van hetgeen was gepland.

In een ideale zereld zouden "community based" interventies de gewenste veranderingen teweeg brengen. In werkelijkheid gebeurt dit meestal niet. Het is daarom belangrijk een interventie in zijn werkelijke. context te plaatsen om datgene eruit te halen dat leidt tot succes, hoe minimaal dan ook, waardoor hopelijk een beter begrip van het bredere vraagstuk ontstaat. 